\title{
PPEXILA JOURALL
}

\section{Texila International Journal}

BASIC MEDICAL SCIENCE

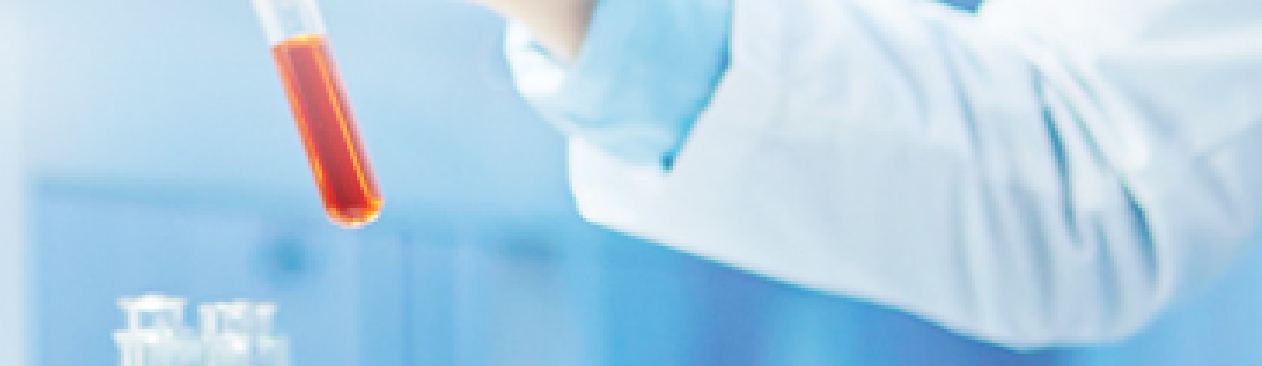

Volume 2 Issue 2 ISSN : 2519-500X 


\section{EDITORIAL POLICY}

Papers must be submitted with the understanding that they have not been published elsewhere (except in the form of an abstract or as part of a published lecture, review, or thesis) and are not currently under consideration by another journal published or any other publisher. The submitting (Corresponding) author is responsible for ensuring that the article's publication has been approved by all the other coauthors. It is also the authors' responsibility to ensure that the articles coming from a particular institution are submitted with the approval of the necessary institution. Only an acknowledgment from the editorial office officially establishes the date of receipt. It is a condition for submission of a paper that the authors permit editing of the paper for readability. All enquiries concerning the publication of accepted papers should be addressed to nadipelly.j@tau.edu.gy.

\section{EDITORIAL TEAM}

Chief Patron:

Dr. A. Anand, Vice Chancellor, TAU, Guyana.

Executive Editor: Dr. Jagan Nadipelly, Faculty of Medicine - Pharmacology, TAU, Guyana.

Managing Editor: Dr. Kumar Ponusamy, Asso. Professor of Biochemistry, TAU, Guyana.

\section{PEER REVIEWERS}

Dr. Pendru Raghunath, Asso. Prof. of Microbiology, TAU, Guyana.

Dr. S. Esakki Muthu, Professor and HOD, Premedical Department, TAU, Guyana.

Dr. Edna D Cuaresma, Asso. Prof., Clinical Sciences, TAU, Guyana.

Mr. Dave C. Paguntalan, Asst. Prof., Nursing Sciences, TAU, Guyana.

Dr. Nagesh Venkatasubbareddy, Asst Prof., Pharmacology, TAU, Guyana.

Dr. Sankalan Sarkar, Asst. Prof. of Physiology, TAU, Guyana.

Dr. Rajini Kurup, Asst Prof., Microbiology, Uni. of Guyana, Guyana.

\section{PRINCIPAL CONTACT INFORMATION}

Dr. Kumar Ponusamy,

Managing Editor, TIJBMS,

Associate Professor of Biochemistry \& Genetics,

Texila American University (TAU), George Town, Guyana, South America,

E-mail: kumar.ponusamy@tau.edu.gy

Skype: kumar.ponusamy@tau.edu.gy

Mobile: +5926747458 


\section{ABOUT PLAGIARISM}

Plagiarism is the use or close imitation of the language and ideas of another author and representation of them as one's own original work. Duplicate publication, sometimes called self-plagiarism, occurs when an author reuses substantial parts of his or her own published work without providing the appropriate references. This can range from getting an identical paper published in multiple journals, where authors add small amounts of new data to a previous paper.

Plagiarism can be said to have clearly occurred when large chunks of text have been cut and pasted. Such manuscripts would not be considered for publication in TIJBMS Journal. But minor plagiarism without dishonest intent is relatively frequent, for example when an author reuses parts of an introduction from an earlier paper. The editors will judge any case of which they become aware (either by their own knowledge of and reading about the literature, or when alerted by referees) on its own merits.

The paper containing the plagiarism will be obviously returned back to the author's for review, but we earnestly request the authors to avoid submitting plagiarized. 


\section{DISCLAIMER}

Texila International Journal of Basic Medical Science's (TIJBMS) make every effort to ensure the accuracy of all the information (the "Content") contained in its publications. However, the TIJBMS and its agents make no representations or warranties whatsoever as to the accuracy, completeness or suitability for any purpose of the Content and disclaim all such representations and warranties whether express or implied to the maximum extent permitted by law. Any views expressed in this publication are the views of the authors and are not necessarily the views of the Editor's or Texila International Journal of Basic Medical Science's. 


\section{TABLE OF CONTENT}

1 Bio Activity of Sesbania Grandiflora against Hepatic Damage in Albino Rats

K. Padmalochana

2 Determination of Molecular Property, Bioactivity Score and Binding Energy of the 8 Phytochemical Compounds Present in Cassia Auriculata by Molinspiration and DFT Method

Chandra Mohan. A

3 Nephroprotective Potential Compounds from Leaves Extracts of Andrographis Paniculata

K. Padmalochana

4 Pharmacological Activities of Compound Present in Cassia Auriculata by Pass 30 Prediction Method

Chandra Mohan. A

5 Analysis of Total Phenol, Cellulose and Tannin Content by Using Different Parameters in Ethanol Extract of Pomegranate Peel

Vijayalakshmi. T

6 Reflective Assessment of Learning Outcomes [RALO] in Basic Medical Sciences Subjects - [TAU MODEL]

Arulsamy Anand

7 The Human Inter Vertebral Disc - A Histological Approach

Anuradha $\mathrm{K}$

8 Assess the Pre Test Knowledge and Practice of Post-Operative Exercises among Abdominal Surgery Patients Before Video Assisted Teaching

\section{Chakrapani Cheekavolu}

9 Role of Artificial Sweeteners in Development of Type 2 Diabetes Mellitus (DM): A 63 Review

Jagan Nadipelly 


\title{
Bio Activity of Sesbania Grandiflora against Hepatic Damage in Albino Rats
}

\author{
Article by K. Padmalochana ${ }^{1}$ and M.S. Dhana Rajan ${ }^{2}$ \\ ${ }^{1}$ Research Scholar, Bharathiar University, Coimbatore, Tamil Nadu, India \\ ${ }^{2}$ Registrar, Texila American University, Guyana, South America \\ E-mail: kpadmalochana@gmail.com ${ }^{1}$
}

\begin{abstract}
A phytotherapeutic approach to modern drug development can provide many invaluable drugs from traditional medicinal plants. Medicinal plants have been considered as important therapeutic aid for alleviating ailment of humankind. Numerous plants and polyherbal formulations are used for the treatment of liver diseases. This present investigation was aimed to assessing the hepatoprotective activity of aqueous, ethanol and acetone extract of Sesbania grandiflora leaves against carbon tetra chloride $\left(\mathrm{CCl}_{4}\right)$ induced liver damage in albino rats. Silymarin as standard drug for comparing the activity. The activity was assessed by comparing the biochemical parameters in serum levels such as serum glutamate pyruvate transaminase, serum glutamate oxalate transaminase, total bilirubin, alkaline phosphatase of plant extracts treated group with carbon tetrachloride treated animals. Results showed, ethanolic extract treated group showed highly significant activity ( $p<0.001)$, whereas aqueous extract treated group has shown the significant $(p<0.01)$ action but less compared with ethanolic extract, acetone treated group showed moderate action. Plant extracts restores biochemical enzymes and brings down to normal as compared to standard drug silymarin. This results shows and confirms the significant protective activity against $\mathrm{CCl}_{4}$ induced hepatotoxicity.
\end{abstract}

Keywords: Phytotherapeutic, Sesbania Grandiflora, Antioxidant, Carbon Tetra Chloride, Hepatotoxicity.

\section{Introduction}

Liver is very important organ in the human body. It regulates metabolic functions such as detoxification and play vital role in bio-chemical conversion. During the process of elimination there is chance of accumulation different kinds of toxic materials inside the hepatocytes and there is chance of liver infection, and hepatic disorders such as hepatitis 1. Liver diseases caused by various toxic chemicals, chemotherapeutic agents, excessive consumption of alcohol and microorganisms. Hepatotoxicity is an acute adverse effect in liver in caused by over dosages of drugs, toxic chemicals, viruses, bacteria and parasites $^{2}$.

Hepatotoxicity is a slight changes in hepatic structure and function which may result hypertension, ascites, jaundice, increased bleeding and cause multiple metabolic changes affecting other organs ${ }^{3,4}$. The magnitude of derangement of liver by disease or hepatotoxin is generally measured by the level of glutamate pyruvate transaminase (ALT), glutamate oxaloacetate transaminase (AST), alkaline phosphatase (ALP), bilirubin, albumin, and whole liver homogenate ${ }^{4,5}$.

$\mathrm{CCl}_{4}$ is a widely used industrial chemical and a potent hepatotoxin. It induces hepatotoxicity by producing free radical, putting oxidative stress hence causing lipid peroxidation in liver tissues, consequently necrotic liver damage ${ }^{6,7}$. Liver diseases such as hepatitis, cirrhosis and fatty liver are worldwide. Various commercial synthetic drugs are used to treat liver disorders also cause side effect to the liver. Hence, Herbal drugs have become increasingly popular and their use is widespread. Herbal medicines have been used in the treatment of liver diseases for a long time. In India numerous medicinal plants are used for treatment of liver disorders ${ }^{8}$. Hepatoprotective effect of some plants like Spirulina maxima ${ }^{9}$ Eclipta alba ${ }^{10}$, Boehmerianivea ${ }^{11}$, Cichorium intybus ${ }^{12}$, and Picrorhiza kurroa ${ }^{13}$, Boswellia Serrata ${ }^{4}$, Psidium quajava ${ }^{14}$, Coccinia indica ${ }^{15}$ has been well documented. 
Sesbania grandifloraa Figure. 1 fast growing tree belongs to the family, Fabaceae, is commonly known as agathi in regional language Tamil. The leaves, used as greens for cattle and poultry, have got anthelmintic property against selected helminthes ${ }^{16,17}$. The bark, leaves, flowers and roots are also used medically herbs distributed in the tropical regions of the globe ${ }^{18}$. Juice of leaves and flowers is popular remedy for nasal catarrh and headache when it is sniffed up the nostrils. Juice of the flowers is squeezed into the eyes to relieve the dimness of vision.

Juice of flower is ideal as expectorant ${ }^{19}$. The leaves of the plant have been reported to have anxiolytic and anticonvulsant effect while the flowers have been reported to have anti-microbial activity ${ }^{20}$. It shows hypolipemic, anti-ulcer and anti-inflammatory properties as well. Therefore, to justify the traditional claims, we have assessed the hepatoprotective effect of Sesbania grandiflora leaves extract in albino rats using biochemical enzyme based analysis.

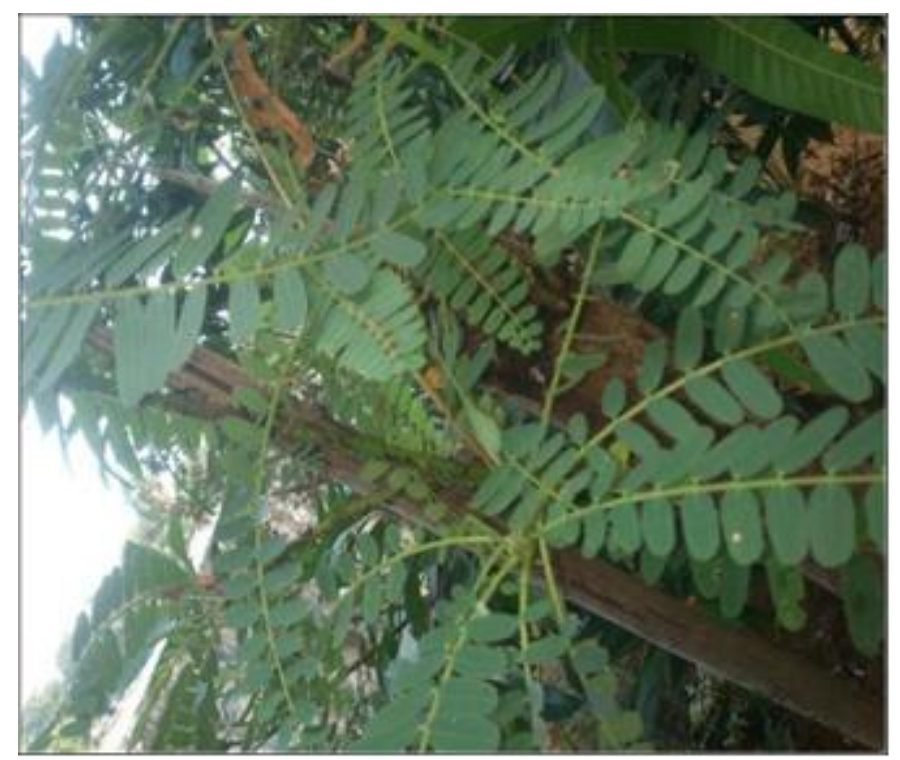

Figure 1. Sesbania grandiflora leaves

\section{Materials and methods}

Chemicals: Analytical grade carbon tetra chloride, Silymarin and other chemicals were purchased from Himedia laboratories private limited, Mumbai. Sesbania grandiflora plant was collected from, Tiruvannamalai, South India.

\section{Preparation of plant extracts}

Sesbania grandiflora leaves were collected and shade dried at room temperature. The shade dried leaves were powdered and extracted by using aqueous, ethanol and acetone. Aqueous extracts was prepared by subjecting a $100 \mathrm{~g}$ of dried powdered leaves in to $100 \mathrm{ml}$ of distilled water and incubated in water bath shaker for $12 \mathrm{~h}$ at $40^{\circ} \mathrm{C}$. Ethanol and acetone extract prepared by the coarsely powdered leaves was extracted using soxhlet and extracted with $80 \%$ ethanol and $70 \%$ acetone for $24 \mathrm{~h}$ at $60{ }^{\circ} \mathrm{C}$ and $55^{\circ} \mathrm{C}$, respectively. The extracted were collected and concentrated by drying under vaccum and semisolid suspensions were obtained. These suspensions were used to assess hepatoprotective activity.

\section{Experimental design for hepatoprotective activity of sesbania grandiflora}

Adult male Wister albino rats maintained at the college weighing between $150 \mathrm{~g}-170 \mathrm{~g}$ were used for the hepatoprotective studies. Animals were divided into six groups in six rats each:

Group I (Normal): Orally received distilled water for 7 days.

Group II (Induced): Orally received carbon tetra chloride ( $2 \mathrm{~g} / \mathrm{kg}$ body weight) only for 7 days. 
Group III (Standard): Orally received Silymarin ( $20 \mathrm{mg} / \mathrm{kg}$ body weight) along with $\mathrm{CCl}_{4}(2 \mathrm{~g} / \mathrm{kg}$ body weight) for 7 days.

Group IV (Treatment): Orally received Aqueous leaf extracts $(300 \mathrm{mg} / \mathrm{kg}$ body weight) along with $\mathrm{CCl}_{4}(2 \mathrm{~g} / \mathrm{kg}$ body weight $)$ for 7 days.

Group V (Treatment): Orally received ethanol leaf extracts $\left(300 \mathrm{mg} / \mathrm{kg}\right.$ body weight) along with $\mathrm{CCl}_{4}$ $(2 \mathrm{~g} / \mathrm{kg} /$ body weight) for 7 days.

Group VI (Treatment): Orally received acetone leaf extracts (300mg/kg body weight) along with $\mathrm{CCl}_{4}$ $(2 \mathrm{~g} / \mathrm{kg}$ body weight $)$ for 7 days.

Silymarin was used as positive control for comparing hepatoprotective potential of different leaves extract of Sesbania grandiflora.

\section{Hepatoprotective activity of S. grandiflora}

\section{Collection of blood and biochemical analysis}

On the $8^{\text {th }}$ day, all the animals were scarified and blood samples were collected in glass tube from retroorbital puncture to obtain haemolysis for $30 \mathrm{~min}$ at $37^{\circ} \mathrm{C}$. Serum glutamate oxaloacetate transaminase, serum glutamate pyruvate transaminase, serum bilirubin and alkaline phosphatase and Serum protein ${ }^{21,22}$ were obtained from serum following centrifugation process was used for the biochemical analysis.

\section{Antioxidant activity of S. grandiflora}

\section{Liver homogenate preparation}

Liver homogenates were prepared by using a 100mM KCl buffer (pH7.0) containing 0.3mM EDTA and centrifuged at $6000 \mathrm{rpm}$ for $45 \mathrm{~min}$ at $4{ }^{\circ} \mathrm{C}$. After completion of centrifugation process collect the supernatant was used for estimation of antioxidant levels were analyzed Superoxide dismutase (SOD) ${ }^{23}$, Catalase $(\mathrm{CAT})^{24}$ and Glutathione Peroxidase (GP) ${ }^{25}$.

\section{Statistical analysis}

The difference of biochemical parameters were measured using the statistical method i.e. Analysis of Variance (ANOVA). Analysis of Variance refers to the examination of differences among the samples and the results are expressed as mean \pm SEM and $\mathrm{p}<0.05, \mathrm{p}<0.01, \mathrm{p}<0.001$ was considered to be statistically significant.

\section{Results and discussion}

The hepatoprotective and antioxidant activity of $S$. grandiflora leaves extracts are shown in Figure. 24. the biochemical parameters such as serum glutamate oxaloacetate transaminase, serum glutamate pyruvate transaminase, serum bilirubin and alkaline phosphatase were estimated to assess the liver function. The marked increase in SGOT, SGPT and ALP levels were observed in $\mathrm{CCl}_{4}$ treated group II animals are $94.98 \pm 0.69,29.98 \pm 0.67$ and $299.68 \pm 0.12 \mathrm{IU} / \mathrm{L}$, respectively. The increased level of SGOT, SGPT, ALP and bilirubin is conventional indicator of liver injury. However these levels were reversed to near normal levels of group I animals with treatment of aqueous, ethanol and acetone extract of Sesbania grandiflora, which are statistically significant. The activities of extracts were comparable to a standard drug. These extracts has restored the all the biochemical parameters levels in serum. And also the standard silymarin has restored the biochemical levels of SGOT, SGPT, and ALP significantly $(\mathrm{p}<0.01)$ i.e. 69.42 \pm 0.38 , $24.42 \pm 0.33$, and $170.12 \pm 0.25 \mathrm{IU} / \mathrm{L}$ respectively in serum. In case of bilirubin and total protein there was a noticeable increase i.e. in serum levels treating with $\mathrm{CCl}_{4}$. Treatment with aqueous, ethanol and acetone extract has reversed the serum bilirubin and total protein in serum levels to $(0.50 \pm 0.07$ and $6.85 \pm 0.12$ $\mathrm{mg} / \mathrm{dl}),(0.45 \pm 0.09$ and $6.59 \pm 0.32 \mathrm{mg} / \mathrm{dl}),(0.47 \pm 1.06$ and $6.26 \pm 1.07 \mathrm{mg} / \mathrm{dl})$, respectively which are statistically highly significant $(\mathrm{p}<0.001)$ when compared with $\mathrm{CCl} 4$ treated animals. 
DOI: 10.21522 /TIJBMS.2016.02.02.Art001

ISSN: 2519-500X

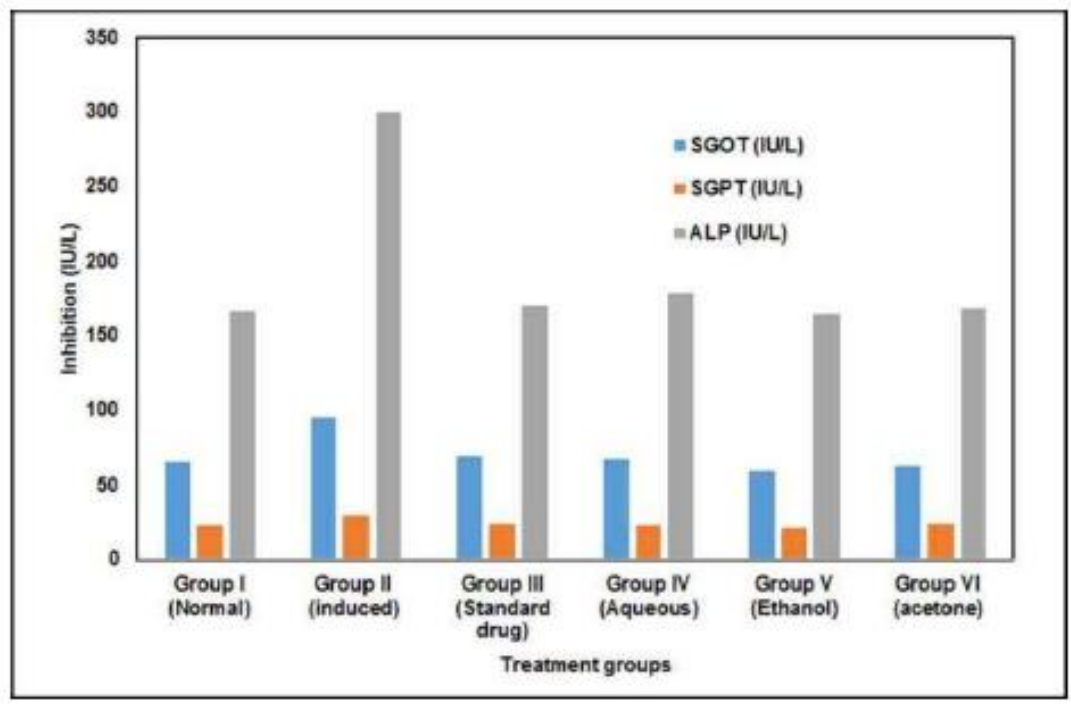

Figure. 2. Hepatoprotective activity in carbon tetra chloride induced hepatotoxic model shows changes serum enzymes sgot, sgpt and alp in serum

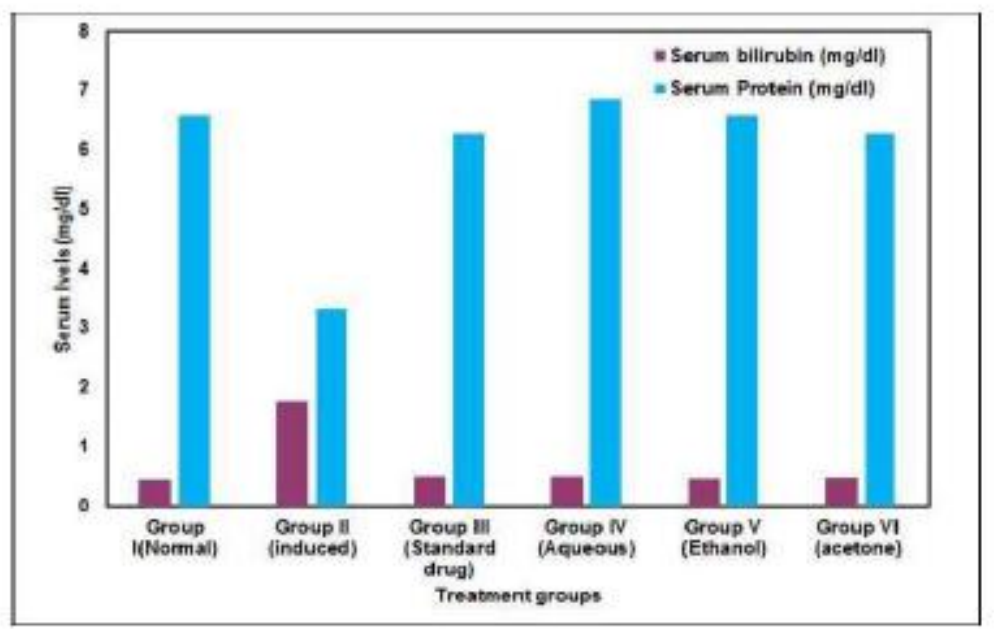

Figure 3. Hepatoprotective activity in carbon tetra chloride induced hepatotoxic model shows changes serum bilirubin and total protein

The restoration of biochemical factors in serum was also noticed in treating with the standard drug silymarin $(0.49 \pm 0.04$ and $6.26 \pm 0.16 \mathrm{mg} / \mathrm{dl})$. It is stipulated that the extract treated group was protected from hepatic cell damage caused by $\mathrm{CCl}_{4}$ induction. The extract at a dose of $300 \mathrm{mg} / \mathrm{kg}$ body wt. exhibited orally, significant protective effect by lowering the serum levels of transaminases (SGOT and SGPT), bilirubin and alkaline phosphatase (ALP).

The effects produced were comparable to that of a standard hepatoprotective agent silymarin. In ethanol extract treated animals, the toxicity effect of carbon tetrachloride was controlled significantly by restoration of the levels of serum bilirubin and enzymes as compared to the normal and standard drug silymarin-treated groups. Antioxidant activities of hepatic SOD, CAT and GPx were estimated and shown in the Table 3, Figure. 4 SOD, CAT and GPx activities were significantly $(\mathrm{p}<0.001)$ enhanced only in the orally received ethanol extract of $S$. grandiflora leaves. The antioxidant activities of aqueous, ethanol and acetone extract shows significant activity near to the normal group of animals. 
Table 1. Hepatoprotective activity in carbon tetra chloride induced hepatotoxic model shows changes serum enzymes sgot, sgpt and alp in serum

\begin{tabular}{llll}
\hline Parameters & SGOT(IU/L) & SGPT(IU/L) & ALP(IU/L) \\
\hline Group I (Normal) & $65.15 \pm 0.14^{* * *}$ & $23.15 \pm 0.17 * * *$ & $166.15 \pm 0.22^{* * *}$ \\
Group II (induced) & $94.98 \pm 0.69^{*}$ & $29.98 \pm 0.67 *$ & $299.68 \pm 0.12^{*}$ \\
Group III (Standard drug) & $69.42 \pm 0.38^{* *}$ & $24.42 \pm 0.33^{* * *}$ & $170.12 \pm 0.25^{* * *}$ \\
Group IV (Aqueous) & $67.48 \pm 0.39 * *$ & $23.48 \pm 0.38^{* *}$ & $178.48 \pm 0.28^{* * *}$ \\
Group V (Ethanol) & $59.59 \pm 0.76^{* * *}$ & $21.59 \pm 0.74 * * *$ & $164.51 \pm 0.17 * * *$ \\
Group VI (acetone) & $62.58 \pm 0.34 * * *$ & $24.58 \pm 0.35^{* *}$ & $168.59 \pm 0.73 * * *$ \\
\hline
\end{tabular}

$* \mathrm{p}<0.05,{ }^{*} \mathrm{p}<0.01,{ }^{* * *} \mathrm{p}<0.001$ value are considered statistically significant (BMRT)

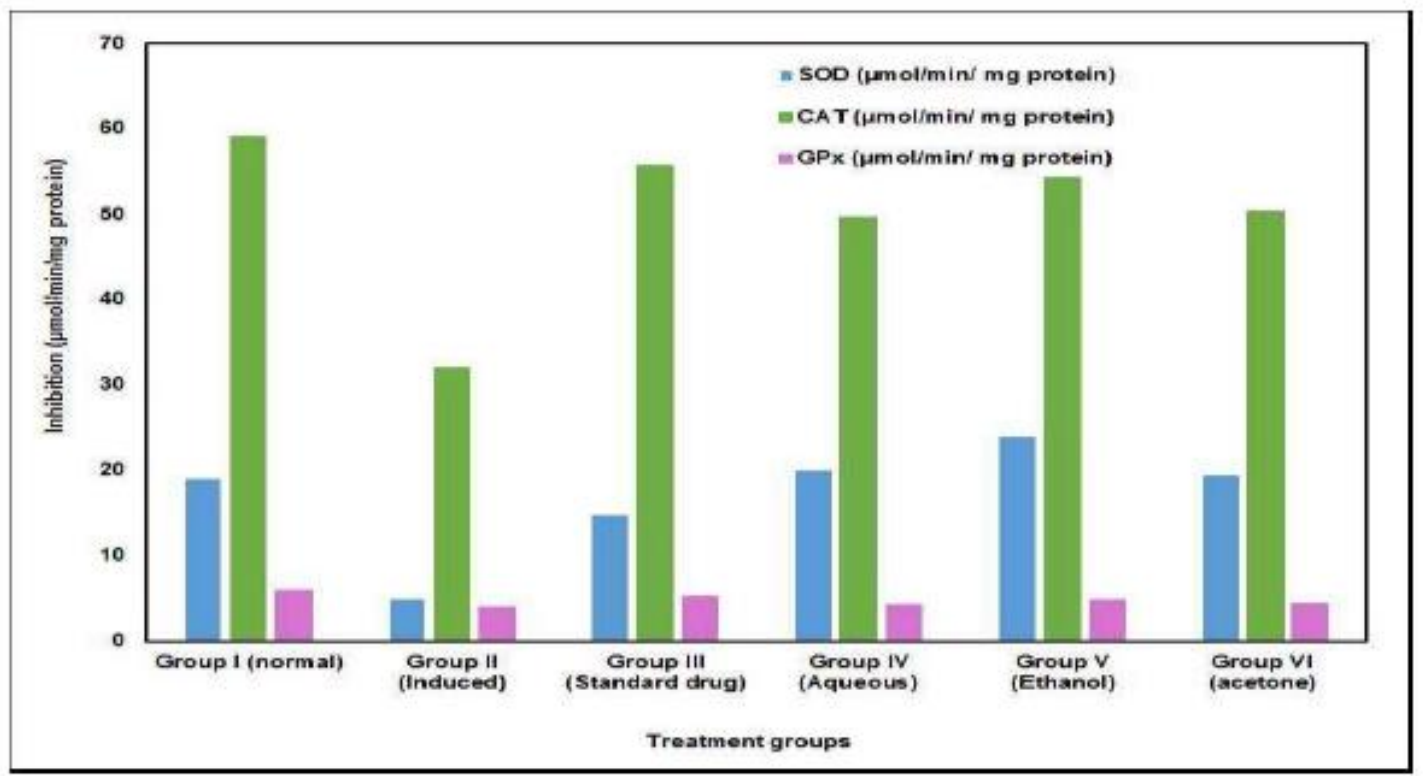

Figure 4. Antioxidant levels in carbon tetra chloride induced hepatotoxic model shows changes in the levels of sod, cat and GPx

Table 2. Hepatoprotective activity in carbon tetra chloride induced hepatotoxic model shows changes serum bilirubin and total protein

\begin{tabular}{lll}
\hline Parameters & $\begin{array}{l}\text { Serum bilirubin } \\
(\mathbf{m g} / \mathbf{d l})\end{array}$ & $\begin{array}{l}\text { Serum Protein } \\
(\mathbf{m g} / \mathbf{d l})\end{array}$ \\
\hline Group I(Normal) & $0.44 \pm 0.03^{* * *}$ & $6.58 \pm 0.06^{* * *}$ \\
Group II(induced) & $1.76 \pm 0.10^{*}$ & $3.32 \pm 0.04^{*}$ \\
Group III(Standard drug) & $0.49 \pm 0.04^{* * *}$ & $6.26 \pm 0.16^{* *}$ \\
Group IV (Aqueous) & $0.50 \pm 0.07^{* *}$ & $6.85 \pm 0.12^{* *}$ \\
Group V (Ethanol) & $0.45 \pm 0.09^{* * *}$ & $6.59 \pm 0.32^{* * *}$ \\
Group VI (acetone) & $0.47 \pm 1.06^{* *}$ & $6.26 \pm 1.07 * * *$ \\
\hline
\end{tabular}

$* \mathrm{p}<0.05, * * \mathrm{p}<0.01, * * * \mathrm{p}<0.001$ value are considered statistically significant (BMRT) 
DOI: 10.21522 /TIJBMS.2016.02.02.Art001

ISSN: $2519-500 \mathrm{X}$

Table 3. Antioxidant levels in carbon tetra chloride induced hepatotoxic model Shows changes in the levels of sod, cat and GPX

\begin{tabular}{llll}
\hline Parameters & $\begin{array}{l}\text { SOD }(\boldsymbol{\mu m o l} / \mathbf{m i n} / \\
\mathbf{m g} \text { protein) }\end{array}$ & $\begin{array}{l}\text { CAT }(\boldsymbol{\mu m o l} / \mathbf{m i n} / \\
\mathbf{m g} \text { protein) }\end{array}$ & $\begin{array}{l}\mathbf{G P x} \\
(\boldsymbol{\mu} \mathbf{m o l} / \mathbf{m i n} / \\
\mathbf{m g} \mathbf{p r o t e i n})\end{array}$ \\
\hline Group I (Normal) & $18.91 \pm 0.31^{* * *}$ & $58.99 \pm 4.80^{* * *}$ & $5.98 \pm 2.46^{* * *}$ \\
Group II(induced) & $04.94 \pm 0.21^{*}$ & $31.89 \pm 3.43^{*}$ & $3.98 \pm 0.35^{*}$ \\
Group III(Standard drug) & $14.73 \pm 0.39^{* *}$ & $55.67 \pm 3.13^{* *}$ & $5.34 \pm 2.11^{* *}$ \\
Group IV (Aqueous) & $20.01 \pm 0.17^{* *}$ & $49.68 \pm 0.55^{* * *}$ & $4.32 \pm 1.92^{* *}$ \\
Group V (Ethanol) & $23.92 \pm 0.27^{* * *}$ & $54.23 \pm 3.17^{* * *}$ & $4.84 \pm 1.70^{* * *}$ \\
Group VI (acetone) & $19.46 \pm 0.11^{* * *}$ & $50.38 \pm 0.18^{* * *}$ & $4.42 \pm 1.02^{* * *}$ \\
\hline
\end{tabular}

$* \mathrm{p}<0.05, * * \mathrm{p}<0.01, * * * \mathrm{p}<0.001$ value are considered statistically significant (BMRT).

\section{Conclusion}

In the present report stated that the aqueous, ethanol and acetone extract of commonly available plant Sesbania grandiflora leaves was extensively investigated for its hepatoprotective potential against $\mathrm{CCl}_{4}$ induced hepatotoxicity. There was a significant increase in serum levels of bilirubin, alanine transaminase, aspartate transaminase and alkaline phosphatase with a decrease in total protein level, in the $\mathrm{CCl}_{4}$ treated animals, reflecting liver injury. In the extracts treated animals there was a decrease in serum levels of the markers and significant increase in total protein, indicating the recovery of hepatic cells. A strong conclusion can be drawn that, extract of Sesbania grandiflora possess most significant $(\mathrm{p}<0.001)$ hepatoprotective activity compared with the standard drug silymarin. So that the development of medicines using the extracts of plant materials or bioactive compounds with standards of safety and efficacy can revitalize treatment of liver disorders and hepatoprotective activity.

\section{References}

[1].Aneja S, M Vats, S Aggarwal, S Sardana, Phytochemistry and hepatoprotective activity of aqueous extract of Amaranthus tricolor Linn. Roots, Journal of Ayurveda \& Integrative Medicine, 2013, Vol 4, Issue 4, 211-215.

[2].Aebi H., Catalase invitro. Methods in Enzymol, 1984, 105, 121-126.

[3].Bhawna S, S Upendra Kumar, Hepatoprotective activity of some indigenous plants, International Journal of PharmTech Research vol. 1, No.4, pp 1330-1334.

[4].Berhaut, J., 1976. Flore illustrated of Senegal. Tome V Government of Senegal, pp: 505-520.

[5].Duke JA, Handbook of Energy Crops (Unpublished).Purdue University. 1983.

[6].Fernandez-ChecaJc, Hirano T, Tsukamoto H, Kaplowitz N. Mitochondrial Glutanothione depletion in alcoholic liver disease, Alcohol 1993;10;469-475.

[7].Krasaekoopt W. and Kongkarchanatip A, Antimicrobial properties of Thai Traditional Flower Vegetable Extracts, A.U J.T. 9(2): $71-74,2005$.

[8].KhinMaMa, NyuntNyunt and Maung tin: The protective effects of Ecliptaalba on carbon tetrachloride Induced Acute Liver Damage. Toxicol. And Applied Pharmacol. 1978; 45:723-728.

[9].Ibrahim M, KZ Uddin and ML Narasu, Hepatoprotective activity of Boswellia serrate extracts: in vitro and in vivo studies. International Journal of Pharmaceutical Applications, 2011, 2(1): 89-98.

[10]. Lin CC, Yen MH, Lo TS, Lin JM. Evaluation of the hepatoprotective and Antioxidant activity of Boehmerianivea var. nivea and B. niveavar. tenacisssima. J Ethnopharmacol 1998; 60: 9-17.

[11]. Manokaran S , Jaswanth A, Sengottuvelu S , Nandhakumar J, Duraisamy R, Karthikeyan D, et al. Hepatoprotective activity of Aervalanata Linn against paracetamol induced hepatotoxicity in rats. Res J Pharm Tech 2008; 1: 398-400.

[12]. Okawa M, Kinjo J, Nohara T, Ono M. DPPH (1, 1-diphenyl-2- picrylhydrazyl) radical scavenging activity of flavonoids obtained from some medicinal plants. Biol Pharm Bull 2001; 24:1202-5. 
[13]. Patel BA, Patel JD, Raval BP. Hepatoprotective activity of Sachharum officinarum against paracetamol induced hepatotoxicity in rats. Int J Pharm Sci Res 2010; 1: 102-8.

[14]. Ram VJ, Goel A (1999) Curr. Med. Chem., 6, 217-254.

[15]. Roy CK, JV Kamath, M Asad, Heaptoprotective acitivity of Psidiumquajava Linn. Leaf extract, Indian Journal of Experimental Biology, 2006, 44: 305-311.

[16]. Sharma SK, Ali M, Gupta J. Evaluation of Indian Herbal Hepatoprotective Drugs. Recent Progress in Medicinal Plants (Phytochemistry and Pharmacology). Vol. 2. Houston: Research Periodicals and Book Publishing House; 2002. p. 253-70.

[17]. Saxena AK, Singh B, Anand KK. Hepatoprotective effects of Ecliptaalba on Subcellular levels in rats. J Ethnopharmacol 1993; 40: 155-161.

[18]. Saraswat B, Visen PK, Patnaik GK, Dhawan BN. Ex vivo and in vivo Investigations of picroliv from picrorhizakurroa in an alcohol in toxication model in rats. J Ethnopharmacol 1999; 66: 263-269.

[19]. Shyam Kumar B, Gnanasekaran D, Jaishree V, Channabasavaraj KP. Hepatoprotective activity of Coccinia indica leaves extract, Int J Pharm Biomed Res., 2010, 1(4), 154-156.

[20]. Sharma PC, Yelre HB and Dennis JJ. Database on medicinal plants used in CCRAS publication, Ayurveda, 2005; $1-6$.

[21]. Schuppan D, Athionson J, Ruehl M, Riecken EO, Alcohol and liver fibrosis-Pathobiochemistry and treatment. Z Gastroenterol, 1995; 33; 546-550.

[22]. Torres-Duran PV, Miranda-Zamora R, Paredes-Carbajal MC, Mascher D, Ble-Castello J, Diaz- Zagoya JC, Juarez-Oropeza MA. Studies on the preventive effect of Spirulina maxima on fatty liver development induced by carbon tetrachloride, in the rat. J Ethnopharmacol 1999; 64: 141-147.

[23]. UkedaH; S Maeda; T Ishii; M Sawamura; Anal. Biochem. 1997, 251, 206-209.

[24]. Vaidhyaratnum PSV. Indian medicinal plants. A compendium of 500 species. Volume V, Orient Longman, Madras, India, 1996; 17 -118.

[25]. Zafar R, Mujahid Ali S. Anti-hepatotoxic effects of root and root callus extracts Of Cichoriumintybus L. J Ethnopharmacol 1998; 63:227-231. 


\title{
Determination of Molecular Property, Bioactivity Score and Binding Energy of the Phytochemical Compounds Present in Cassia Auriculata by Molinspiration and DFT Method
}

\author{
Article by Chandra Mohan. $\mathrm{A}^{1}$, Geetha. $\mathrm{S}^{2}$, Gajalakshmi. $\mathrm{R}^{3}$, Divya. S. $\mathrm{R}^{4}$, and Dhanarajan \\ M.S $\mathrm{S}^{5}$ \\ ${ }^{1}$ Professor \\ ${ }^{2,34}$ Assitant Professor, PG and Research Department of Biochemistry and Chemistry, Jaya \\ College of Arts and Science, India \\ ${ }^{5}$ Registrar, Texila American University, Guyana, South America \\ E-mail: chandru2c813@gmail.com ${ }^{1}$
}

\begin{abstract}
Phytoconstituent present in Cassia Auriculata were found to obey the Lipinski's rule (MiLog $P<5$ ) $\alpha$-Tocopherol (2.007) indicated their drug likeness property. Among these compounds, $\alpha$-Tocopherol exhibited highest score towards GPCR ligand, (0.25) nuclear receptor ligand (0.43) and inhibitory activities towards protease (0.29), enzyme (0.25) and kinase (-0.22) inhibitors compared to others. Insilico determination of binding energy using DFT method proved that $\alpha$-Tocopherol was found to possess good binding energy (B3LYP and HF method were found to -1228.3913, -1236.9904 \&1243.4557 a.u. and $-1220.2810,-1228.4658$ \&-1234.8000 a.u.) among others hence it was found to be more stable.
\end{abstract}

Keywords: Cassia auriculata phytochemical compounds, Molinspiration software, DFT methods and Insilico prediction.

\section{Introduction}

Cassia auriculata is one of the herbaceous plants that found throughout central and southern India, also cultivated in Punjab, Haryana, Uttar Pradesh and West Bengal. The shrub usually occurs on roadsides, waste line, and railway embankments. Avaram (Cassia auriculata Linn), family Caesalpiniaceae, is also known as Avaram tree. Cassia auriculata Linn (Family: Caesalpiniaceae) commonly known as Tanners senna, is distributed throughout hot deciduous forests of India and holds a very prestigious position in Ayurveda and Siddha systems of medicine. It was profoundly used in Ayurvedic medicine as a tonic, astringent and as a remedy for diabetes, conjunctivitis and opthalmia [1]. It is one of the principle constituents of 'Avaarai panchaga chooranam'- an Indian herbal formulation used in the treatment of diabetes to control the blood sugar level [2].

The plant has been reported to possess antipyretic [3], hepatoprotective [4], antidiabetic, antiperoxidative and antihyperglyceamic [5], microbicidal [6] and antihyperlipidaemic activities [7]. The flowers are used to treat urinary discharges, nocturnal emissions, diabetes and throat irritation [8]. They are one of the constituent of polyherbal formulation 'Diasulin' in the concentration range of 40 $\mathrm{mg} / \mathrm{dl}$ which is proven to have antidiabetic activity [9].

It has been found to possess antitumor, oncogenic, and diabeto genic properties [10]. The antioxidant and radical scavenger function of $\alpha$-tocopherol is essentially dependent on the free state of its hydroxyl group. Spectacular antiallergic and antiinflamatory activities have been attributed to DL- $\alpha$ - tocopheryl$\alpha$ - D-mannopyranoside and DL- $\alpha$-tocopheryl- $\beta$-D-galactopyranoside [11]. Hexadecanoic acid methyl ester, also known as Methyl palmitate, in the methanol fraction is an aliphatic acid ester reported to cause growth inhibition and apoptosis induction in human gastric cancer cells [12].

The phytoconstituent of a plant will often determine the physiological action on the human body. Cassia species are rich sources of Polyphenols, Anthraquinone derivatives, Flavanoids, Polysaccharides, Saponins, Tannins, and Steroids. Some of the Cassia species are rich in Glycerides with linoleic, oleic, stearic, and palmitic acids .Cassia species are well known for their laxative and purgative constituents and are also used for the treatment of skin diseases. Leaves are anthelmintic and 
also used to treat ulcers, skin diseases, and leprosy. An aqueous extract of leaves possesses hypoglycemic activity. The leaves are eaten as a vegetable in times of scarcity, the infusion of leaves possesses a slight purgative activity.

\section{Molnispiration}

Molinspiration, web based software was used to obtain parameter such as MiLogP, TPSA, drug likeness scores. MiLogP is calculated by the methodology developed by Molinspiration as a sum of fragment based contributions and correction factors. MiLog P parameter is used to check good permeability across the cell membrane. Partition coefficient or $\log \mathrm{P}$ is an important parameter used in rational drug design to measure molecular hydrophobicity. Hydrophilic/lipophilic nature of drug molecule affects drug absorption, bioavailability, drug-receptor interactions, metabolism of molecules, as well as their toxicity. Molecular Polar Surface Area TPSA is calculated based as a sum of fragment contributions of $\mathrm{O}$ and $\mathrm{N}$ - centered polar fragments. Total polar surface area (TPSA) is closely related to the hydrogen bonding potential of a molecule and is a very good predictor of drug transport properties such as intestinal absorption, bioavailability, blood brain barrier penetration etc. Calculation of volume developed at Molinspiration is based on group contributors. Number of rotatable bonds measures molecular flexibility. It is a very good descriptor of absorption and bioavailbility of drugs. Through drug likeness datas of molecule, it can be checked molecular properties and structure feature in respect to known drugs.

Bioactivity of the drug can be checked by calculating the activity score of GPCR ligand, ion channel modulator, nuclear receptor legend, kinase inhibitor, protease inhibitor, enzyme inhibitor. All the parameters were checked with the help of software .Calculated drug likeness score of each compounds were compared with the specific activity of other compounds and the results were compared with standard drug. For organic molecules the probability is if the bioactivity score is $(>0)$, then it is active, if $(-5.0-0.0)$ then moderately active, if $(<-5.0)$ then inactive. The drug likeness scores were calculated by considering MiLogP (partition coefficient), molecular weight, number of heavy atoms, number of hydrogen donor, number of hydrogen acceptor and number of violation, number of rotatable bonds and volume [13-18].

\section{i) Lipinski's rule}

Lipinski's rule of five also known as the Pfizer's rule of five or simply the Rule of five (RO5) is a rule of thumb to evaluate drug likeness or determine if a chemical compound with a certain pharmacological or biological activity has properties that would make it a likely orally active drug in humans. The rule was formulated by Christopher A. Lipinski in 1997.

The rule describes molecular properties important for a drug's pharmacokinetics in the human body, including their absorption, distribution, metabolism, and excretion ("ADME") Components of the Lipinski's rule:

\section{ii) Lipinski's rule states}

- Not more than 5 hydrogen bond donors (nitrogen or oxygen atoms with one or more hydrogen atoms).

- Not more than 10 hydrogen bond acceptors (nitrogen or oxygen atoms).

- A molecular mass less than 500 daltons.

- An octanal-water partition coefficient $\log P$ not greater than 5 .

- No more than one number of violation.

\section{iii) Drug likeness score}

Molinspiration, web based software was used to obtain parameter such as MiLogP, TPSA, drug likeness. MiLogP, is calculated by the methodology developed by Molinspiration as a sum of fragment based contributions and correction factors. MiLog P parameter is used to check good permeability across the cell membrane. TPSA is related to hydrogen bonding potential of compound. Calculation of volume developed at Molinspiration is based on group contributors. Number of rotatable bonds measures molecular flexibility. It is a very good descriptor of absorption and bioavailbility of drugs. 
Through drug likeness datas of molecule, it can be checked molecular properties and structure feature in respect to known drugs.

\section{iv) Bioactivity score}

Bioactivity of the drug can be checked by calculating the activity score of GPCR ligand, ion channel modulator, nuclear receptor legend, kinase inhibitor, protease inhibitor, enzyme inhibitor. All the parameters were checked with the help of software Molinspiration drug-likeness score online (www.molinspiration.com). Calculated drug likeness score of each compounds and compared with the specific activity of each compound, and the results were compared with standard drug. For organic molecules the probability is if the bioactivity score is $(>0)$, then it is active, if (-5.0-0.0) then moderately active, if $(<-5.0)$ then inactive.

\section{DFT using gaussian}

"Density", because the central quantity being computed and manipulated is not the wave function but the electron density. "Functional" because the central operators in the theory are functional -mathematic objects that take functions as arguments and return new functions as output. The "right" functional had been proven to exist, but nobody knows what it is. "Theory", because its science. We call things theories.

A variety of computational methods thus exists to reformulate the "exact" QM equations in one way or another, and then solve those equations algorithmically on a computer. Two basic approaches are DFT and something called Hartree-Fock (HF) theory. A variety of methods have also been developed that either extend HF theory (these are usually called post-HF methods), or mix HF and DFT. Nobel prize in chemistry in 1998 was awarded to Kohn and Pople basically for developments in DFT and HF respectively.

The cytochrome P450 enzymes (CYPs) metabolize many drug compounds. They catalyze a wide variety of reactions, and potentially, a large number of different metabolites can be generated. Density functional theory (DFT) has, over the past decade, been shown to be a powerful tool to rationalize and predict the possible metabolites generated by the CYPs as well as other drug-metabolizing enzymes.

DFT is a useful tool for prediction of the site of metabolism. The use of small models of the enzymes work surprisingly well for most CYP isoforms. This is probably due to the fact that the binding of the substrates is not the major determinant. When binding of the substrate plays a significant role, the wellknown issue of determining the free energy of binding is the challenge.

\section{Materials and methods}

\section{Materials}

Then the plant was identified and authenticated by Plant Anatomy Research Centre (PARC/2017/3467). Phytochemical compounds present in Cassia Auriculata like Dodecanoic acid, Ethyl Caprylate, Glycine (trifluroacetyl) - methyl butyl ester, $\alpha$ - Tocopherol and $\mathrm{n}$ - Hexadecanoic acid as given in (Figure - 1 to 6) were selected for insilico prediction.

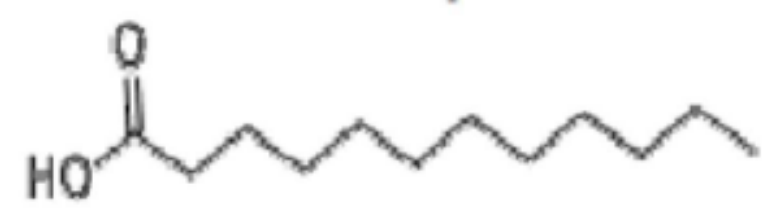

Figure 1. Dodecanoic acid 
DOI: 10.21522/TIJBMS.2016.02.02.Art002

ISSN: 2519-500X

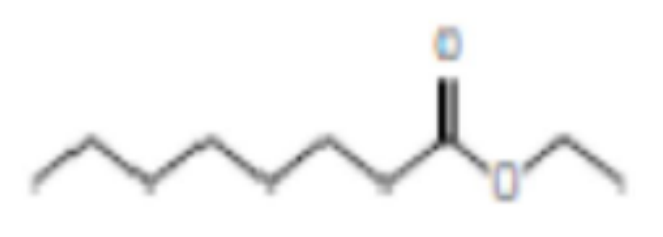

Figure 2. Ethyl caprylate

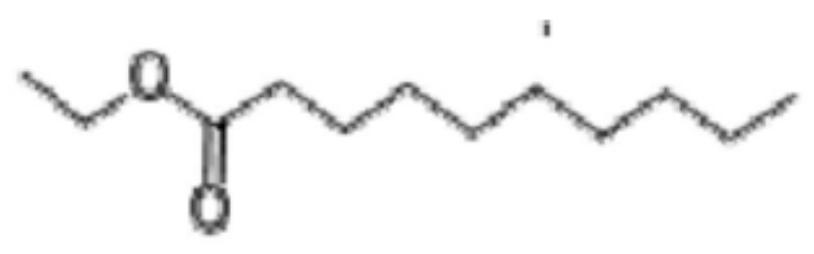

Figure 3. Capric acid ethyl ester

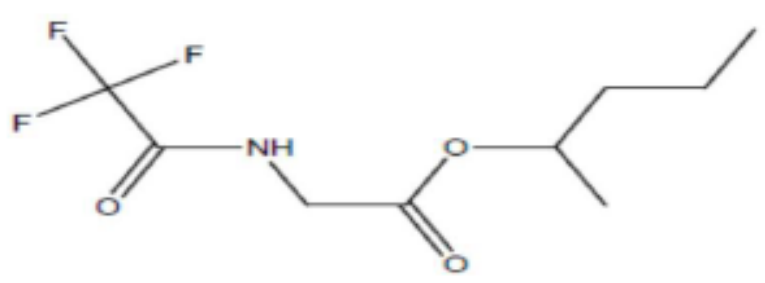

Figure 4. Glycine (trifluoroacetyl)-methyl butyl ester

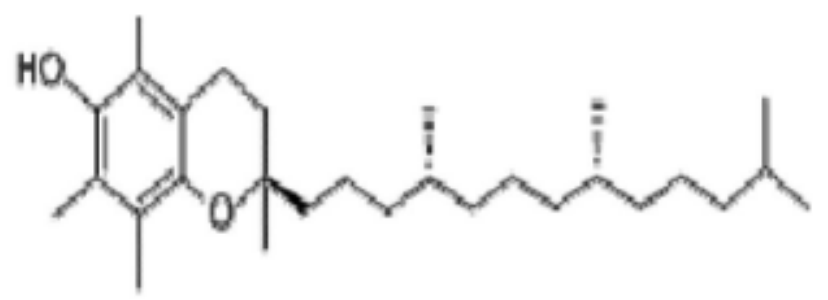

Figure 5. $\alpha$ - Tocopherol

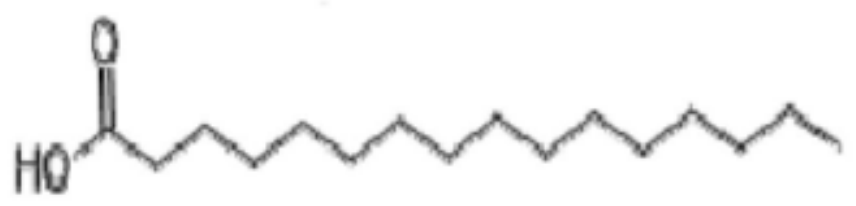

Figure 6. n-Hexadecanoic acid

\section{Methods}

\section{Molinspiration}

Structures of six phytochemical compounds selected for our work as given in Figure - 1 to $\mathbf{6}$ (reported in the literature resources) were drawn using online molinspiration for the calculation of molecular properties like MiLog P, Total polar surface area (TPSA), number of hydrogen bond donors 
Texila International Journal of Basic Medical Science Volume 2, Issue 2, Dec 2017

and acceptors, molecular weight, number of atoms, number of rotatable bonds etc., and bioactivity scores like GPCR ligands, kinase inhibitors, ion channel modulators, enzymes and nuclear receptors.

- The molecular properties and bio-activity scores predicted by molinspiration were given in Table - I a \& b. 


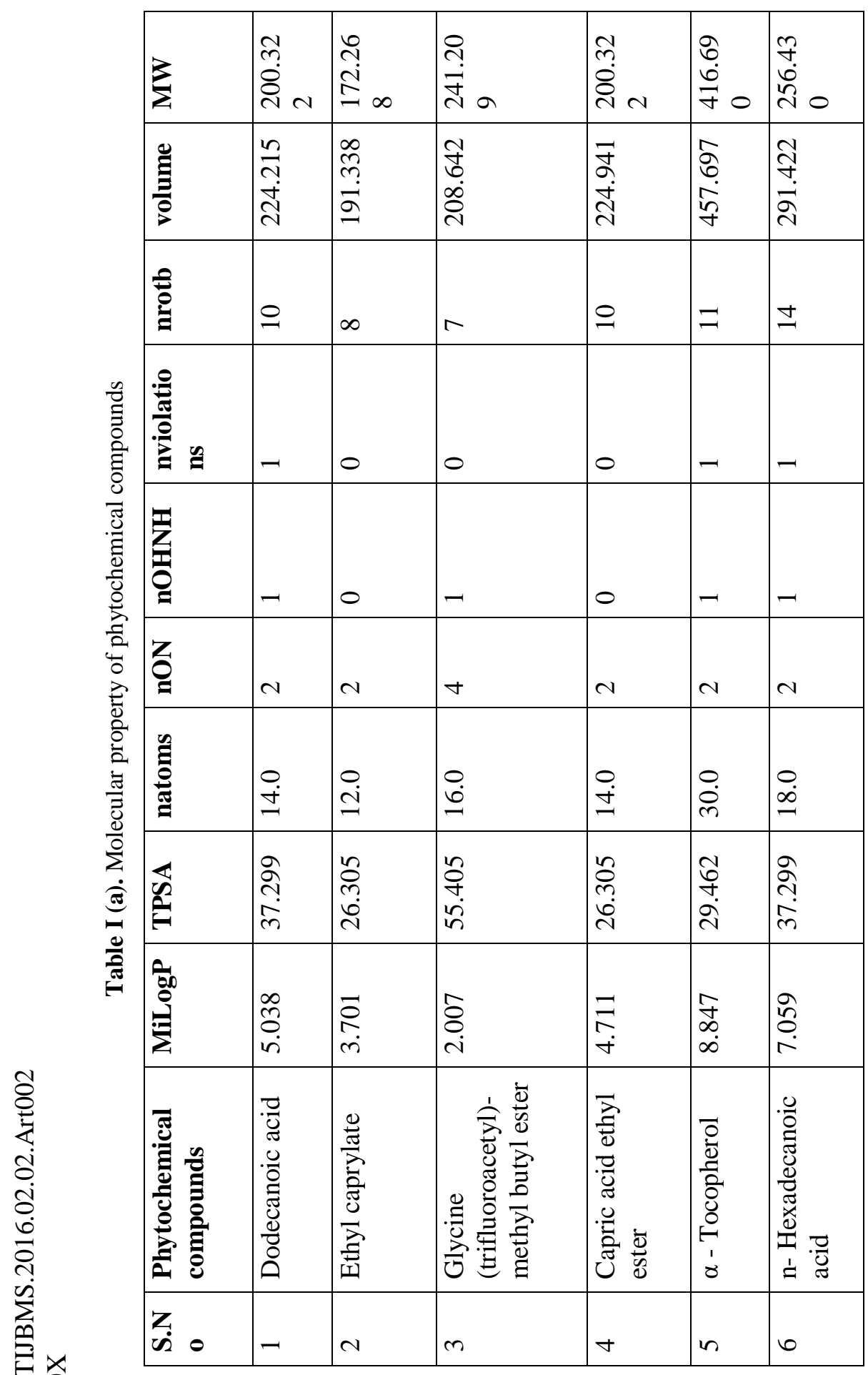

층

กิ่

言就 


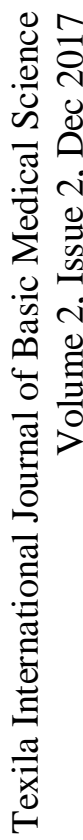

\begin{tabular}{|c|c|c|c|c|c|c|}
\hline 童 & $\stackrel{+}{0}$ & 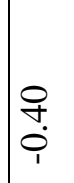 & $\frac{1}{i}$ & 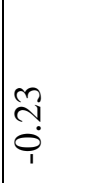 & 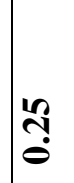 & $\frac{\infty}{0}$ \\
\hline 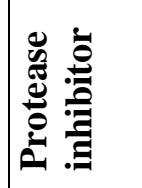 & $\begin{array}{l}\infty \\
\infty \\
i \\
1\end{array}$ & $\mid \begin{array}{l}0 \\
\infty \\
i \\
1\end{array}$ & $\frac{\infty}{i}$ & 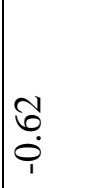 & స్తి & $\begin{array}{l}0 \\
0 \\
\dot{0}\end{array}$ \\
\hline 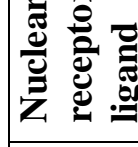 & î & 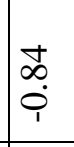 & $\vec{m}$ & 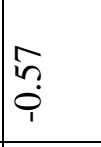 & ָ̂̃ & 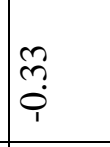 \\
\hline 产 & 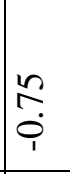 & 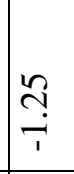 & $\begin{array}{l}\infty \\
\infty \\
\substack{1 \\
i}\end{array}$ & 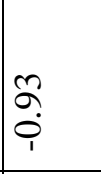 & ָ̂̃ & 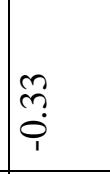 \\
\hline 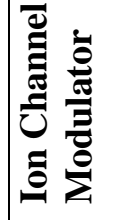 & $\begin{array}{l}\text { to } \\
0 \\
0\end{array}$ & 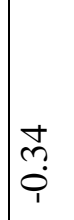 & 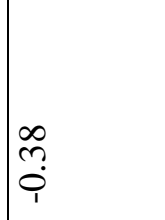 & 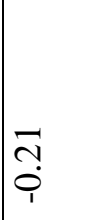 & $\frac{10}{8}$ & $\begin{array}{l}8 \\
0 \\
0\end{array}$ \\
\hline 突 & 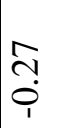 & $\mid \begin{array}{l}\infty \\
\infty \\
0 \\
1\end{array}$ & 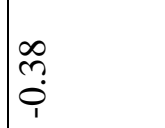 & $\begin{array}{l}0 \\
0 \\
0 \\
0\end{array}$ & 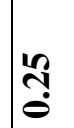 & $\underset{0}{0}$ \\
\hline 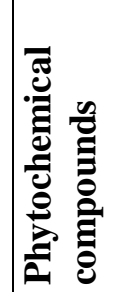 & 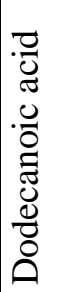 & 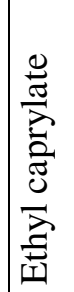 & 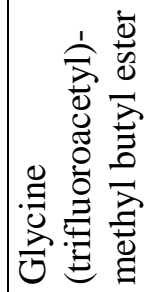 & 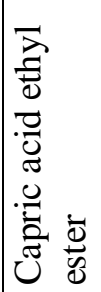 & $\begin{array}{l}\overline{0} \\
\overline{0} \\
\overline{0} \\
\overline{0} \\
0 \\
0 \\
0 \\
1 \\
1 \\
0\end{array}$ & 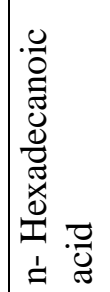 \\
\hline $\begin{array}{l}\sum_{\dot{m}} \\
\dot{\infty}\end{array}$ & - & N & $m$ & t & in & 0 \\
\hline
\end{tabular}


DOI: 10.21522/TIJBMS.2016.02.02.Art002

ISSN: $2519-500 \mathrm{X}$

- For the prediction of Molecular property, the following steps were followed

- Structures were drawn in Molinspiration by opening www.molinspiration.com

- After drawing the structure Click "Go for prediction" button, the Molecular property will appear as given in (Figure-7).

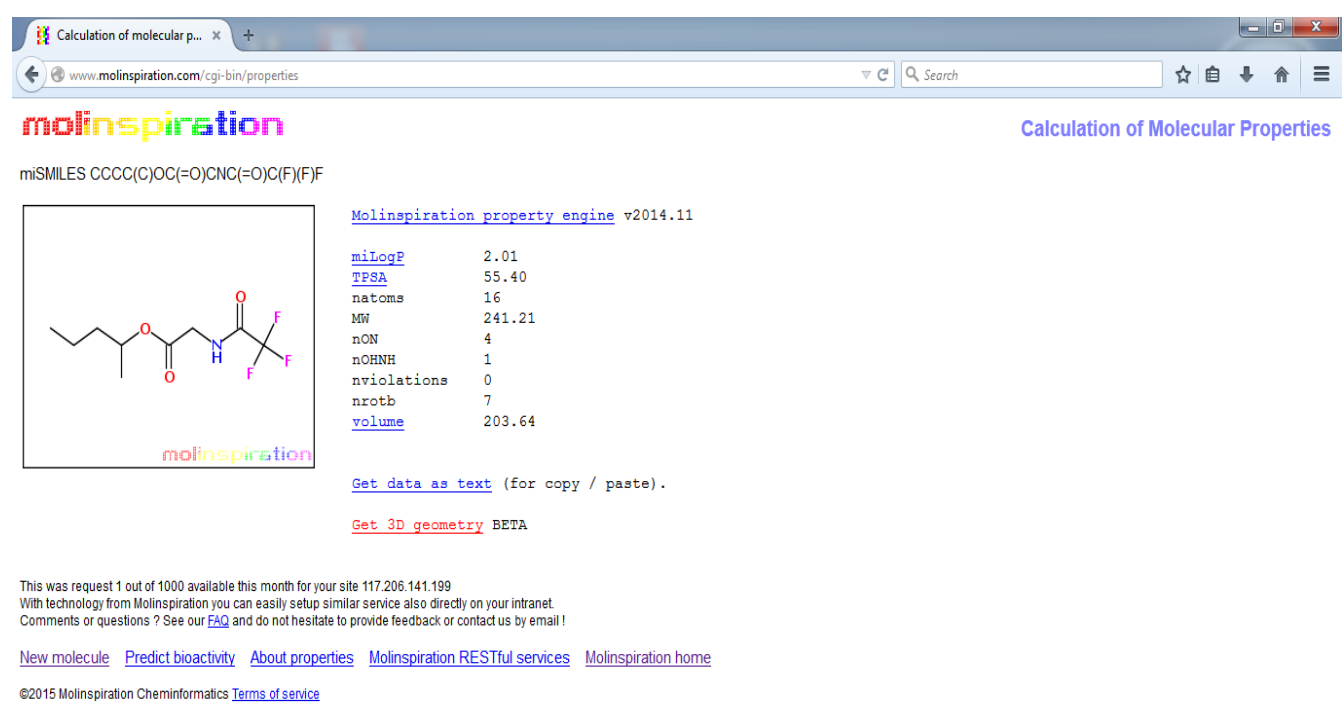

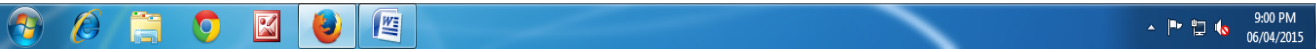

Figure 7. Molecular property setup window

- For bioactivity score prediction Click "Predict bioactivity" the window will appear as given in (Figure-8).

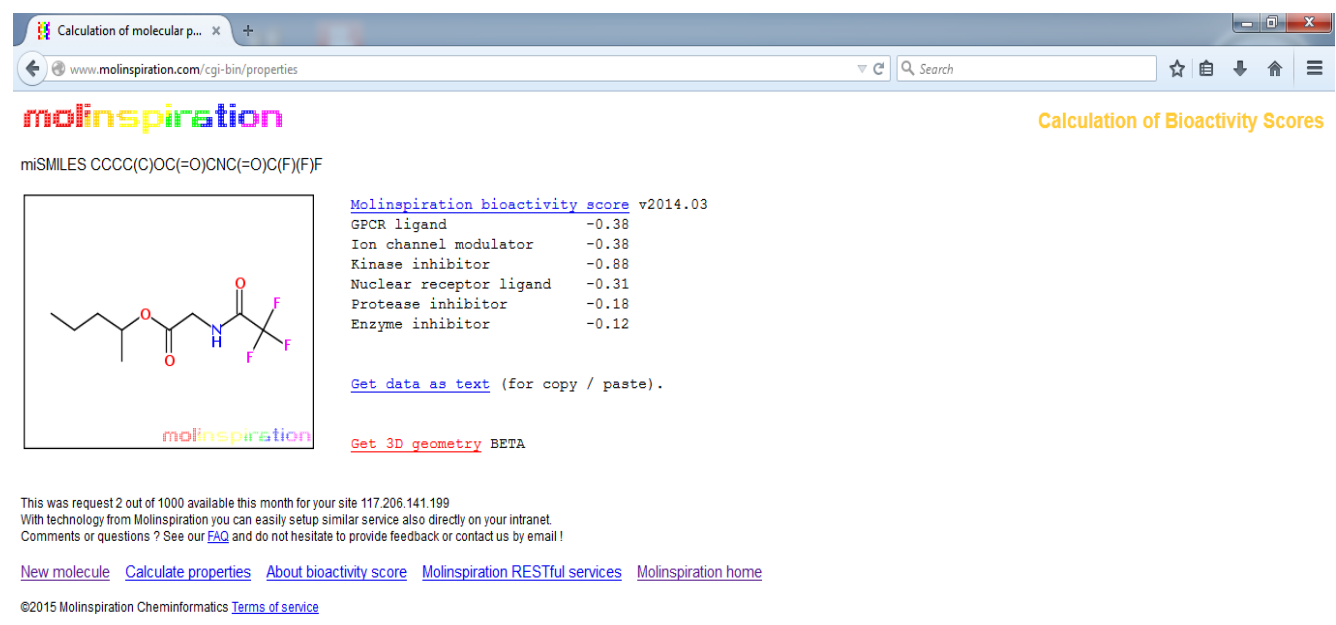

\section{(49) CA}

Figure 8. Bioactivity score setup window

\section{DFT calculation using gaussian}

DFT calculations were carried out using Gaussian software 05. Binding energies of the phytochemical constituent present in Cassia auriculata leaves like Dodecanoic acid, Ethyl caprylate, Glycine (trifluoroacetyl)-methyl butyl ester, Capric acid ethyl ester, $\alpha-$ Tocopherol and n- 
Hexadecanoic acid were calculated by B3LYP and HF methods using STO-3G, 3-21G, 6-31G basis sets [18-19].

In order to predict the binding energy of the phytoconstituents the following steps were carried out.

\section{To draw the structure}

\section{a) Using Gauss View 5.0}

i) To draw the structure of the compounds various steps involved in drawing the chemical structure were

- Open the Gauss view software

- To start a new blank workspace, go to File New Create molecule group

- Go to "View" and L-click the "builder" option "builder" window will open.

- After adding all desired atoms (excluding hydrogens) start the bonding by using the "Modify Bond" option in the "Builder". The two chosen atoms change color and are marked as 1 and 2. In addition, a new window "Semichem Smart Slide" will open press the "OK" push button after choosing the bond.

- Add hydrogen atoms by using the "Add valence" option on the "Builder" window.

- Remove atoms from the structure by using the "Delete Atom" icon on the "Builder" window.

- To save the structure, in Gaussian input file, File save as in "Gaussian input file" as *gif*. The saved file appeared as given in (Figure-9).

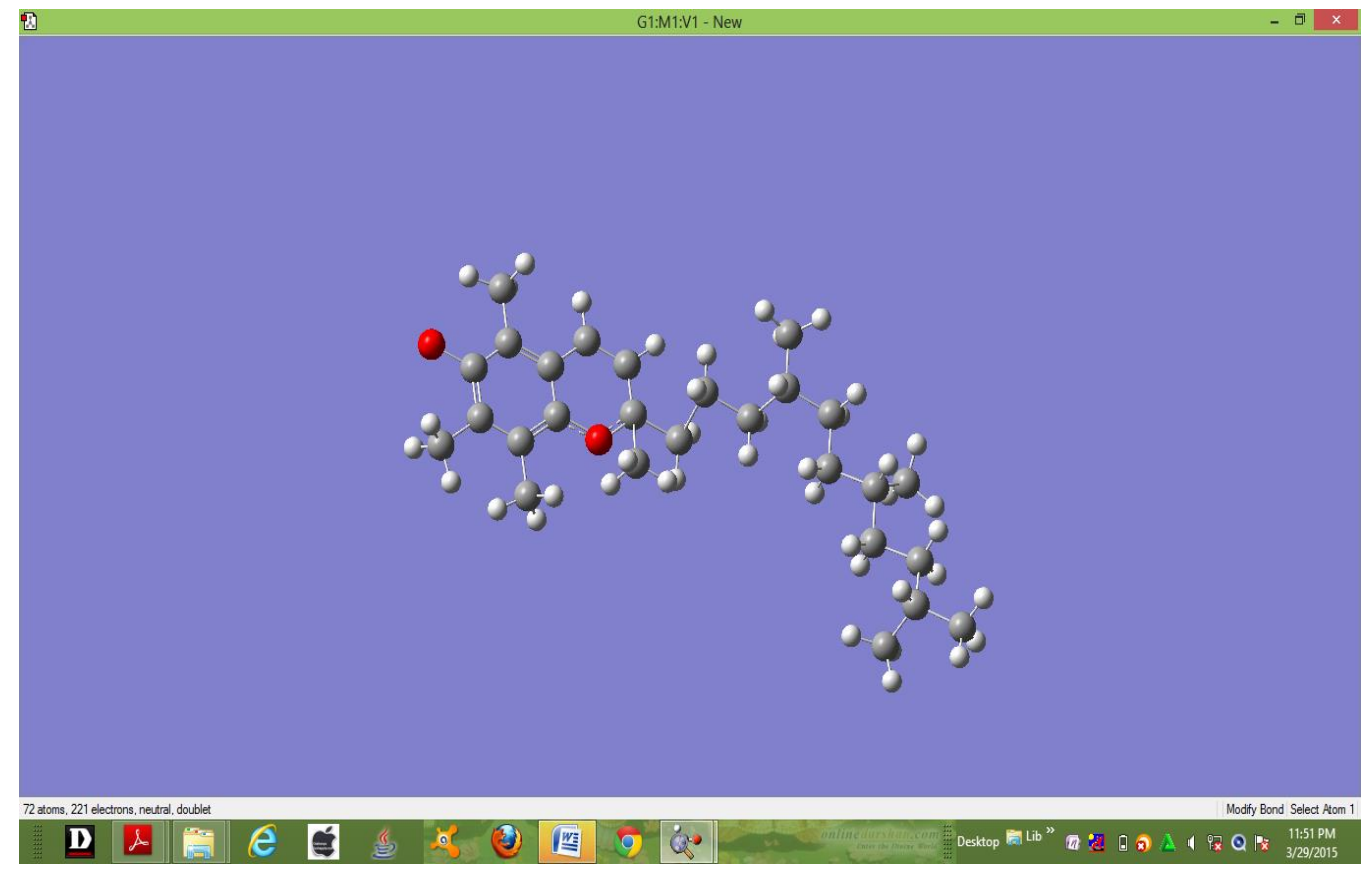

Figure 9. Gauss view of $\alpha$-tocopherol

- Click calculation option in the Gauss view main window menu then open the the Gaussian calculation setup window, which appear as given in (Figure-10). 


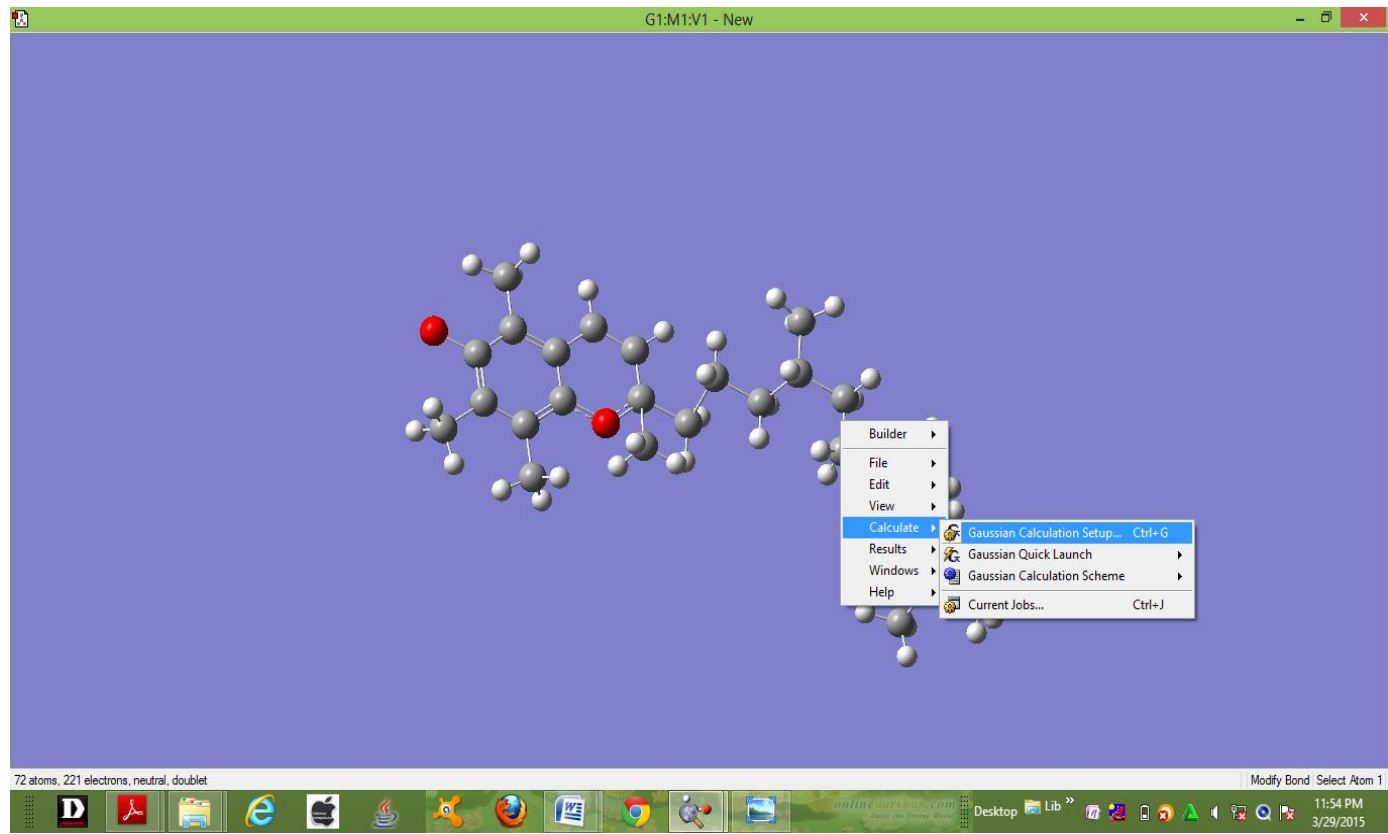

Figure 10. Calculation setup window

Under Job type, look at the various calculation options - like Optimization, frequency scan and energy calculations were used. Choose optimization to calculate the optimum geometry and the window looks like the window given as appeared as (Figure-11).

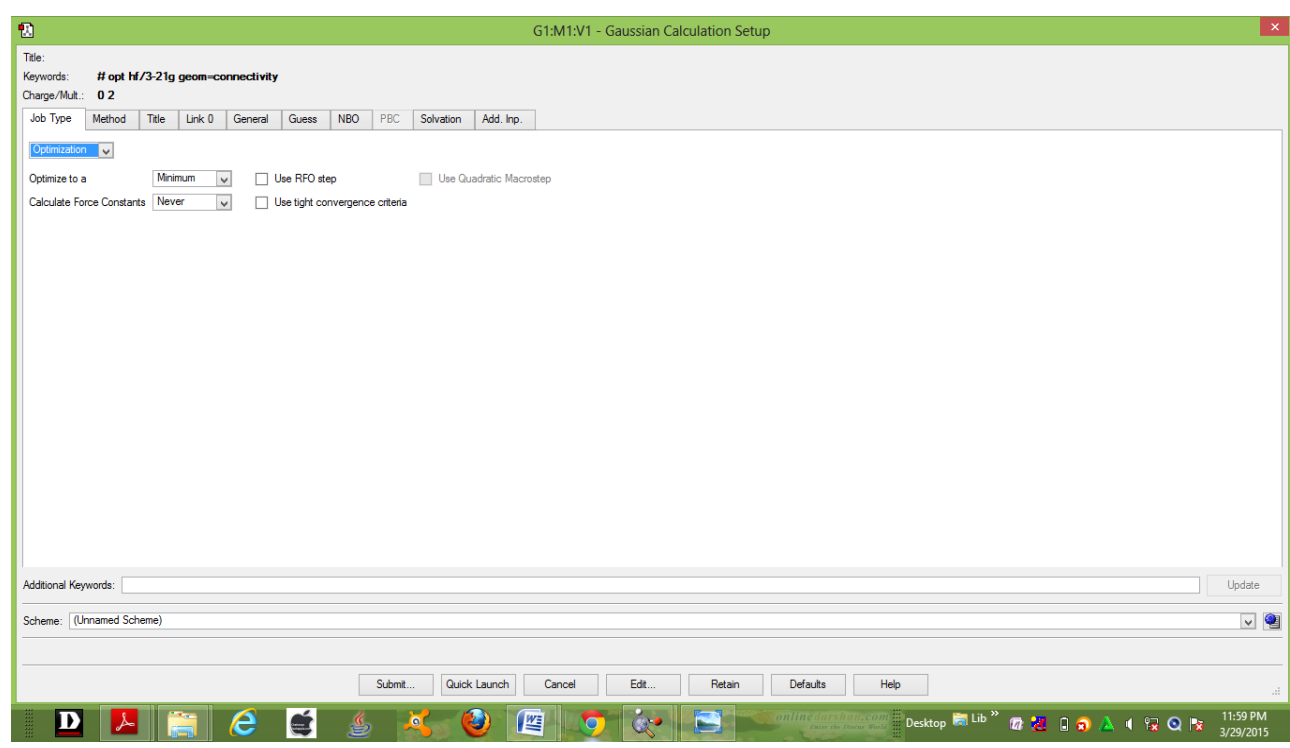

Figure 11. Optimization setup window

To calculate the binding energy by B3LYP, Select B3LYP and the corresponding basis set. The windows appear as given in (Figure-12). 


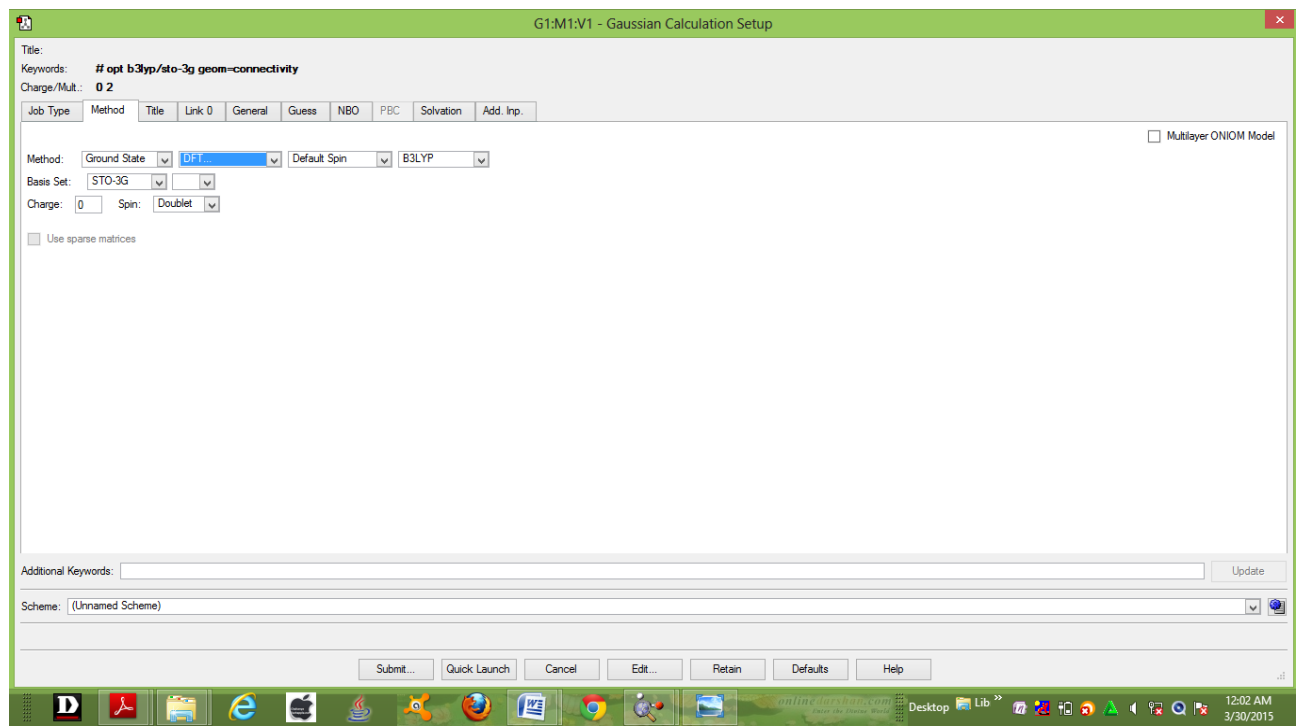

Figure 12. Energy calculation setup window in B3LYP method

On pressing submit button, it send the calculation from Gauss view to Gaussian. After finishing the calculation press "OK" to save the output file. The binding energy of the above six phytochemical compounds predicted by B3LYP method were given in Tables-II.

Table II. Binding energy of phytochemical compounds in B3LYP method

\begin{tabular}{|c|c|c|c|c|}
\hline \multirow[t]{2}{*}{ S.No } & \multirow[t]{2}{*}{ Compounds } & \multicolumn{3}{|l|}{ Basis Sets } \\
\hline & & STO-3G & $3-21 G$ & $6-31 G$ \\
\hline 1 & Dodecanoic acid & -612.9438 & -617.5225 & -620.7334 \\
\hline 2 & Ethyl caprylate & -534.0572 & -538.2141 & -541.0285 \\
\hline 3 & $\begin{array}{l}\text { Glycine(trifluoroacetyl)-methyl butyl } \\
\text { ester }\end{array}$ & -916.3646 & -923.9007 & -928.7137 \\
\hline 4 & Capric acid ethyl ester & -604.5936 & -609.3381 & -612.6145 \\
\hline 5 & $\alpha-$ Tocopherol & -1228.3913 & -1236.9904 & -1243.4557 \\
\hline 6 & n-Hexadecanoic acid & -769.2641 & -774.6944 & -778.7309 \\
\hline
\end{tabular}

To carry out energy calculation using an Abinitio Hartree -Fock model.

Select ground state, HF and set the basis set for 3-21G, the windows appear as (Figure-13). 
DOI: $10.21522 /$ TIJBMS.2016.02.02.Art002

ISSN: $2519-500 \mathrm{X}$

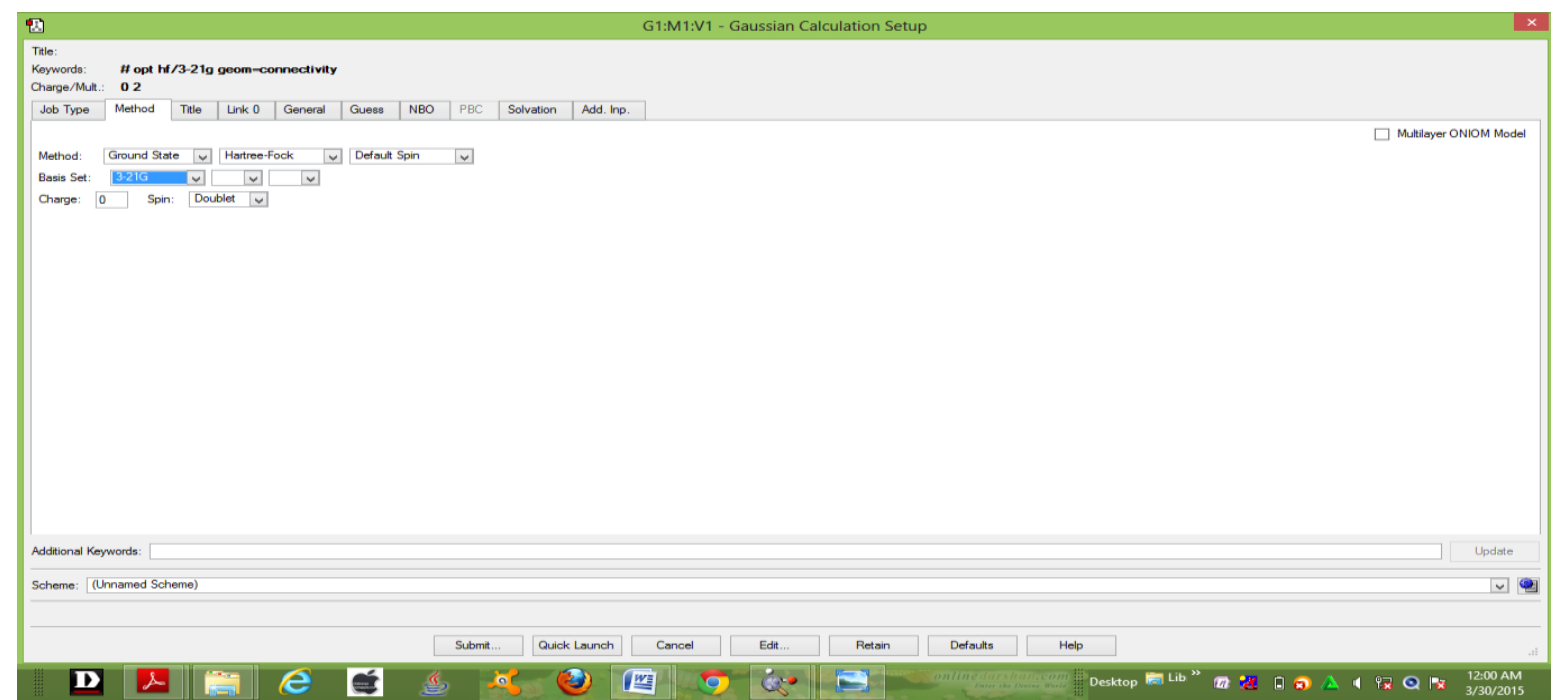

Figure 13. Energy calculation setup window in HF method

The binding energy of the above six phytochemical compounds were predicted by HF method was given in Table-III.

Table III. Binding energy of phytochemical compounds in HF method

\begin{tabular}{|l|l|l|l|l|}
\hline \multirow{2}{*}{ S.No } & Compounds & \multicolumn{2}{l|}{ Basis sets } \\
\cline { 3 - 5 } & & STO-3G & $\mathbf{3 - 2 1 G}$ & $\mathbf{6 - 3 1 G}$ \\
\hline 1 & Dodecanoic acid & -608.6248 & -613.1928 & -616.3251 \\
\hline 2 & Ethyl caprylate & -530.3398 & -534.3699 & -537.1198 \\
\hline 3 & $\begin{array}{l}\text { Glycine(trifluoroacetyl)- } \\
\text { methyl butyl ester }\end{array}$ & -911.4252 & -918.6482 & -923.3547 \\
\hline 4 & Capric acid ethyl ester & -600.4629 & -605.0965 & -608.3111 \\
\hline 5 & $\alpha-$ Tocopherol & -1220.2810 & -1228.4658 & -1234.8000 \\
\hline 6 & n-Hexadecanoic acid & -764.2778 & -769.4424 & -773.3822 \\
\hline
\end{tabular}

\section{Results and discussion}

\section{Molecular property and bio-activity scores}

\section{a) Molecular property of the phytochemical compounds}

Among the six phytochemical compounds selected for insilico drug activity prediction by molinspiration showed that compound 2 and 3 obeyed the Lipinski's rule of five and showed good drug likeness scores. MiLog P values of these compounds were found to be $<5$ (range 2.007 to 3.701) indicated their good permeability across the cell membrane.

All the phytochemical compounds were found to have TPSA well below 160Á2 (26.305 to 55.403), molecular weight $<500$, Number of hydrogen bond donors $<5$, hydrogen bond acceptors $<4$, number of rotatable flexible bonds $<5$ and $n$-violations 0 . These facts indicated that all the six phytoconstituents were found to have drug likeness property. 


\section{b) Bioactivity scores of the compounds}

The bioactivity scores of the six compounds observed were as follows:

\section{i) GPCR ligand}

$\alpha$-Tocopherol (0.25) compound was found to be highly bioactive towards GPCR ligands $(>0)$ and others were found to be moderately active $(<-5-0)$.

\section{ii) Ion channel modulator}

The Ion channel modulator property $\alpha$ - Tocopherol $(0.15)$ was higher $(>0)$ than other compounds $(<0)$.

\section{iii) Kinase inhibitor}

Kinase inhibitor activities of Dodecanoic acid (-0.75), Ethyl caprylate (-1.25), Glycine (trifluoroacetyl)-methyl butyl ester (-0.88), Capric acid ethyl ester (-0.21), $\alpha$-Tocopherol (-0.22) and nHexadecanoic acid (-0.33) were found to moderate as their scores values were found to be less than zero.

\section{iv) Nuclear receptor ligand}

Nuclear receptor ligand as the six compounds was observed to be moderate.

\section{v) Protease inhibitor}

$\alpha$ - Tocopherol was found to be active as Protease inhibitor $0.29(>0)$. Whereas other compounds were found to be moderately active $(<0)$.

\section{vi) Enzyme inhibitor}

$\alpha$-Tocopherol (0.25) and n-Hexadecanoic acid (0.18) were exhibited the enzyme inhibitory action higher $(>0)$ than other compounds $(<0)$. Among these two compound $\alpha$-Tocopherol the enzyme inhibitor activity was higher.

\section{IV - DFT Calculation}

\section{a) B3LYP method}

The binding energy calculation by using three basis sets (STO-3G, 3-21G, 6-31G) listed in Table-II showed the following result.

The binding energies for the Dodecanoic acid, Ethyl caprylate, Glycine (trifluoroacetyl) methyl butyl ester, Capric acid ethyl ester, $\alpha$ - Tocopherol and n-Hexadecanoic acid compounds using STO-3G basis were to be $-612.9438,-534.0572,-916.3646,-604.5936,-1228.3913$ and -769.2641 a.u. From the above data it was found that $\alpha$ - Tocopherol was found to have good binding energy as -1228.3913 a.u. among the other bio-active constituents. Using 3-21G basis sets, the binding energies were found to be 617.5225, -538.2141, -923.9007, -609.3381, - 1236.9904 and -774.6944 a.u. for the above compounds respectively. From these data it was found that $\alpha$-Tocopherol have a good binding energy as -1236.9904 a.u among the other bio-active constituents. The binding energies of the above six compounds by 6$31 \mathrm{G}$ basis sets were found to be $-620.7334,-541.0285,-928.7137,-612.6145,-1243.4557$ and 778.7309 a.u. From the above data it was concluded that $\alpha$-Tocopherol was found to have a good binding energy as -1243.4557 a.u. among the other bio-active constituents. It was observed that $\alpha$ Tocopherol was found to have $\mathbf{- 1 2 2 8 . 3 9 1 3 , - 1 2 3 6 . 9 9 0 4 , ~ - 1 2 4 3 . 4 5 5 7}$ a.u. binding energies as per the above three basis sets and hence it was found to be more stable than other bio-active constituents.

\section{b) HF method}

The binding energy calculation by HF method were listed in Table-III showed the following Observations. STO-3G basis sets, the binding energy for the selected six compounds were found $608.6248,-530.3398,-911.4252,-600.4629,-1220.2810$ and -764.2778 a.u. and it was found that $\alpha-$ Tocopherol (-1220.2810 a.u.) have good binding energy. 
Using 3-21G basis sets, the binding energies were found to be $-613.1928,-534.3699,-918.6482$, $605.0965,-1228.4658$ and -769.4424 a.u. for the six compounds. From these data, $\alpha$-Tocopherol (1228.4658 a.u.) was found to be more stable.

The binding energies observed using 6-31G basis sets for the above six compounds were found to $616.3251,-537.1198,-923.3547,-608.3111,-1234.8000$ and -773.3822 a.u. From these data it was found that $\alpha$ - Tocopherol (-1234.8000 a.u.) was found to be more stable among other compounds.

- Phytochemical compounds selected for our work (Figure- 1 to 6) were found to obey the Lipinski's rule (MiLog P <5) and $\alpha$ - Tocopherol (2.007) exhibited higher drug likeness properties compared to others. $\alpha$ - Tocopherol exhibited the highest score towards GPCR ligand, $(0.25)$ nuclear receptor ligand (0.43) and inhibitory activities towards protease (0.29), enzyme (0.25) and kinase $(-0.22)$ inhibitors as higher compared to others.

- DFT method for determination of binding energy of the six phytoconstituent revealed that $\alpha$ Tocopherol was found to possesses good binding energy among others hence it was found to be more stable.

\section{Conclusion}

Phytochemical compounds selected for our work (Figure- 1 to 6) were found to obey the Lipinski's rule (MiLog $\mathrm{P}<5)$ and $\alpha$ - Tocopherol (2.007) exhibited higher drug likeness properties compared to others. $\alpha$ - Tocopherol exhibited the highest score towards GPCR ligand, $(0.25)$ nuclear receptor ligand $(0.43)$ and inhibitory activities towards protease $(0.29)$, enzyme $(0.25)$ and kinase $(-0.22)$ inhibitors as higher compared to others. DFT method for determination of binding energy of the six phytoconstituent revealed that $\alpha$ - Tocopherol was found to possesses good binding energy among others hence it was found to be more stable.

\section{References}

[1]. Anastas, P.T. I.J. Levy, K.E. Parent (Eds). Green Chemistry Education. Changing the Course of Chemistry, ACS Publications, Washington DC, 2009.

[2]. Basu and Kirtikar. Indian Medicinal Plants. Vol. II, Second edition .International Book distributors Dehradun India, 867-868; 1935.

[3]. Diebold. U. The surface science of titanium dioxide. Sur Sci Rep, 48: 53-229; 2003. http://www.molinspiration.com.

[4]. Evans. W.C. Trease and Evans Pharmacognosy W.B. Saunders Company Ltd., London, pp (14th Edition). 19-20; 2000.

[5]. Grossman. E. Chasing Molecules: Poisonous Products, Human Health, and the Promise of Green Chemistry. Island Press, New York, 2009.

[6]. Lipinski, C.A. F. Lombardo, B.W. Dominy, P.J. Feeney. Adv Drug Delivery Rev., 23(1-3):3-25; 1997.

[7]. Lipinski, C.A. F. Lombardo, B.W. Dominy, P.J. Feeney. Adv Drug Deliv Rev; 46 (1-3): 3-26; 2001.

[8]. Lipinski. C.A. Drug Discovery Today: Technologies; 1 (4): 337-34; 2004.

[9]. Mossi, Mazutti, A.J. M. Paroul, N. Corazza, M.L. Dariva, C. Cansian \& R.L. Oliveira, O.R. Rocha, R.F. Dantas, M.M.M.B. Duarte, et al. Oil sludge treatment by photocatalysis applying black and white light. Chem Eng J, 157: 80-85; 2010.

[10]. Mukunthan, K.S. E.K. Elumalai, N.P. Trupti, V. Ramachandra Murty. Catharanthus roseus: a natural source for the synthesis of silver nanoparticles. Asian Pacific Journal of Tropical Biomedicine, 270-274; 2011.

[11]. Newman, D.J. G.M. Cragg, K.M. Snadder. J. Nat. Prod., 66(7): 1022 -1037; 2003.

[12]. Prakash. S.K. Int. J. Poultry Sci. 5: 259-261; 2006.

[13]. Sharma. S.K. Green Chemistry for Environmental Sustainability. Series: Advancing Sustainability Through Green Chemistry and Engineering. CRC Press, Boca Raton, FL, 2010.

[14]. Thirumurgan, A. N.A. Tomy, R. Jai Ganesh, S. Gobikrishnan. Biological reduction of silver nanoparticles using plant leaf extracts and its effect an increased antimicrobial activity against clinically isolated organism. $D e$. Phar. Chem, 2: 279-284; 2010.

[15]. Tripathy, A. A.M. Raichur, N. Chandrasekaran, T.C. Prathna, A. Mukherjee. J. Nanopart. Res.12, 237; 2010.

DOI: $10.1007 / \mathrm{s} 11051-009-9602-5$

[16]. Tagboto, S. S. Townson. Adv. Parasitol., 50: 199-295; 2001. 
Texila International Journal of Basic Medical Science Volume 2, Issue 2, Dec 2017

[17]. Thompson, T.L. J.T. Yates Jr. Surface science studies of the photoactivation of TiO2-New photochemical processes. Chem Rev, 106: 4428-4453; 2006. 


\title{
Nephroprotective Potential Compounds from Leaves Extracts of Andrographis Paniculata
}

\author{
Article by K. Padmalochana ${ }^{1}$ and M.S. Dhana Rajan ${ }^{2}$ \\ ${ }^{1}$ Research Scholar, Bharathiar University, Coimbatore, Tamil Nadu, India \\ ${ }^{2}$ Registrar, Texila American University, Guyana, South America \\ E-mail: kpadmalochana@gmail.com ${ }^{1}$
}

\begin{abstract}
Nephrotoxicity is the third most common problem of the renal system. Medicinal plants potentially useful for the treatment of severe renal disorders. In the present study, the effect of aqueous, ethanol and acetone extract of Andrographis paniculata leaves was evaluated by pretreating three groups of rat animals. Renal failure was induced by antibiotic drug gentamicin which was orally administered to group II animals and untreated control model was maintained. After oral administration for 10 days, serum levels of urea, uric acid, creatinine and total protein were assayed. All the biochemical parameters were significantly controlled $(p<0.01$ and $p<0.001)$ on $10^{\text {th }}$ day after the treatment of aqueous, ethanol and acetone extracts as compared than the gentamicin induced nephrotoxic animals $(p<0.05)$. Maximum nephroprotection was offered by the ethanol extract of A. paniculata leaves $(p<0.001)$. The histological structure of renal was observed by staining with haemotoxylin- eosin viewed using light microscope. Gentamicin treated animals showed acute tubular necrosis due the injury in kidney. In aqueous, ethanol and acetone extract treated animals showed histopathological changes in renal revealed the nephroprotective activity of A. paniculata leaves. Finally, ethanol extract of A. paniculata was more suitable for nephroprotective action against gentamicin induced renal failure was evidenced by biochemical estimation and by restoration of histological changes of renal system.
\end{abstract}

Keywords: Kidney, Nephroprotection, Andrographis paniculata, Herbal Medicine.

\section{Introduction}

Kidney is the complex and major organ of our body perform several important functions like formation of urine, water and salt metabolism, acid-base balance, regulation of blood calcium level ${ }^{[1]}$ and secretion of hormones. ${ }^{[2]}$ Kidney affected by the diseases are mainly kidney blockage and kidney stones. Major types of stones in kidney are calcium stones, stuvite stones, uric acid stones and cysteine stones. ${ }^{[3]}$ Acute renal failures and chronic renal failure are common and serious problems. Acute renal failure is reversible loss of kidney function whereas chronic renal failure is irreversible loss of kidney function. ${ }^{[4]}$

Nephrotoxicity is one of the major kidney problems caused by drug or toxin ${ }^{[5]}$ Drugs, diagnostic agents, chemical reagents and heavy metals are well known to be nephrotoxic. ${ }^{[6]}$ In recent years, development of modern medical, and surgical practices has been followed for the treatment of renal failure like haemodialysis, renal transplantation and chemotherapy. These procedures are complicated and high cost has been utilized to cure the kidney damage. So that the traditional medicine using herbal plant is best method than the conventional method. However, when using these chemotherapy method may induce the side effects to the body. ${ }^{[7]}$ Nephroprotective agents are the substances which possess protective activity against nephrotoxicity. Drugs like gentamicin, cisplatin, cyclosporine, Carbon tetrachloride are common source of acute kidney injury. Gentamicin is an amino glycoside antibiotics used for the treatment of Gram negative bacterial infections. Overdose of gentamicin causes renal damage. It may give serious side effects while continuous consuming at higher concentrations.

Medicinal plants are have curative properties and therapeutic values due to the presence of various complex phytochemical compounds. This traditional medicines are assuming greater important because of very effective, safer, locally available, and no side effects. ${ }^{[8,9]}$ A. paniculata, a member of the family of Acanthaceae is locally and commonly available plant in India. It is commonly called as "nilavembu or siriyanangai" in Tamil and "King of bitters" in English. It has been shown hepatoprotective, anti- 
DOI: 10.21522/TIJBMS.2016.02.02.Art003

ISSN: $2519-500 \mathrm{X}$

parasitic, antioxidant anti-inflammatory and antimicrobial activity. And used helps in malaria treatment and treatment of cancer. ${ }^{[10]}$ In this study reported that curative properties of the medicinal plant Andrographis paniculata against nephrotoxicity induced by gentamicin in albino rats. Nephroprotective activity was confirmed by examine biochemical tests for urea, uric acid creatinine and protein level in blood and histopathological studies carried out using light microscopic observations.

\section{Materials and methods}

\section{Preparation of plant leaf extracts}

Leaves of Andrographis paniculatawere collected and shade dried for 3-5 days and grinded into powder. Aqueous extract was prepared by adding dried powder into $100 \mathrm{ml}$ water and incubate overnight. $100 \mathrm{~g}$ dry powder was extracted with $80 \%$ ethanol at $55^{\circ} \mathrm{C}$ for 24 hours in soxhlet apparatus. Acetone extract was prepared by mixing of dried leaf powder with the $80 \%$ acetone. Solvent elimination was done at room temperature and stored. The resulting aqueous, ethanol and acetone extracts were then used for nephroprotective activity.

\section{Experimental Design for nephroprotective Activity of Andrographis paniculata}

Adult male Wister albino rats maintained at the college weighing between $150 \mathrm{~g}-170 \mathrm{~g}$ were used for the nephroprotective studies. Animals were divided into six groups insix rats each. Group I (Normal): Orally received distilled water for 10 days.

Group II (Induced): Orally received Gentamicin ( $80 \mathrm{mg} / \mathrm{kg}$ body weight) only for 10 days. Group III (Standard): Orally received Cystone $(20 \mathrm{mg} / \mathrm{kg}$ body weight) along with gentamicin $(80 \mathrm{mg} / \mathrm{kg}$ body weight) for 10 days.

Group IV (Treatment): Orally received aqueousleaf extract (300mg/kg body weight) along with Gentamicin ( $80 \mathrm{mg} / \mathrm{kg}$ body weight) for 10 days.

Group V (Treatment): Orally received ethanol leaf extract $(300 \mathrm{mg} / \mathrm{kg}$ body weight) along with Gentamicin ( $80 \mathrm{mg} / \mathrm{kg}$ body weight) for 10 days.

Group VI (Treatment): Orally received acetone leafextract (300mg/kg body weight) along with Gentamicin ( $80 \mathrm{mg} / \mathrm{kg}$ body weight) for 10 days.

Cystone was used as positive control for comparing nephroprotective potential of different leaves extract of A. paniculata. Gentamicin is act as nephrotoxin which induces the kidney damage.

\section{Histopathological and biochemical study}

After 10 days, all animals from every group were sacrificed and separated the kidneys by dissection procedure. Pieces of kidneys obtained from each group were immediately fixed in $10 \%$ formalin solution. The fixed formalin fixed kidneys were embedded in paraffin and serial section were made and stained with haemotoxylin and eosin. The stained sections were examined under light microscope. Blood samples were collected from jugular vein. Serum was separated from the blood for the analysis of the parameters like Blood Urea ${ }^{[11]}$, Uric Acid ${ }^{[12]}$, Creatinine ${ }^{[13]}$ and Total Protein. ${ }^{[14]}$

\section{Statistical analysis}

Data were analyzed using one way Analysis of Variance (ANOVA) and expressed as mean \pm S.E.M. Statistical significance was fixed $\mathrm{p}<0.05$.

\section{Results and discussion}

\section{Biochemical studies}

The nephroprotective activity of aqueous, ethanol and acetone extract of A. paniculata leaves was assessed against nephrotoxicity induced using gentamicin in albino rats. The nephroprotective activity was determined by biochemical tests and histopathological studies. Table 1 shows the changes of urea and uric acid level in blood. Blood urea and blood uric acid in the control (group I) was estimated to be $30.16 \pm 1.72 \mathrm{mg} / \mathrm{dl}$ and $5.08 \pm 0.21 \mathrm{mg} / \mathrm{dl}$, respectively. In the negative control i.e. group II animals received only gentamicin which shows level of urea and uric acid in blood to be $59.00 \pm 2.19 \mathrm{mg} / \mathrm{dl}$ and $8.25 \pm 0.54 \mathrm{mg} / \mathrm{dl}$, respectively. Group IV, V and VI animals received gentamicin along with aqueous leaf extract, ethanol and acetone extract demonstrated a significant increase $(p<0.05$ to $p<0.001)$ in 
blood urea and uric acid as compared with negative control group. In the ethanol treated groups shows most significant changes $(\mathrm{p}<0.001)$ in urea and uric acid recorded as $33.28 \pm 0.54 \mathrm{mg} / \mathrm{dl}$ and $5.21 \pm 0.12 \mathrm{mg} / \mathrm{dl}$ as compared with aqueous and acetone extract (Figure 1).

Creatinine concentrations in blood was significantly increased $(p<0.05)$ in the gentamicin treated negative control group of animals $(2.88 \pm 0.11 \mathrm{mg} / \mathrm{dl})$ compared to the normal animals indicating the induction of severe nephrotoxicity. Treatment with plant extracts of A. paniculata showed significant $(\mathrm{p}<0.01$ and $\mathrm{p}<0.001)$ increase in creatinine concentrations. Ethanol extract treated animals showed increased significant changes $(\mathrm{p}<0.001)$ recorded as $0.82 \pm 0.54 \mathrm{mg} / \mathrm{dl}$ concentrations of creatinine, indicates that nephrotoxicity curative properties of A. paniculata leaves (Table 2).

Normal total protein level was observed in group I animals. Gentamicin treated group II animals showed low amount of secretion of total proteins $(\mathrm{p}<0.05)$ as compared to normal animals. This low protein level in serum is probably due to an inhibitory action of protein synthesis induction of tissue damage and may leads to increased excretion of protein in urine (Ramesh et al 2014). Treatment with the plant extracts of $A$. paniculata (group IV, V and VI) showed ( $<<0.01$ and $\mathrm{p}<0.001$ ) increase in concentrations of total protein compared to the gentamicin treated groups (group II) (Table 2, Figure 2).

This inhibitory action of A. paniculata leaves extract against nephrotoxin was confirmed through biochemical and histopathological studies. This activity may due to the presence of secondary metabolites like flavonoid and polypheolic compounds which may be responsible for the kidney protective activity.

\section{Figure captions}

Table 1. Effect of aqueous, ethanol and acetone extract of $A$. paniculata leaves on blood urea and uric acid in gentamicin induced nephrotoxic rats

\begin{tabular}{|l|l|l|}
\hline Parameters & $\begin{array}{l}\text { Blood } \\
\text { Urea(mg/dl) }\end{array}$ & $\begin{array}{l}\text { Blood Uric } \\
\text { acid (mg/dl) }\end{array}$ \\
\hline Group I (Normal) & $30.16+1.72$ & $5.08+0.21$ \\
\hline Group II (induced) & $59.00+2.19^{*}$ & $8.28+0.54^{*}$ \\
\hline Group III (Standard drug) & $34.83+3.06^{* *}$ & $5.95+0.21^{* *}$ \\
\hline Group IV (Aqueous) & $36.16+2.48^{* *}$ & $6.12+0.33^{* *}$ \\
\hline Group V (Ethanol) & $33.28+0.54^{* * *}$ & $5.21+0.12^{* * *}$ \\
\hline Group VI (acetone) & $39.08+0.21^{* * *}$ & $6.36+0.13^{* * *}$ \\
\hline
\end{tabular}

$* \mathbf{p}<\mathbf{0 . 0 5}, * * \mathbf{p}<\mathbf{0 . 0 1}, * * * \mathbf{p}<\mathbf{0 . 0 0 1}$ value are considered statistically significant $(\mathrm{BMRT})$

Table 2. Effect of aqueous, ethanol and acetone extract of A. paniculata leaves on creatinine and total protein levels in gentamicin induced nephrotoxic rats

\begin{tabular}{|l|l|l|}
\hline Parameters & $\begin{array}{l}\text { Creatinine } \\
(\mathbf{m g} / \mathbf{d l})\end{array}$ & $\begin{array}{l}\text { Total protein } \\
(\mathbf{m g} / \mathbf{d l})\end{array}$ \\
\hline Group I (Normal) & $0.79+0.02$ & $6.91+0.59$ \\
\hline Group II (induced) & $2.88+011^{*}$ & $3.02+0.84^{*}$ \\
\hline Group III (Standard drug) & $1.21+0.12^{* *}$ & $7.55+0.70^{* *}$ \\
\hline Group IV (Aqueous) & $1.11+0.13^{* * *}$ & $7.12+0.77^{* *}$ \\
\hline Group V (Ethanol) & $0.82+0.54^{* * *}$ & $7.91+0.12^{* * *}$ \\
\hline Group VI (acetone) & $1.38+0.21^{* *}$ & $7.56+0.13^{* * *}$ \\
\hline
\end{tabular}

$* \mathbf{p}<\mathbf{0 . 0 5}, * * \mathbf{p}<\mathbf{0 . 0 1}, * * * \mathbf{p}<\mathbf{0 . 0 0 1}$ value are considered statistically significant $(\mathrm{BMRT})$ 
DOI: 10.21522/TIJBMS.2016.02.02.Art003

ISSN: $2519-500 \mathrm{X}$

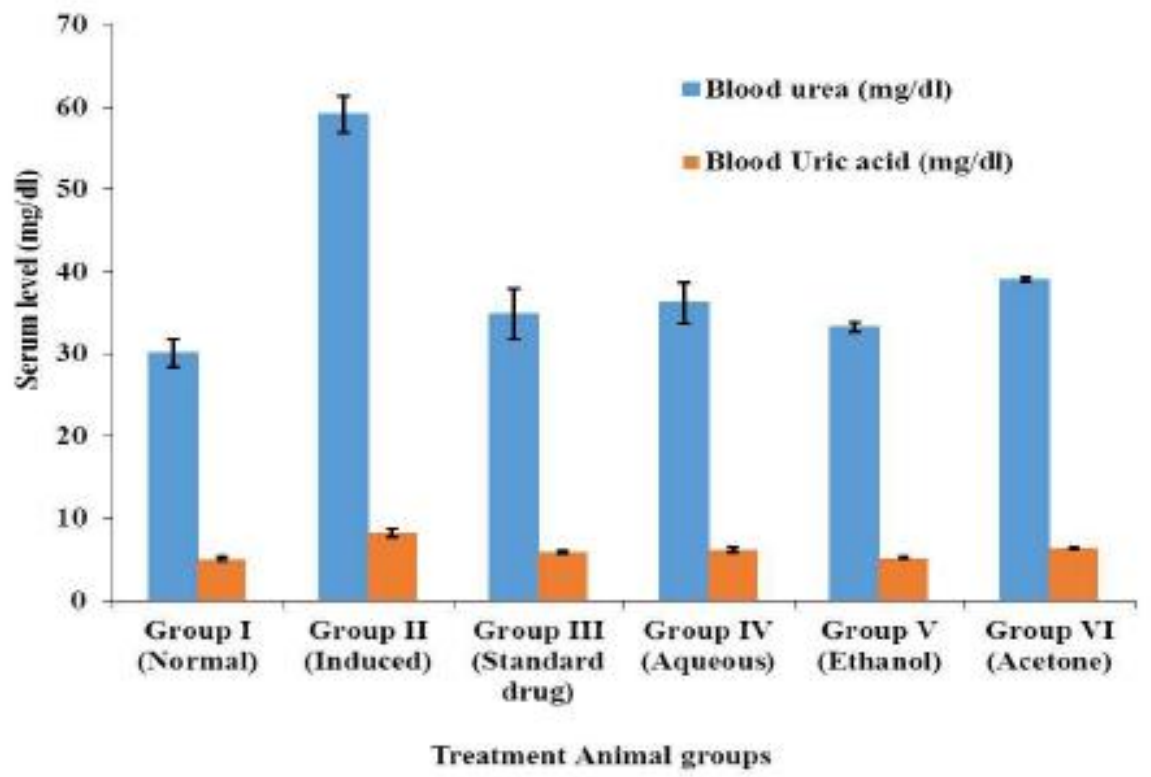

Figure 1. Effect of aqueous, ethanol and acetone A. paniculata leaves extract on the alterations of urea, and uric acid level in blood

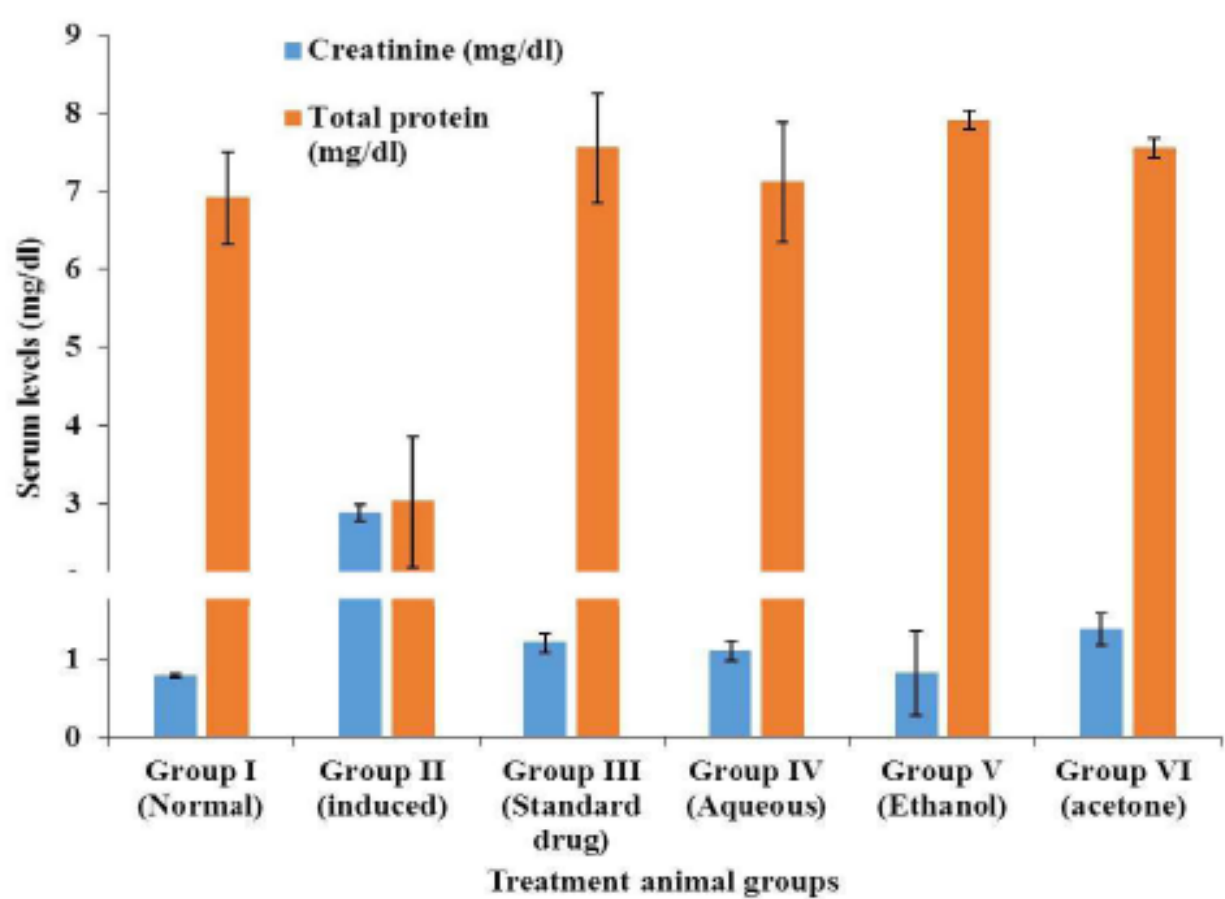

Figure 2. Effect of aqueous, ethanol and acetone A. paniculata leaves extract on the alterations of creatinine, and total protein level in blood 

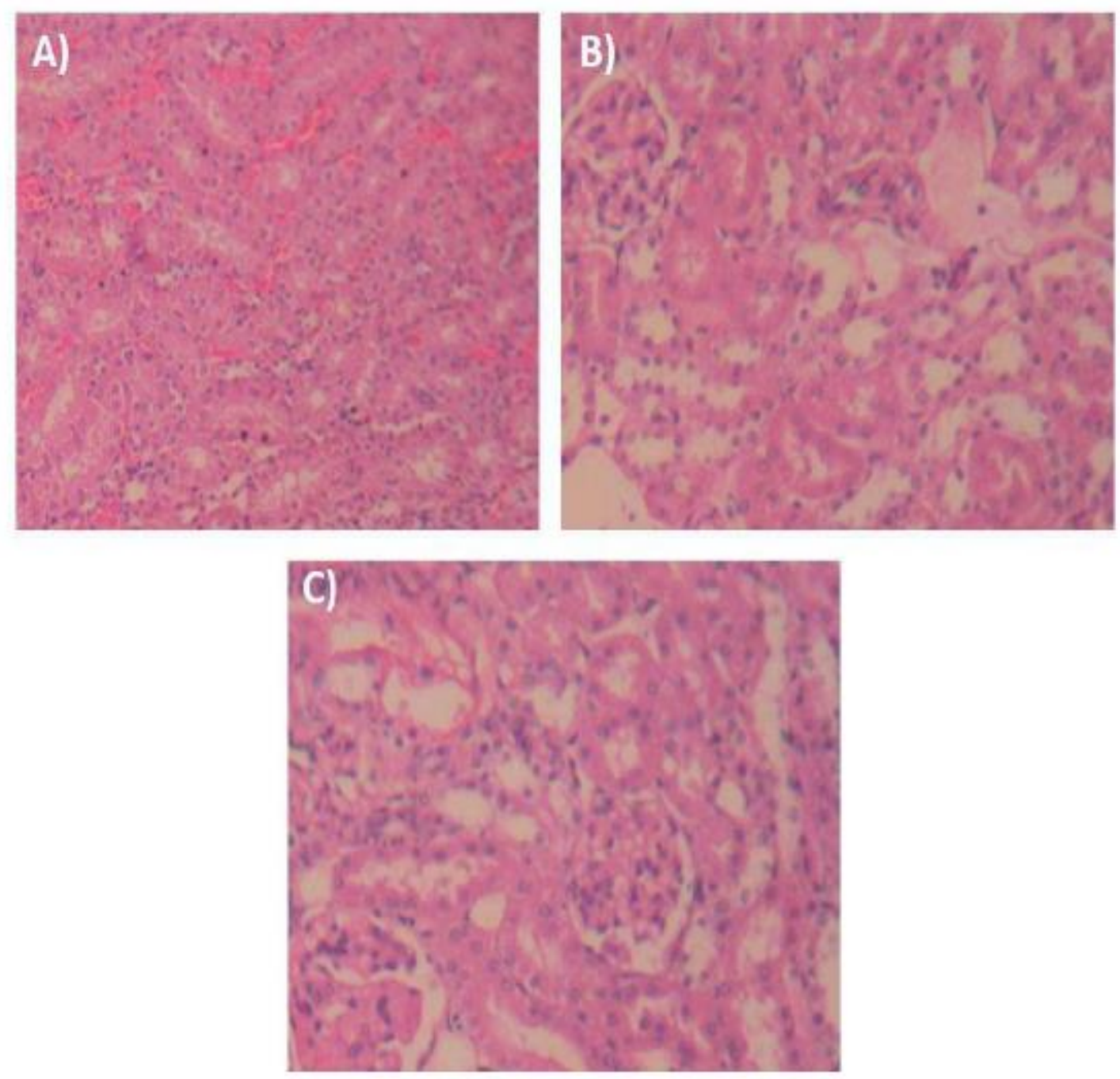

Figure 3. Sectioning of (A) normal kidney showing tubular brush borders and intact glomeruli in renal tissues without alterations (B) Representing the tubular necrosis in gentamicin treated animals (C) shows microscopic observation of normalized kidney structure on treated with cystone is a positive control 
DOI: 10.21522/TIJBMS.2016.02.02.Art003

ISSN: $2519-500 \mathrm{X}$
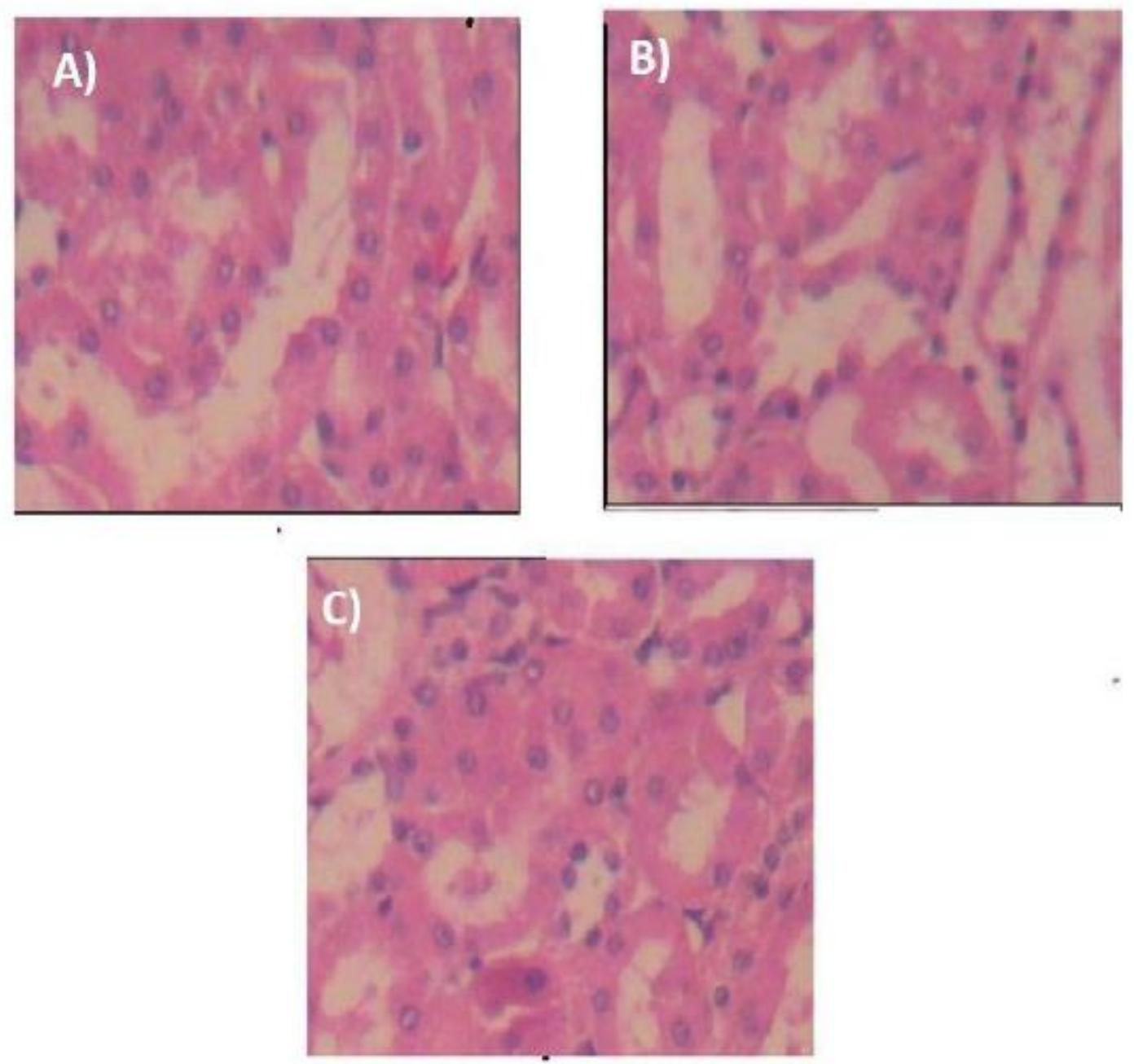

Figure 4. Shows histological structure of kidney treated with (A) aqueous extract (B) ethanol extract (C) acetone extract of A. paniculata leaves on gentamicin induced nephrotoxicity rat animals revealed normalized and restored function of renal system

\section{Conclusion}

Herbal medicine have useful for the development of effective therapy to treat variety of diseases. Nephrotoxicity induced by gentamicin in rats developed significant kidney injuries was estimated from increased levels of urea, uric acid, and creatinine $(\mathrm{p}<0.05)$ and decreased levels of total protein in blood serum. These parameters were more significantly $(\mathrm{p}<0.001)$ altered and restored by oral supplementation of aqueous, ethanol and acetone extract of $A$. paniculata leaves to gentamicin intoxicated rats. Our present study clearly indicated a significant nephroprotective activity by normalize the elevated biochemical and restoration of renal system using with the extract of A. paniculata leaves and supported the traditional usage of the plant in the medicinal system.

\section{References}

[1]. Anil Kumar, Jyotsna Dora, Anup Singh and Rishikant Tripathi, A review on king of bitter (Kalmegh), International Journal of Research in Pharmacy and Chemistry, 2012; 2(1): 116-124.

[2]. Alam M, Khan H, Samiullah L, and Shakir Jamil S, Nephroptrotective activities of herbal plants and their products- a review, International Journal of Pharmaceutical Research and Development, 2013; 5(9): 032-049.

[3]. Boneses RN and Taussk HA On the colorimetric determination of creatinine by the Jaffe reaction. J. Biol. Chem, 1945; 158: 581-591.

[4]. Bhavani R, Nandhini S, Rojalakshmi B, Shobana Rand Rajeshkumar S, Effect of noni (Morindacitrifolia) extract on treatment of ethylene glycol and ammonium chloride induced kidney disease, International Journal of Pharma Sciences and Research, 2014; 5(6): 249-256. 
[5]. Gardner CR, Laskin JD, Dambach DM, Sacco M, Durham SK, Bruno Mk, Choen SD, Gordon MK, Gerecke DR, Zhou P and Laskin DL. Reduced hepatotoxicity of acetaminophen in mice lacking inducible nitric oxide synthase: potential role of tumor necrosis factor-alpha and interleukin-10. Toxicol. Appl. Pharmacol., 2002; 184: 27-36.

[6]. Hall JE. Text Book of Medical Physiology. 12 ed. Philadelphia: Saunders Elsevier, 2011; 307-326.

[7]. Klose S., Stoltz M., Munz E., Portenhauser R., Determination of uric acid on continuous flow (Autoanlyser II and SMA) systems with a uricase/phenol/ 4.amino phenazine color test. ClinChem, 1978; 24(2): $250-255$.

[8]. Lowry O H., Rosebrough N J., Lewisfarr A., Randall R J., Protein measurement with the Folin's phenol reagent. J. BiolChem, 1951; 193: 265-275.

[9]. Mohana Lakshmi S, UshaKiran Reddy T, and Sandhya Rani KS,A review on medicinal plants for nephroprotective activity, Asian J Pharm Clin Res, 2012; 5(4): 8-14

[10]. Movaliya V, Khamar D and Manjunath Setty M, Nephro-protective activity of aqueous extract of Aerva javanica roots in Cisplatin induced renal toxicity in ratsPharmacologyonline1, 2011; 68-74.

[11]. Natelson S., Scott ML., Beffa C., A rapid method for the estimation of urea in biological fluid. Am JClin Pathol, 1951; 21: 275-281.

[12]. Newton J, Hoefle D, Gemborys M, Mugede G and Hook J, Metabolism and excretion of a glutathione conjugate of acetaminophen in the isolated rat kidney. J. Pharmacol. Exp. Ther., 1996; 237: 519-524.

[13]. Porter GA and Bennett WM. Nephrotoxic acute renal failure due to common drugs American journal of Physiology, 1981; 241(7): F1-F8.

[14]. Okokon JE, Nwafor PA, Noah K, Nephroprotective effect of Croton zambesicusroot extract against gentamicin-induced kidney injury, Asian Pacific Journal of Tropical Medicine, 2011; 969-972.

[15]. Ramesh K, Manohar S and Rajeshkumar S, Nephroprotective activity of Ethanolic Extract of Orthosiphon stamineus Leaves on Ethylene Glycol induced Urolithiasis in Albino Rats, Int.J.PharmTech Res, 2014, 6(1): 403408.

[16]. Singh RP, Shokala KP, Pandey BL Singh RG, Usha Singh RH. Recent Approach in Clinical Experimental Evaluation of Diuretic Action of Punarnava (B. diffusa) with Special Reference to Nephrotic Syndrome. Journal of Research and Education in India Medicine, 1992; 7(1): 29-35.

[17]. Sarumathy K, M.S. Dhana Rajan, T. Vijay, J. Jayakanthi, Evaluation of phytoconstituents, nephroprotectiveand antioxidant activities of Clitoriaternatea, Journal of Applied Pharmaceutical Science, 2011; 01(05): 164-172.

[18]. Saumya R. pani, Satyaranjan Mishra, Sabujsahoo and prasana K. Panda, Protective effect of herbal drug in cisplatin induced nephrotoxicity, Indian journal of pharmacology, 2011; 43(2): 200-202.

[19]. Trumper L, Monasterolo LA and Elias MM. Probenecid protects against in vitro acetaminophen induced nephrotoxicity in male Wistar rats. J. Pharmacol. Exp. Therapeat., 1998; 283: 606-610. 


\title{
Pharmacological Activities of Compound Present in Cassia Auriculata by Pass Prediction Method
}

\author{
Article by Chandra Mohan. $\mathrm{A}^{1}$, Geetha. $\mathrm{S}^{2}$, Gajalakshmi. $\mathrm{R}^{3}$, Divya. S. $\mathrm{R}^{4}$, and Dhanarajan \\ M.S $S^{5}$ \\ ${ }^{1}$ Professor \\ ${ }^{2,3,4}$ Assitant Professor, PG and Research Department of Biochemistry and Chemistry, Jaya \\ College of Arts and Science, India \\ ${ }^{5}$ Registrar, Texila American University, Guyana, South America \\ E-mail: chandru2c813@gmail.com ${ }^{1}$
}

\begin{abstract}
PASS Prediction of pharmacological activity for the above compound indicated that these compounds were found to possess various pharmacological activities in the range $69.3-97.8 \%$. Both Dodecanoic Acid and n-hexadecanoic Acid were found to exhibit similar pharmacological activities as Acylcarnitine hydrolyse inhibitor (97.3\%). $\alpha$-Tocopherol exhibit the highest pharmacological activity as Lipid peroxidase inhibitor (97.8\%) among the six phytoconstituent selected for PASS prediction.
\end{abstract}

Keywords: Cassia auriculata, Phytochemical compounds, Pharmacological activity and PASS prediction.

\section{Introduction}

Cassia auriculata is one of the herbaceous plants that found throughout central and southern India, also cultivated in Punjab, Haryana, Uttar Pradesh and West Bengal. The shrub usually occurs on roadsides, waste line, and railway embankments. Avaram (Cassia auriculata Linn), family Caesalpiniaceae, is also known as Avaram tree. Cassia auriculata Linn (Family: Caesalpiniaceae) commonly known as Tanners senna, is distributed throughout hot deciduous forests of India and holds a very prestigious position in Ayurveda and Siddha systems of medicine. It was profoundly used in Ayurvedic medicine as a tonic, astringent and as a remedy for diabetes, conjunctivitis and opthalmia [1]. It is one of the principle constituents of 'Avaarai panchaga chooranam'- an Indian herbal formulation used in the treatment of diabetes to control the blood sugar level [2].

The plant has been reported to possess antipyretic [3], hepatoprotective [4], antidiabetic, antiperoxidative and antihyperglyceamic [5], microbicidal [6] and antihyperlipidaemic activities [7]. The flowers are used to treat urinary discharges, nocturnal emissions, diabetes and throat irritation [8]. They are one of the constituent of polyherbal formulation 'Diasulin' in the concentration range of 40 $\mathrm{mg} / \mathrm{dl}$ which is proven to have antidiabetic activity [9].

It has been found to possess antitumor, oncogenic, and diabeto genic properties [10]. The antioxidant and radical scavenger function of $\alpha$-tocopherol is essentially dependent on the free state of its hydroxyl group. Spectacular antiallergic and antiinflamatory activities have been attributed to DL- $\alpha$ - tocopheryl$\alpha$ - D-mannopyranoside and DL- $\alpha$-tocopheryl- $\beta$-D-galactopyranoside [11]. Hexadecanoic acid methyl ester, also known as Methyl palmitate, in the methanol fraction is an aliphatic acid ester reported to cause growth inhibition and apoptosis induction in human gastric cancer cells [12].

The phytoconstituent of a plant will often determine the physiological action on the human body. Cassia species are rich sources of Polyphenols, Anthraquinone derivatives, Flavanoids, Polysaccharides, Saponins, Tannins, and Steroids. Some of the Cassia species are rich in Glycerides with linoleic, oleic, stearic, and palmitic acids .Cassia species are well known for their laxative and purgative constituents and are also used for the treatment of skin diseases. Leaves are anthelmintic and also used to treat ulcers, skin diseases, and leprosy. An aqueous extract of leaves possesses hypoglycemic activity. The leaves are eaten as a vegetable in times of scarcity, the infusion of leaves possesses a slight purgative activity. 


\section{PASS prediction}

PASS provides simultaneous predictions of many types of biological activity based on the structure of organic compounds. It can predict more than 1500 pharmacological effects, molecular mechanism of action and toxicities on basis of structural descriptors of compounds. Thus, PASS can be used to estimate the biological activity profiles for virtual molecules, prior to their chemical synthesis and biological testing. Pa (probability to be active) estimates the chance that the studied compound is belonging to the sub-class of active compounds resembles the structures of molecules, which are the most typical in a sub-set of actives in PASS training set.

$\mathrm{Pi}$ (probability to be inactive) estimates the chance that the studied compound is belonging to the sub-class of inactive compounds resembles the structures of molecules, which are the most typical in a sub-set of inactive in PASS training set. PASS (Prediction of Activity Spectra for Substance) which is commonly used technique in drug discovery and development. PASS predict the biological activity spectrum for a compound on the basis of its structural formula [13-15].

\section{Materials and methods}

\section{Materials}

Then the plant was identified and authenticated by Plant Anatomy Research Centre (PARC/2017/3467). Phytochemical compounds present in Cassia Auriculata like Dodecanoic acid, Ethyl Caprylate, Glycine (trifluroacetyl) - methyl butyl ester, $\alpha$ - Tocopherol and $\mathrm{n}$ - Hexadecanoic acid as given in (Figure - 1 to 6) were selected for insilico prediction.

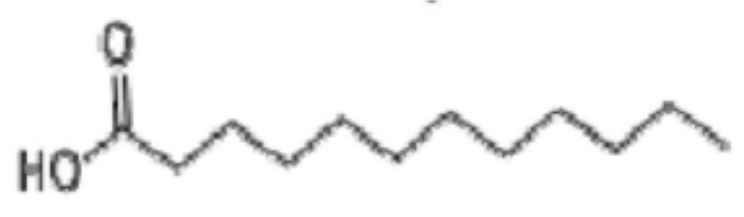

Figure 1. Dodecanoic acid

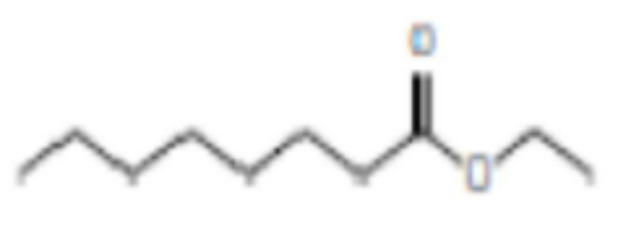

Figure 2. Ethyl caprylate

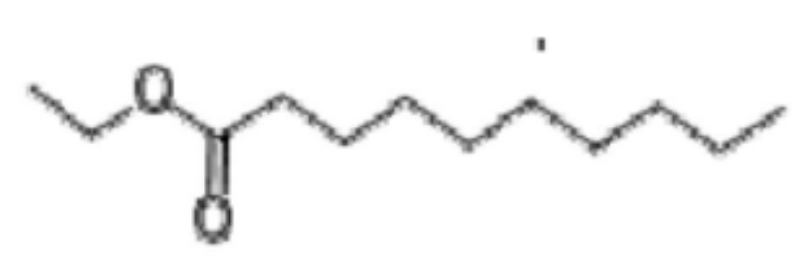

Figure 3. Capric acid ethyl ester

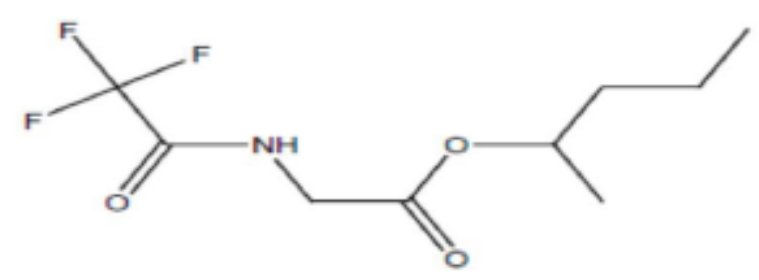

Figure 4. Glycine (trifluoroacetyl)-methyl butyl ester 


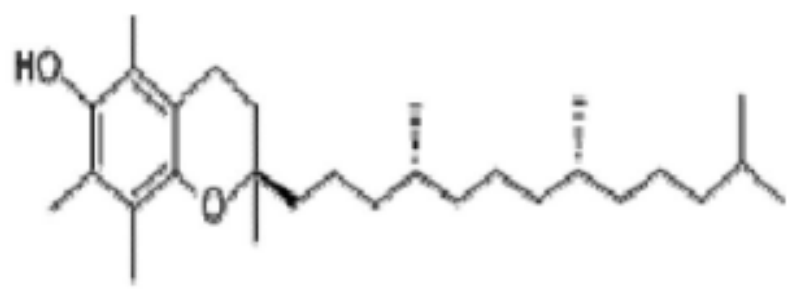

Figure 5. $\alpha$ - Tocopherol

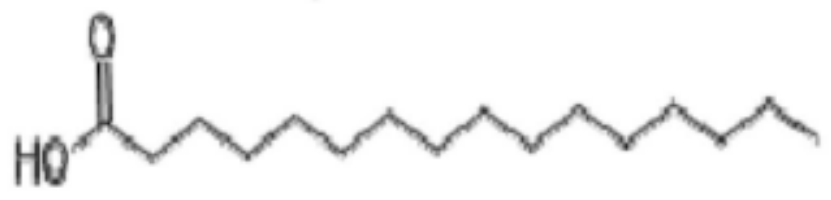

Figure 6. n-Hexadecanoic acid

\section{Methods}

\section{Pass prediction of pharmacological activity}

Various constituents of Cassia auriculata leaves extract reported were selected for predicting pharmacological activity using PASS $[16,17]$. Phytochemical compounds like a) Dodecanoic Acid, b) n-Hexadecanoic acid, c) Ethyl Caprylate, d) Capric acid ethyl ester, e) Glycine (trifluoroacetyl)-methyl butyl ester and f) $\alpha$-Tocopherol were selected. The structures of phytochemical compounds were drawn in Molinspiration online software and appear as given in (Figure-7) and their structures were saved in mol file with *.mol*.
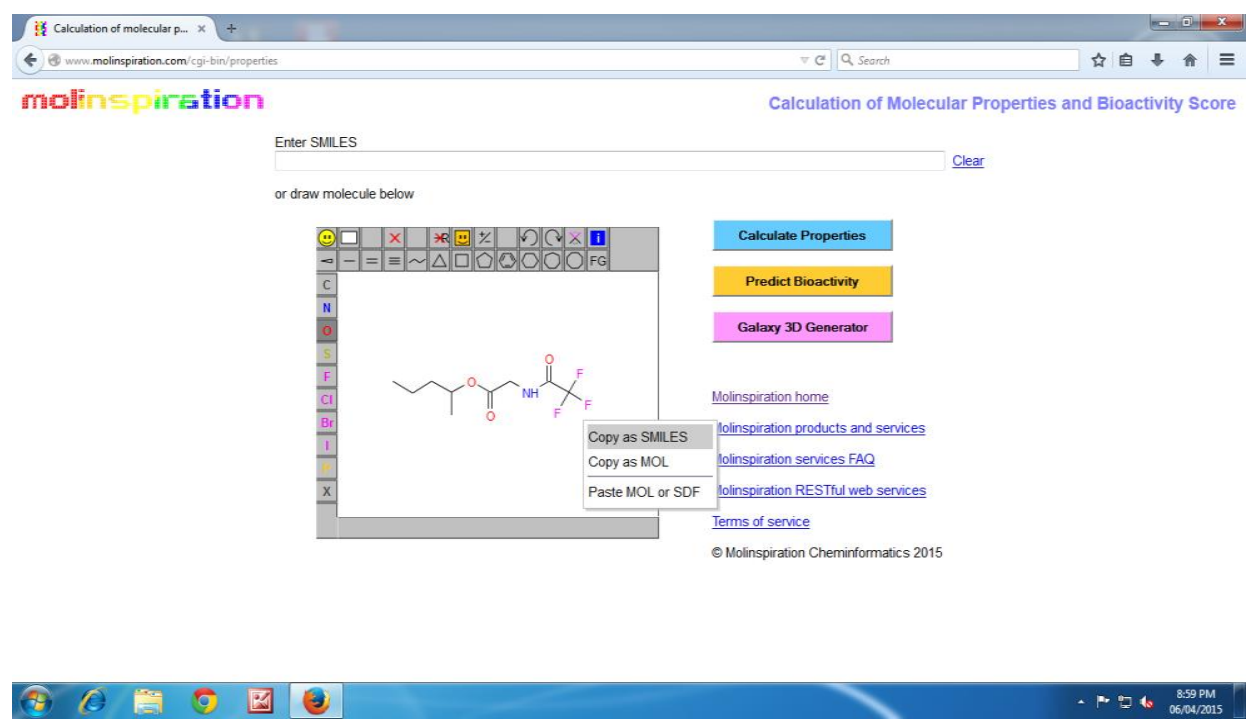

Figure 7. Molinspiration structure

PASS prediction window for prediction of pharmacological activity appeared as given in Figure-8 \& 9. 
DOI: 10.21522/TIJBMS.2016.02.02.Art004

ISSN: $2519-500 \mathrm{X}$

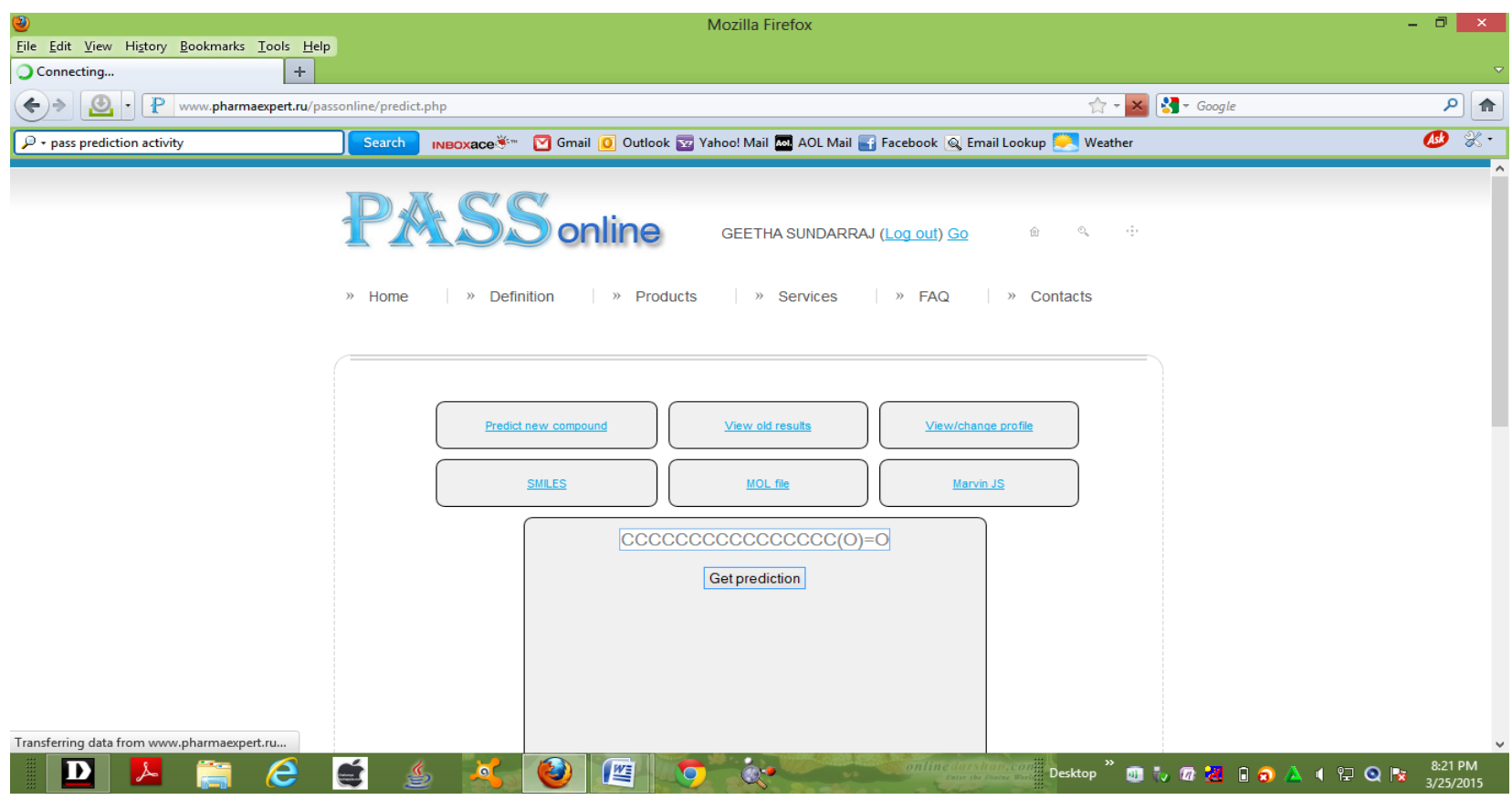

Figure 8. PASS online software setup window

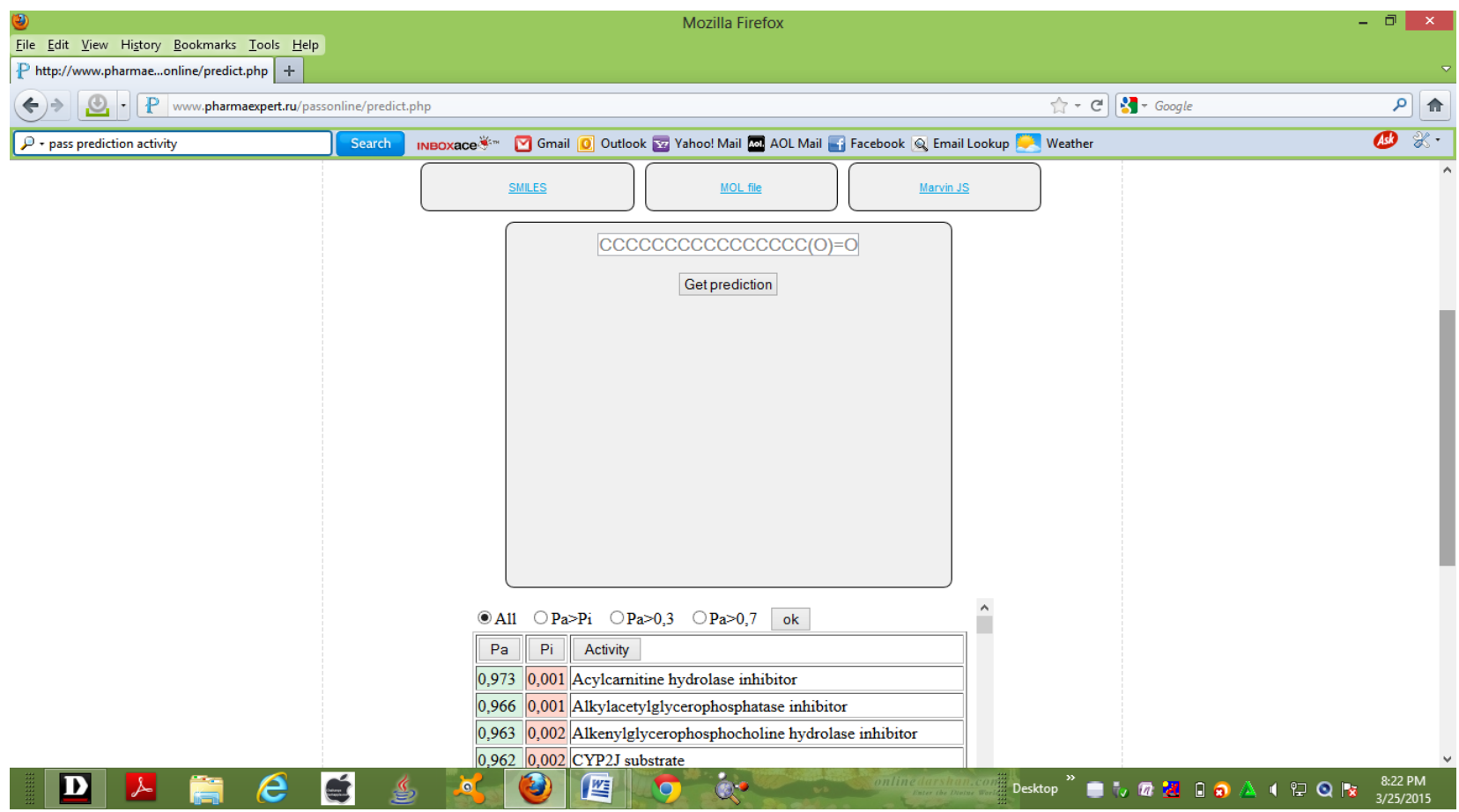

Figure 9. PASS Prediction window setup

\section{Result and discussion}

\section{PASS prediction}

All the phytochemical compounds were found to exhibit various Pharmacological activities in the range (69.3-97.8\%) as given in Table-I (a, b \& c). 
Table I (a). PASS prediction of bioactivity

\begin{tabular}{|l|l|l|l|l|}
\hline S.No & Name of the compound & Activity & $\mathbf{P}_{\mathbf{a}}$ & $\mathbf{P}_{\mathbf{i}}$ \\
\hline 1 & Dodecanoic acid & Acylcarnitine hydrolyse inhibitor & 0.973 & 0.001 \\
& & Alkylacetylglycerophosphatase inhibitor & 0.966 & 0.001 \\
& & Alknylglycerophosphocholine hydrolase & 0.963 & 0.002 \\
& & inhibitor & 0.962 & 0.002 \\
& & CYP2J substrate & 0.961 & 0.001 \\
& & CYP2J2 substrate & 0.961 & 0.002 \\
& & Acrocylindropepsin inhibitor & 0.961 & 0.002 \\
& & Chymosin inhibitor & 0.961 & 0.002 \\
& & Saccharopepsin inhibitor & 0.957 & 0.001 \\
& \multirow{5}{*}{2} & Dextranase inhibitor & 0.954 & 0.001 \\
& & CarboxypeptidaseTag inhibitor & & \\
& & All-trans-retinyl-paluitate hydrolase & 0.953 & 0.001 \\
& & inhibitor & 0.946 & 0.001 \\
& & Cutinase inhibitor & 0.934 & 0.003 \\
& & Acylcarnitine hydrolase inhibitor & 0.930 & 0.002 \\
& & Alkanal monooxygenase (FMN- linked) & 0.924 & 0.003 \\
& & inhibitor & 0.922 & 0.004 \\
& & Sugar-phosphatase inhibitor & 0.919 & 0.004 \\
& & Alkenylglycerophosphocholine & 0.919 & 0.004 \\
& & hydrolase inhibitor & 0.919 & 0.004 \\
& & Acrocylindropepsin inhibitor & 0.919 & 0.004 \\
& & Chymosin inhibitor & & \\
& & Saccharopepsin inhibitor & & \\
& & Antieczematic & & \\
& & &
\end{tabular}

Table I (b). PASS prediction of bioactivity

\begin{tabular}{|c|c|c|c|c|}
\hline 3 & $\begin{array}{l}\text { Glycine(trifluoroacetyl)- } \\
\text { methyl butyl ester }\end{array}$ & $\begin{array}{l}\text { Acrocylindropepsin inhibitor } \\
\text { Chymosin inhibitor } \\
\text { Saccharopepsin inhibitor } \\
\text { Acetylesterase inhibitor } \\
\text { Acylcarnitine hydrolase inhibitor } \\
\text { Fucosterol-epoxide lyase inhibitor } \\
\text { Pro-opiomelanocartin converting } \\
\text { enzyme inhibitor } \\
\text { Polyporopepsin inhibitor } \\
\text { Macrophage colony stimulating factor } \\
\text { agonist } \\
\text { Cutinase inhibitor }\end{array}$ & $\begin{array}{l}0.839 \\
0.839 \\
0.839 \\
0.798 \\
0.788 \\
0.745 \\
0.733 \\
0.719 \\
0.695 \\
0.693\end{array}$ & $\begin{array}{l}0.013 \\
0.013 \\
0.013 \\
0.005 \\
0.015 \\
0.011 \\
0.023 \\
0.035 \\
0.014 \\
0.010\end{array}$ \\
\hline 4 & Capric acid ethyl ester & $\begin{array}{l}\text { All-trans-retinyl-paluitate hydrolase } \\
\text { inhibitor } \\
\text { Cutinase inhibitor } \\
\text { Acylcarnitine hydrolase inhibitor } \\
\text { Alkanal monooxygenase (FMN- linked) } \\
\text { inhibitor } \\
\text { Sugar-phosphatase inhibitor } \\
\text { Alkenylglycerophosphocholine } \\
\text { hydrolase inhibitor } \\
\text { Acrocylindropepsin inhibitor } \\
\text { Chymosin inhibitor } \\
\text { Saccharopepsin inhibitor }\end{array}$ & $\begin{array}{l}0.953 \\
0.946 \\
0.934 \\
0.930 \\
0.924 \\
0.922 \\
0.919 \\
0.919 \\
0.919 \\
0.919\end{array}$ & $\begin{array}{l}0.001 \\
0.001 \\
0.003 \\
0.002 \\
0.003 \\
0.004 \\
0.004 \\
0.004 \\
0.004 \\
0.004\end{array}$ \\
\hline
\end{tabular}




\begin{tabular}{|l|l|l|l|l|}
\hline & Antieczematic & & \\
\hline
\end{tabular}

Table I (c). PASS prediction of bioactivity

\begin{tabular}{|l|l|l|l|l|}
\hline 5 & $\alpha$ - Tocopherol & Lipid peroxidase inhibitor & 0.978 & 0.002 \\
& & Peroxidase inhibitor & 0.971 & 0.001 \\
& & Antioxidant & 0.968 & 0.002 \\
& & TP53 expression inhibitor & 0.959 & 0.003 \\
& & CYP2C12 substrate & 0.955 & 0.004 \\
& & Acute neurologic disorders treatment & 0.935 & 0.004 \\
& & Antihypercholesterolemic & 0.932 & 0.003 \\
& & Antiischemic, cerebral & 0.931 & 0.005 \\
& n-Hexadecanoic acid & Reductant & 0.924 & 0.003 \\
& & AR expression inhibitor & 0.851 & 0.002 \\
\hline 6 & Acylcarnitine hydrolyse inhibitor & 0.973 & 0.001 \\
& & Alkylacetylglycerophosphatase inhibitor & 0.966 & 0.001 \\
& & Alknylglycerophosphocholine hydrolase & 0.963 & 0.002 \\
& inhibitor & 0.962 & 0.002 \\
& & CYP2J substrate & 0.961 & 0.001 \\
& & CYP2J2 substrate & 0.961 & 0.002 \\
& & Acrocylindropepsin inhibitor & 0.961 & 0.002 \\
& & Chymosin inhibitor & 0.961 & 0.002 \\
& & Saccharopepsin inhibitor & 0.957 & 0.001 \\
& & Dextranase inhibitor & 0.954 & 0.001 \\
& & CarboxypeptidaseTag inhibitor & & \\
\hline
\end{tabular}

Dodecanoic acids various pharmacological activities as given in Table - I (a) showed that this exhibited very good inhibitors as Acylcarnitine hydrolyse inhibitor (97.3\%), Alkylacetyl glycerophosphocholine hydrolyse inhibitor (96.6\%), Alknylglycerophosphocholine Ethyl caprylate was also observed to exhibit various pharmacological activities in the range $91.9-95.3 \%$ as All-transretinyl-paluitate hydrolase inhibitor (95.3\%), Cutinase inhibitor (94.6\%), Acylcarnitine hydrolase inhibitor (93.4\%), Alkanal monooxygenase (FMN- linked) inhibitor (93.0\%), Sugar-phosphatase inhibitor (92.4\%), Alkenylglycerophosphocholine hydrolase inhibitor (92.2\%), Acrocylindropepsin inhibitor (91.9\%), Chymosin inhibitor (91.9\%) and Saccharopepsin inhibitor (91.9\%) respectively.

Glycine (trifluoroacetyl) - methyl butyl ester exhibited various pharmacological acitivities as Capric acid ethyl ester exhibited various pharmacological activities as All-trans-retinyl-paluitate hydrolase inhibitor (95.3\%), Cutinase inhibitor (94.6\%), Acylcarnitine hydrolase $\alpha$ - Tocopherol was also observed to exhibit various pharmacological activities in the range $85.1-97.8 \%$ as Lipid peroxidase inhibitor (97.8\%), Peroxidase inhibitor (97.1\%), TP53 expression inhibitor (95.9\%) and AR expression inhibitor (85.1\%). n-Hexadecanoic acids various pharmacological activities as given in Table - I (c) showed that this exhibited very good inhibitors as Acylcarnitine hydrolyse inhibitor (97.3\%), Alkylacetylglycerophosphocholine hydrolyse inhibitor (96.6\%), Alknylglycerophosphocholine. hydrolase inhibitor (96.3\%), Acrocylindropepsin inhibitor (96.1\%), Chymosin inhibitor (96.1\%),Saccharopepsin inhibitor (96.1\%), Dextranase inhibitor (95.7\%) and CarboxypeptidaseTag inhibitor $(95.4 \%)$ respectively.

\section{Conclusion}

PASS Prediction of pharmacological activity for the above compound indicated that these compounds were found to possess various pharmacological activities in the range $69.3-97.8 \%$. Both Dodecanoic Acid and n-hexadecanoic Acid were found to exhibit similar pharmaceutical activities as Acylcarnitine hydrolyse inhibitor. $\alpha$-Tocopherol exhibit the highest pharmaceutical activity as Lipid peroxidase inhibitor (97.8\%) among the six phytoconstituent selected for PASS prediction. 


\section{Reference}

[1]. Anastas P.T., Levy I.J., Parent K.E. (Eds). Green Chemistry Education. Changing the Course of Chemistry, ACS Publications, Washington DC, 2009.

[2]. Basu and Kirtikar. Indian Medicinal Plants. Vol. II, Second edition .International Book distributors Dehradun India, 867-868; 1935.

[3]. Carp O., Huisman C.L., Reller A., Photoinduced reactivity of titanium dioxide. Prog in Solid State Chem, 32: 33-117; 2004.

[4]. Evans. Trease W.C. and Evans Pharmacognosy W.B. Saunders Company Ltd., London, pp (14th Edition). 19-20; 2000.

[5]. Grossman E. Chasing Molecules: Poisonous Products, Human Health, and the Promise of Green Chemistry. Island Press, New York, 2009.

[6]. Lipinski C.A. Drug Discovery Today: Technologies; 1 (4): 337-34; 2004.

[7]. Mossi A.J., Mazutti, Paroul M., Corazza N., Dariva M.L., Cansian C. \& Oliveira R.L., Rocha O.R., Dantas R.F., Duarte M.M.M.B., et al. Oil sludge treatment by photocatalysis applying black and white light. Chem Eng J, 157: 80-85; 2010.

[8]. Mukunthan K.S., Elumalai E.K., Trupti N.P., Ramachandra Murty V. Catharanthus roseus: a natural source for the synthesis of silver nanoparticles. Asian Pacific Journal of Tropical Biomedicine, 270-274; 2011.

[9]. Mor G.K., Varghese O.K., Paulose M., et al. A review on highly ordered, vertically oriented $\mathrm{TiO}_{2}$ nanotube arrays: Fabrication, material properties, and solar energy applications. Solar Energ Mater Solar Cell, 90: 20112075; 2006.

[10]. Mallikadevi S., Palulsamy T.S., Jamuna S. and Karthika K., Analysis for Phytoceuticals And Bioinformatics Approach For the Evaluation of Therapetic Properties of Whole Plant Methanolic Extract of Mukia Maderaspatana (L.) M.Roem. (Cucurbitaceae) - ATraditional Medicinal Plant in Western Districts of Tamil Nadu, India, Asian Journal of Pharmaceutical and Clinical Research, 5(4):2241; 2012.

[11]. Newman D.J., Cragg G.M., Snadder K.M. J. Nat. Prod., 66(7): 1022 -1037; 2003.

[12]. Prakash S.K... Int. J. Poultry Sci. 5: 259-261; 2006.

[13]. Sharma S.K. Green Chemistry for Environmental Sustainability. Series: Advancing Sustainability through Green Chemistry and Engineering. CRC Press, Boca Raton, FL, 2010.

[14]. Thirumurgan A., Tomy N.A., Jai Ganesh R., Gobikrishnan S.. Biological reduction of silver nanoparticles using plant leaf extracts and its effect an increased antimicrobial activity against clinically isolated organism. De. Phar. Chem, 2: 279-284; 2010;

[15]. Tripathy A., Raichur A.M., Chandrasekaran N., Prathna T.C., Mukherjee A., Nanopart. J. Res.12, 237 ; 2010. DOI: $10.1007 / \mathrm{s} 11051-009-9602-5$.

[16]. Tagboto S., Townson S., Adv. Parasitol., 50: 199-295; 2001. 


\title{
Analysis of Total Phenol, Cellulose and Tannin Content by Using Different Parameters in Ethanol Extract of Pomegranate Peel
}

\author{
Article by Vijayalakshmi. T ${ }^{1}$, Dhanarajan. M. S ${ }^{2}$, Chandra Mohan. $\mathrm{A}^{3}$ \\ ${ }^{1}$ Research Scholar, Jaya College of Arts and Science, Affiliated to University of Madras \\ ${ }^{2}$ Registrar, Texila American University, Guyana, South America \\ ${ }^{3}$ Professor, PG Research, Department of Biotechnology and Biochemistry, Jaya College of \\ Arts and Science, Affiliated to University of Madras \\ E-mail: dhanarajan.m@tau.edu.gy ${ }^{2}$
}

\begin{abstract}
Pomegranate (Punicagranatum L.) is considered one of the oldest known edible fruits. Pomegranate peels are characterized by an interior network of membranes comprising almost 26$30 \%$ of total fruit weight and are characterized by substantial amounts of phenolic compounds, including flavonoids and tannins. Pomegranate fruit and its peel exhibit a high antioxidant potential. Pomegranate peel attracts attention due to its apparent wound healing properties, Antioxidative activity has often been associated with a decreased risk of various diseases. The purpose of the present study was to evaluate the effect of using different parameters with ethanol extract and estimate the efficiency of effective compounds, such as polyphenolic, cellulose and tannin compounds from the pomegranate peel extracts.
\end{abstract}

Keywords: Pomegranate peel extracts, polyphenolic, cellulose and tannin.

\section{Introduction}

Pomegranate (Punica granatum L. Punicaceae; the common name is derived from Latin words ponusandgranatus), a seeded or granular apple, is a delicious fruit consumed worldwide. The fruit is native to Afghanistan, Iran, China and the Indian sub-continent. The ancient sources of pomegranate linked Iran to Pakistan, China and eastern India, where pomegranate shad been under cultivation for thousands of years.

Pomegranate peels are characterized by an interior network of membranes comprising almost 26$30 \%$ of total fruit weight and are characterized by substantial amounts of phenolic compounds, including flavonoids (anthocyanins, catechins and other complex flavonoids) and hydrolyzable tannins (punicalin, pedunculagin, punicalagin, gallic and ellagic acid). These compound sareconcentrated in pomegranate peel (PoP) and juice, which account for $92 \%$ of the antioxidant activity associated with the fruit [1], [11] and [17].

The mechanism of antimicrobial activity of Pomegranate peel phenolics involves precipitation of membrane proteins resulting in microbial cell lysis. The ethno pharmacological profile of PoPx makes it a valuable traditional asset due to its antimicrobial and anti-mutagenic properties. Moreover, the phyto- chemical concentration of PoP is high enough to be effective without further enrichment with the extracts of any other fraction of the fruit [13].

\section{Traditional medicinal uses}

A variety of cultures and traditions in both the developing and developed worlds recommend pomegranate peel to treat common health problems. Traditionally, aqueous PoP extract is obtained by boiling for $10-40 \mathrm{~min}$. The extract has been used to treat diarrhoea, dysentery, and dental plaque, in addition to being used as adouche and enemaagent [8]. Similarly, diarrhoea, intestinal worms, bleeding noses and ulcers have been treated in Indian Subcontinent with dried PoP.

Pomegranate peel attracts attention due to its apparent wound healing properties [3], immune modulatory activity [5] and antibacterial activity [10] antiatherosclerotic and antioxidative capacities [15]. Antioxidative activity has often been associated with a decreased risk of various diseases [16]. The peel packs some of the weight boosting and health enhancing effects of antibiotics and hormones 
without the detrimental effects and it may yield meat with higher level of beneficial antioxidants [14]. Pomegranate Ellagitannin have been identified as the active antioxidant compound and anticancer activities responsible for protecting low density lipoprotein, cholesterol from in the last few years the identification and development of phenolic compounds or extracts from different plants has become a major area of health and medical related research [4]. The present study is undertaken to know the nutritional importance and suitability of de-tanninated pomegranate peel, a by-product of pomegranate juice industry, as a cattle feed supplement.

\section{Materials and methods}

\section{A. Collection of pomegranate peel}

Collection, separation and drying of pomegranate peel. The orange fruits were purchased. The peels were manually separated from the fruit. The peels were shade dried. The dried peels were collected and ground well to form a powder. The powdered orange peel was stored in an airtight container and used for various tests.

\section{B. Preparation of the peel extract}

Preparation of the extracts was assessed by the following methods. One gram of dried bitter orange peel powder was extracted with $20 \mathrm{ml}$ of aqueous, ethanol was soaked overnight at room temperature. The sample was then filtered through Whatman.No.1 paper in a Buchner funnel.

The filtered solution was evaporated under vacuum in a rota-vator at $40^{\circ} \mathrm{C}$ to a constant weight and then dissolved in respective solvents. The dissolving rate of the crude extract was approximately $100 \%$. The extracts were used for further tests.

Qualitative phytochemical analysis: The phytochemical tests were carried out using standard methods of analysis of tannins, saponins, quinones, flavanoids, glycosides, cardiac-glycosides, terpenoids, phenols, coumarins, steroids, alkaloids, anthocyanin and betacyanin.

\section{Materials required}

1) Acetic/Nitric Reagent: Mix $150 \mathrm{ml}$ of $80 \%$ acetic acid and $15 \mathrm{~mL}$ of concentrated nitric acid.

2) Anthrone: Dissolve 200mg anthrone in $100 \mathrm{~mL}$ of ice-cold $95 \%$ sulphuric acid. Prepare fresh and chill for $2 \mathrm{~h}$ before use.

3) $67 \%$ sulphuric acid

4) Folin-Denis Method: This is based on the non-stoichiometric oxidation of the molecules containing a phenolic hydroxyl group.

5) Sodium carbonate

6) Tannic acid

7) Folin-ciocalteau reagent

8) Distilled water

\section{Methods}

\section{Sonication}

Sonication is the process of converting an electrical signal into a physical vibration that can be directed toward a substance. Sonicators are vital lab equipment and are used for a number of purposes. Sonication is usually performed to break apart compounds or cells for further examination. The vibration has a very powerful effect on solutions, causing their molecules to break apart and cells to rupture. A prime example is in DNA testing, where the cells that may contain DNA information are subjected to sonication to break them apart and release the DNA proteins so they can be tested.

The primary part of a sonication device is the ultrasonic electric generator. This device creates a signal (usually around $20 \mathrm{KHz}$ ) that powers a transducer. This transducer converts the electric signal by using piezoelectric crystals, or crystals that respond directly to the electricity by creating a mechanical vibration. This vibration, molecular in origin, is carefully preserved and amplified by the sonicator, until it is passed through to the probe.

The sonication probe transmits the vibration to the solution being sonicated. This probe is a carefully constructed tip that moves in time with the vibration, transmitting it into the solution. The 
probe moves up and down at a very high rate of speed, although the amplitude can be controlled by the operator and is chosen based on the qualities of the solution being sonicated.

\section{E. Magnetic stirrer}

A magnetic stirrer or magnetic mixer is a laboratory device that employs a rotating magnetic field to cause a stir bar (also called "flea") immersed in a liquid to spin very quickly, thus stirring it. The rotating field may be created either by a rotating magnet or a set of stationary electromagnets, placed beneath the vessel with the liquid.

Magnetic stirrers are often used in chemistry and biology, where they can be used inside hermetically closed vessels or systems, without the need for complicated rotary seals. They are preferred over gear-driven motorized stirrers because they are quieter, more efficient, and have no moving external parts to break or wear out (other than the simple bar magnet itself). Magnetic stir bars work well in glass vessels commonly used for chemical reactions, as glass does not appreciably affect a magnetic field.

The limited size of the bar means that magnetic stirrers can only be used for relatively small experiments, of 4 liters or less. Stir bars also have difficulty in dealing with viscous liquids or thick suspensions. For larger volumes or more viscous liquids, some sort of mechanical stirring is typically needed. Because of its small size, a stirring bar is more easily cleaned and sterilized than other stirring devices. They do not require lubricants which could contaminate the reaction vessel and the product. Magnetic stirrers may also include a hot plate or some other means for heating the liquid.

\section{F. Quantitative phytochemical analysis}

1) Estimation of Total phenolic content: Total Phenolic content (TPC) in the ethanol extracts was determined using the Folin-Ciocalteu reagent method [9]. This method depends on the reduction of FCR by phenols to a mixture of blue oxides which have a maximal absorption in the region of 765 $\mathrm{nm}$ using spectrophotometer. Stock solution of leaf extracts was prepared to the concentration of $1 \mathrm{mg} / \mathrm{ml}$. To $0.1 \mathrm{ml}$ of each extract, $5 \mathrm{ml}$ of Folin-Ciocalteu Reagent were added. The mixture solution was vortexed and incubated in the dark for 3 minutes, respectively. To the incubated content $5 \mathrm{ml}$ of sodium carbonate $(75 \mathrm{~g} / \mathrm{L})$ solution was added to the above content and mixed thoroughly. The reaction content was incubated in the dark for 1 hour. The absorbance was read at $765 \mathrm{~nm}$. Blank was maintained with $5 \mathrm{ml}$ Folin-Ciocalteu reagent, $1 \mathrm{ml}$ ethanol and $4 \mathrm{ml}$ sodium carbonate solution. The concentration of total phenolic content in the extract was expressed as $\mathrm{mg}$ of gallic acid equivalent per $\mathrm{g}$ of dry weight (mg GAE/g) of extract. Gallic acid stock solution was prepared to the concentration of $1 \mathrm{mg} / \mathrm{ml}$. Serial dilution was carried out; gallic acid solution was dissolved in ethanol. A linear doseresponse regression curve was generated using absorbance reading of gallic acid at the wavelength of $765 \mathrm{~nm}$.

2) Estimation of Total cellulose content: Add $3 \mathrm{~mL}$ acetic/nitric reagent to a known amount $(0.5 \mathrm{~g}$ or $1 \mathrm{~g}$ ) of the sample in a test tube and mix in a vortex mixture. Place the tube in a water bath at $100^{\circ} \mathrm{C}$ for $30 \mathrm{~min}$. Cool and then centrifuge the contents for 15-20min. Discard the supernatant and Wash the residue with distilled water. Add $10 \mathrm{~mL}$ of $67 \%$ sulphuric acid and allow it to stand for $1 \mathrm{~h}$. Dilute $1 \mathrm{~mL}$ of the above solution to $100 \mathrm{~mL}$. To $1 \mathrm{~mL}$ of this diluted solution, add $10 \mathrm{~mL}$ of anthrone reagent and mix well. Heat the tubes in boiling water bath for $10 \mathrm{~min}$. Cool and measure the color at $630 \mathrm{~nm}$. Set a blank with anthrone reagent and distilled water. Take 100mg cellulose in a test tube and proceed from step No. 6 for standard. Instead of just taking $1 \mathrm{~mL}$ of the diluted solution (Step 7) take a series of volumes (say 0.4 to $2 \mathrm{~mL}$ corresponding to $40-200 \mathrm{mg}$ of cellulose) and develop the color.

3) Estimation of total tannins content: Total Tannin content in the ethanol extract was determined by Folin-Denis method [12] with minor modifications. Stock solution of leaf extracts was prepared to the concentration of $1 \mathrm{mg} / \mathrm{ml}$. To $0.1 \mathrm{ml}$ of each extract, $1 \mathrm{ml}$ of distilled water was added and then mixed with $0.5 \mathrm{ml}$ of Folin-Denis reagent. The reaction mixture was alkalinized by the addition of $1 \mathrm{ml}$ of $15 \%$ (w/v) sodium carbonate solution and kept in dark for $30 \mathrm{~min}$ at room temperature. The absorbance of the solution was read at $700 \mathrm{~nm}$ using spectrophotometer, and the concentration of tannin in the extract was determined using pure tannic acid as standard $(1 \mathrm{mg} / \mathrm{ml})$. A calibration curve was generated using various concentrations of Tannic acid $(20-120 \mu \mathrm{g})$ was 
obtained. Blank consist of all the reagents, except for the extract or standard solution is substituted with $0.1 \mathrm{ml}$ of water. Results were expressed as $\mathrm{mg}$ of Tannic acid equivalent/g of dry weight (mg $\mathrm{TE} / \mathrm{g}$ ) of extracts.

\section{Result and discussion}

The preliminary Phytochemical screening and analysis carryout with standard procedures of ethanol solvent in orange peel extracted and with different parameter a) ultrasonicator b) magnetic stirrer at various temperatures $\left(37^{\circ} \mathrm{C}\right.$ and $\left.50^{\circ} \mathrm{c}\right)$ evaluated the presence of phytochemicals such as Phenol, cellulose and tannins, [6].

The peel samples shows the strong presence of Carbohydrates, Tannins, and Phenols in ethanol extracts. Saponin, coumarins and steroids are present in the methanol extract. Based on the presence of phytocompounds the further estimation will carried out phenol, cellulose and tannin.

As phytochemicals often play an important role in plant defence against prey, microorganism, stress as well as interspecies protections, these plant components have been used as drugs for millennia and hence, screening of phytochemicals serves as the initial step in predicting the types of potential active compounds from plants [2].

These compounds present in a variety of medicinal plants and fruits have significant application against human. Pathogens, including those that cause enteric infections and are reported to have curative properties against several pathogens and therefore could suggest their use in the treatment of various diseases [7].

\section{A. Estimation of total phenolic content (TPC)}

The concentrations of total phenolic content in the extracts were expressed as mg of gallic acid equivalent per $\mathrm{g}$ of dry weight (mg GAE/g) of extract the total phenolic content of the pomegranate of peel extract samples were determined using the Folin-Ciocalteu reagent method. The reduction of FCR by phenols to a mixture of blue oxides which have a maximal absorption in the region of $765 \mathrm{~nm}$ was measured spectro-photometrically.

The results revealed the presence of highest total phenol content in the ethanol extract of pomegranate peel in different parameter at various temperature in $37^{\circ} \mathrm{C}$ and $50^{\circ} \mathrm{C}$ is shown in Fig. 1 . The increasing concentration of ethanolic extract $2 \mathrm{mg}, 4 \mathrm{mg}, 6 \mathrm{mg}, 8 \mathrm{mg}$ and $10 \mathrm{mg}$ showed increasing $\mathrm{OD}$ value respectively. The highest $\mathrm{OD}$ value for ultra sonicator at $37^{\circ} \mathrm{C}$ in $10 \mathrm{mg}$ is $(1.1791)$, where as in magnetic stirrer the highest OD value is seen at 50c in $10 \mathrm{mg}$ is (1.4647). The highest total phenolic content were obtained in Ultra sonicator at 37 in $10 \mathrm{mg}$. Phenolic compounds possess different biological activities, but most important are antioxidant activities. Phenols are able to scavenge reactive oxygen species due to their electron donating properties.

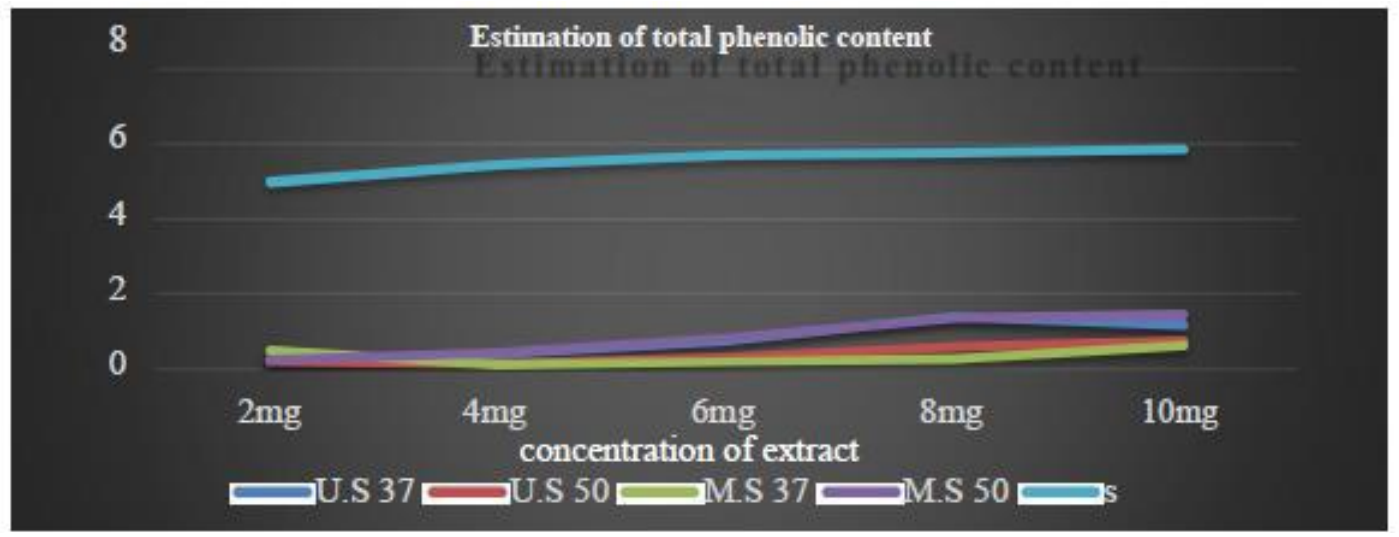

Figure 1. Estimation of total phenolic content from ethanol extracts

\section{B. Estimation of total cellulose content (TCC)}

The total cellulose content of the pomegranate peel extract samples were determined using the anthrone method. The reduction of AR by cellulose to a mixture of blue oxides which have maximal absorption at $630 \mathrm{~nm}$ was measured spectrophotometrically. The result revealed the presence of 
highest total cellulose content in the ethanol extract of pomegranate peel in different parameters at various temperature in $37^{\circ} \mathrm{C}$ and $50^{\circ} \mathrm{c}$ is shown in the Fig. 2.

The increasing concentration of ethanolic extract $2 \mathrm{mg}, 4 \mathrm{mg}, 6 \mathrm{mg}$, $8 \mathrm{mg}$ and $10 \mathrm{mg}$ showed increasing increasing OD value respectively. The highest OD value of ultrasonicator at $37^{\circ} \mathrm{c}$ in $10 \mathrm{mg}$ is (1.5519), where as in magnetic stirrer the highest OD value seen at $50^{\circ} \mathrm{c}$ in $8 \mathrm{mg}(1.1295)$. The highest total cellulose content were obtained in ultra sonicator at $37^{\circ} \mathrm{c}$ in $10 \mathrm{mg}$.

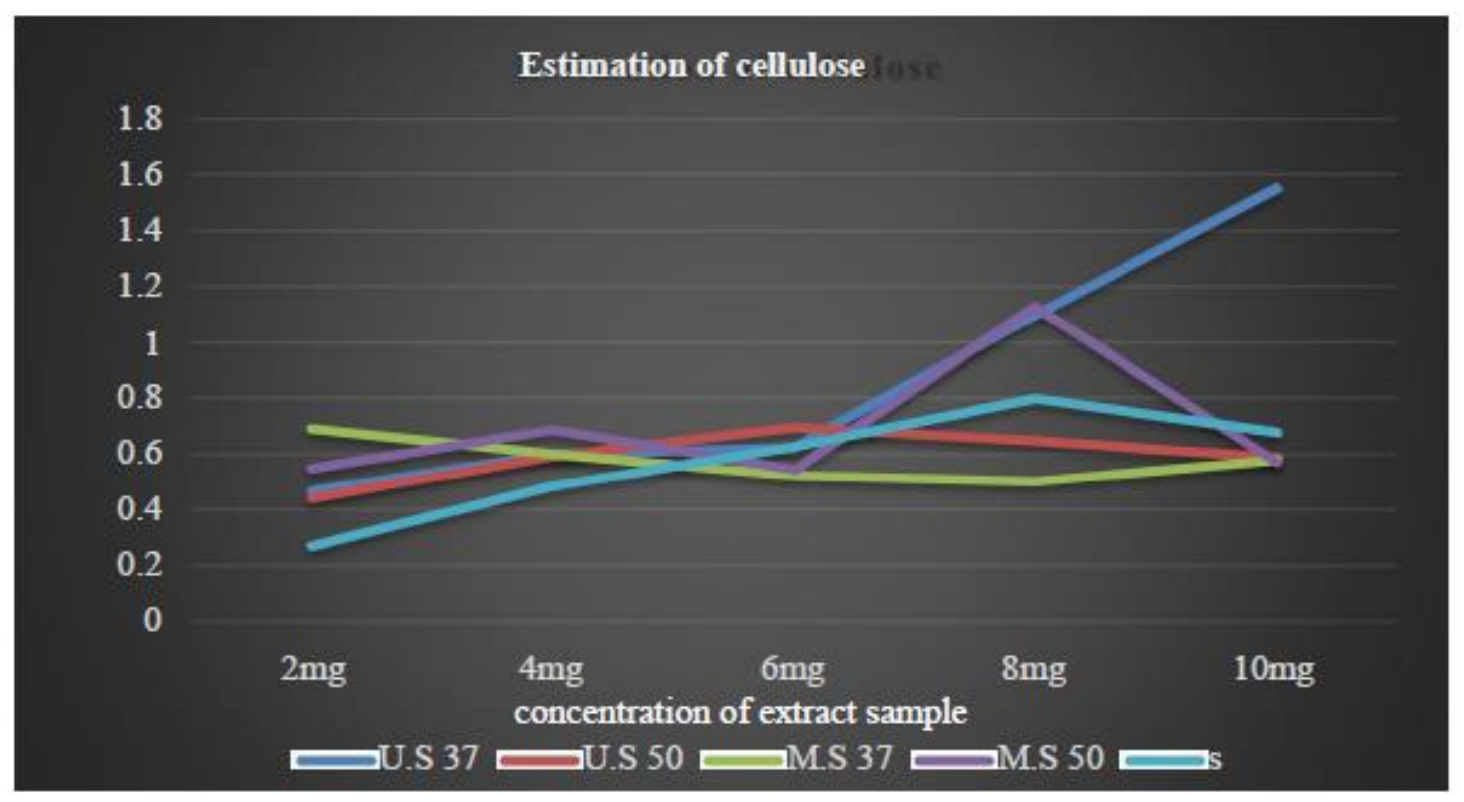

Figure 2. Estimation of total cellulose content from ethanol extracts

\section{Estimation of total Tannin (TTC)}

The concentration of total tannin content was expressed as mg of Tannic acid equivalent/g of dry weight $(\mathrm{mg} \mathrm{E} / \mathrm{g})$ of extracts. The total Tannin content of the pomegranate peel extract samples were determined using by Folin-Denis method. The reduction of FDR by tannin to a mixture of blue oxides which have a maximal absorption in the region at $700 \mathrm{~nm}$ was measured spectrophotometrically.

The result revealed the presence of highest total-Tannin content in the ethanol extract of pomegranate peel in different parameters at various temperature in $37^{\circ} \mathrm{c}$ and $50^{\circ} \mathrm{c}$ in shown in Fig. 3 . The increasing concentration of ethanolic extract, $2 \mathrm{mg}, 4 \mathrm{mg}, 6 \mathrm{mg}, 8 \mathrm{mg}$ and $10 \mathrm{mg}$ showed increasing $\mathrm{OD}$ value respectively. The highest $\mathrm{OD}$ value of ultrasonicator at $37^{\circ} \mathrm{c}$ in $10 \mathrm{mg}$ is $(0.6507)$, where as in magnetic stirrer the highest $\mathrm{OD}$ value is seen at $50^{\circ} \mathrm{c}$ in $10 \mathrm{mg}(0.7009)$. The highest total tannin content were obtained in magnetic stirrer at $50^{\circ} \mathrm{c}$ in $10 \mathrm{mg}$. 
DOI: $10.21522 / \mathrm{TIJBMS} .2016 .02 .02$. Art005

ISSN: 2519-500X

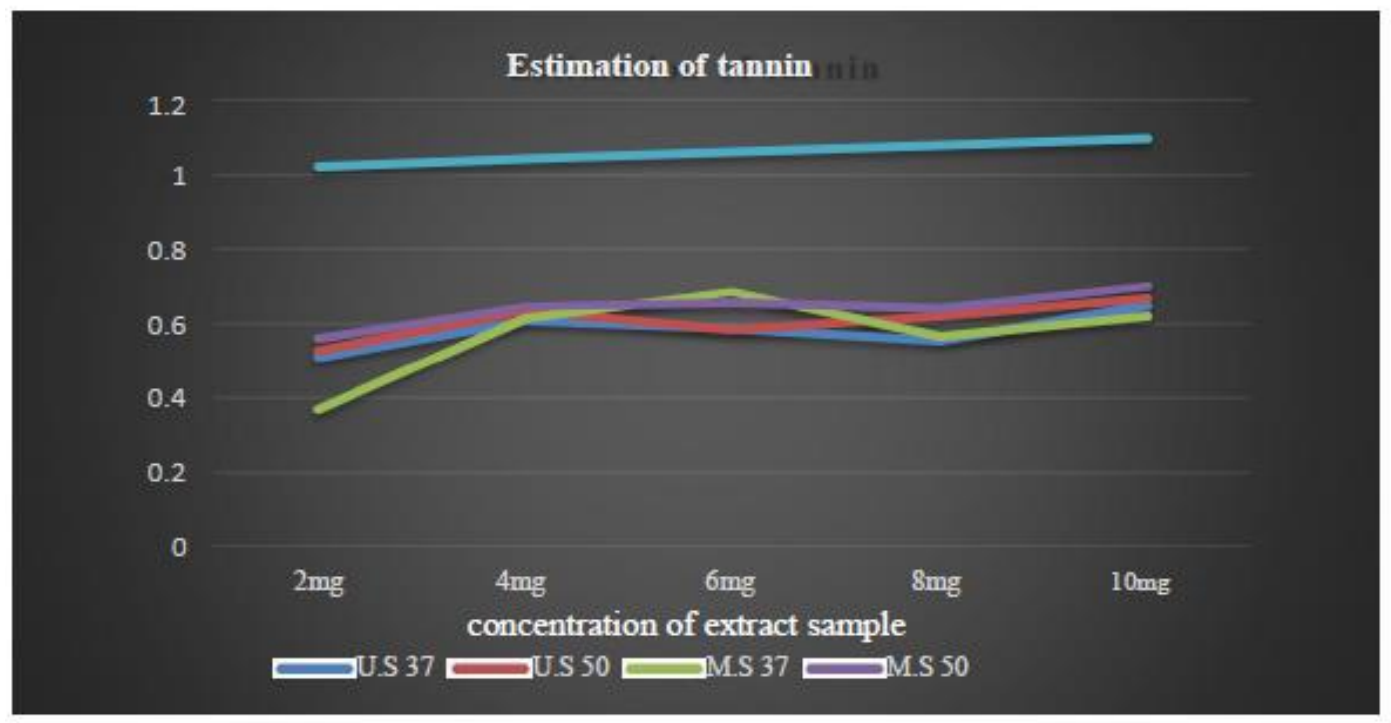

Figure 3. Estimation of Tannin content from ethanol extracts

\section{Conclusion}

Recycling of fruit waste is one of the most important means of utilizing it in a number of innovative ways yielding new products and meeting the requirements of essential products required in human, animal and plant nutrition as well as in the pharmaceutical industry. Pomegranate fruit and its peel exhibit a high antioxidant potential.

\section{References}

[1] Afaq, F., Saleem, M., Krueger, C.G., Reed, J.D., Mukhtar, H., 2005. Anthocyanin- and hydrolyzable tannin-rich pomegranate fruit extract modulates MAPK and NF-kappa B pathways and inhibits skin tumorigenesis in CD-1 mice. International Journal of Cancer 113, 423-433.

[2] Chew, YL, Chan, EWL, Tan, PL, Lim, YY, Stanslas, J \& Goh, JK 2011, assessment of phytochemical content, polyphenolic composition, antioxidant and antibacterial activities of Leguminosae medicinal plants in Peninsular Malaysia, BMC Complementary and Alternative Medicine, 11: 12.

[3] Chidambara M.K.N., Reddy V.K., Veigas J.M., Murthy U.D. 2004. Study on wound healing activity of Punica granatum peel. J. Med. Food, 7: 256-259. doi:10.1089/1096620041224111.

[4] Dai, J. and Mumper, R.J. Plant Phenolics: Extraction, Analysis and their antioxidant and Anticancer Properties. Molecules 2010, 15: 7313-7352.

[5] Gracious R.R., Selvasubramanian S., Jayasundar S. 2001. Immunomodulatory activity of Punica granatum in rabbits -a preliminary study. J. Ethnopharmacol., 78: 85-87. doi: 10.1016/S0378-8741(01)00287-2.

[6] Harborne J.B., (1973). Phytochemical Methods: A Guide to Modern Technique of Plant Analysis.

[7] Hassan, MM, Oyenwale, AO, Abduallahi, MS \& Okonkwo, EM 2004, Preliminary Phytochemical and Antibacterial investigation of crude extract of the root bark of Datarium microcarpum, Journal of Chemical Society Nigeria, 29: 26-29.

[8] Lansky, E., Shubert, S., Neeman, I., 2004. Pharmacological and therapeutic proper-ties of pomegranate. CIHEAM-Options Mediterraneennes xx, 231-235.

[9] Miliauskasa, G, Venskutonisa, PR \& Beekb van, TA 2004, Screening of radical scavenging activity of some medicinal and aromatic plant extracts, Food Chemistry, 85: 231-237.

[10] Navarro V., Villarreal M.L., Rojas G., Lozoya X. 1996. Antimicrobial evaluation of some plants used in Mexican traditional medicine for the treatment of infectious diseases. J. Ethnopharmacol., 53: 143-147. doi: 10.1016/0378-8741(96)01429-8.

[11] Negi, P.S., Jayaprakasha, G.K., Jena, B.S., 2003. Antioxidant and antimutagenic activities of pomegranate peel extracts. Food Chemistry 80, 393-398.

[12] Schanderi, SH 1970, Methods in food analysis, Academic Press, New York.

[13] Sestili, P., Martinelli, C., Ricci, D., Fraternale, D., Bucchini, A., Giamperi, L., Curcio, R., Piccoli, G., Stocchi, V., 2007. Cytoprotective effect of preparations from various parts of Punica granatum L. fruits in 
oxidatively injured mammalian cells in comparison with their antioxidant capacity in cell free systems. Pharmacolo-gical Research: The Official Journal of the Italian Pharmacological Society 56, 18-26.

[14] Shabtay A, E Harel, T Yaakov, O Alla, M Ayala, W Pnina, G Zwika, C Yaira, B Arieh, I Ido and K Zohar , 2008. Nutritive and antioxidative potential of fresh and stored pomegranate industrial byproduct as novel beef cattle feed. J Agric Food Chem, 56: 10063-10070.

[15] Tzulker R., Glazer I., Bar-Ilan I., Holland D., Aviram M., Amir R. 2007. Antioxidant activity, polyphenol content, and related compounds in different fruit juices and homogenates prepared from 29 different pomegranate accessions. J. Agr. Food Chem., 55: 9559-9570. doi:10.1021/jf071413n

[16] Whitley, A. C.; Stoner, G. D.; Darby, M. V.; Walle, T. Intestinal epithelial cell accumulation of the cancer preventive polyphenol ellagic acids Extensive binding to protein and DNA. Biochem. Pharmacol. 2003, 66:907915.

[17] Zahin, M., Aqil, F., Ahmad, I., 2010. Broad spectrum antimutagenic activity of antioxidant active fraction of Punica granatum L. peel extracts. Mutation Research 703, 99-107. 


\title{
Reflective Assessment of Learning Outcomes [RALO] in Basic Medical Sciences Subjects - [TAU MODEL]
}

\author{
Article by Arulsamy Anand \\ Vice Chancellor, Texila American University, Guyana, South America \\ E-mail:vc@tau.edu.gy
}

\begin{abstract}
The assessment of learning outcomes at the program level has been a topic of international interest as a method for quality assessment and ongoing program quality enhancement. According to UNESCO report, increasing global integration and exchange of both students and instructors has been an important international objective in higher education in recent years. This trend requires institutions to identify standards of quality, resulting in an increased emphasis on both learning outcomes and evidence from course assessments to demonstrate that students have mastered the expected learning.

Medical educators are increasingly laying emphasis in the assessment and learning outcome, and over a period of time standardized assessment methods like, OSPE and OSCE came into existence and they are widely used in many institution and also by the international examining bodies worldwide.

However, there aren't many assessment methods devised, wherein the medical students themselves can assess their level of understanding in basic medical sciences. Continuous methods of understanding the level of knowledge gained by a student will give him/her insight into his learning outcomes and as well as to the teachers.

This concept paper provides an overview of experience gained in developing a selfassessment methods of learning outcome of the medical students.

In 2014 Texila American University created the concept of Reflective Assessment of Learning Outcome, initially this method of assessment was experimented on the distance and blended learning programs, having found it to be very effective in terms of understanding the learning outcomes, this model was implemented for the Doctor of Medicine [MD] students in the year 2016.
\end{abstract}

Keywords: RALO - Reflective Assessment of Learning Outcome.

\section{Introduction}

\section{History of reflective learning}

The origins of thinking and writing about reflection started in the last century when John Dewey (1933) first described the concept and how it could help an individual to develop thinking and learning skills.

Dewey defined the concept of reflection as "the active, persistent and careful consideration of any belief or supposed form of knowledge in the light of the grounds that support it and the further consideration to which it tends" (Dewey, 1933).

A wider recognition of the importance of reflection for learning emerged in the mid-1980s in the work of David Kolb (1984) who suggested that learning can happen as result of reflection on experience- experiential learning. He suggested that reflection enables the experiential learner to move through steps from concrete experience to sense-making through reflection. Learners can explore abstract conceptualization- the application of theory- which informs further action and new experiences.

At the same time in the early 1980s the concept of reflection was developed further by Donald Schön (1982), a social scientist. He developed the idea of reflecting on experience to gain professional knowledge and develop professional skills in his seminal book The Reflective Practitioner: How Professionals think in action. 


\section{Reflective learning}

\section{Reflective learning enables one}

- To accept responsibility for his own personal growth

- To see a clear link between the effort one has put into his/her development activity and the benefits he/she get out of it

- To help see more value in each learning experience, by knowing why he/she is doing it and what's in it for him/her

- Learn how to 'learn' and add new skills over time.

\section{Reflecting on learning}

Reflecting on learning enables an individual to link his professional development to practical outcomes and widens the definition of what counts as useful activity. Quite simply, one need to keep asking 'what did I get out of this?'

As a reflective learner, an individual will think about how he will use new knowledge and skills in his future activities - so learning is always linked to action, and theory to practice. It's also useful to reflect on how he learn best.

\section{How often one should reflect on his learning?}

Reflection should become a routine part of college life that is more or less instinctive. People who routinely plan, record and reflect on their learning tend to see more opportunities for personal development.

Reflection also involves drawing forth cognitive and emotional information from several sources: visual, auditory, kinesthetic, and tactile. To reflect, one must act upon and process the information, synthesizing and evaluating the data. In the end, reflecting also means applying what one has learned to contexts beyond the original situations in which he learned something.

\section{What is Reflective Assessment of Learning Outcome [RALO]}

This is a self-assessment done by the students on the learning outcomes. Student learning outcomes articulate what a student should know or can do after completing a course or program. Reflective assessment of learning outcome helps the students to check their mastery level obtained based on the learning outcome determined in the syllabus. Students determines his/her level of understanding of the learning outcomes

\section{Why student self-assessment?}

"Self-assessment by pupils, far from being a luxury, is in fact an essential component of formative assessment. When anyone is trying to learn, feedback about the effort has three elements: recognition of the desired goal, evidence about present position, and some understanding of a way to close the gap between the two.

\section{Benefits for students}

- Development of metacognitive skills - students become more skilled at adjusting what they are doing to improve the quality of their work (Cooper, 2006).

- Increased responsibility for students' own learning as a result of more opportunities for self-reflection (Cyboran, 2006).

- Positive effects for low achievers -reducing achievement gaps (Black \& Wiliam, 1998; Chappuis, \& Stiggins, 2002).

- Development and refinement of students' capacity for critical thinking (Cooper, 2006)

\section{RALO feedback and growth continuum}

RALO provides a concrete feedback on the learning outcomes and as well the comparison between the objective and subjective assessment. RALO can also prove to be a feedback system for the teachers to know how effectively they had imparted their classes. This 
feedback will act as benchmark for the curriculum committee to make necessary modifications in determining the outcomes

Ralo feedback and growth continuum

\begin{tabular}{|c|c|c|c|c|}
\hline & Students & Faculty & & Institution \\
\hline $\begin{array}{l}\text { Learning } \\
\text { Outcomes }\end{array}$ & $\begin{array}{l}\text { What is expected to } \\
\text { be learned by the } \\
\text { students by the end of } \\
\text { the course }\end{array}$ & $\begin{array}{l}\text { Focus on } \begin{array}{r}\text { CORE } \\
\text { Competencies. }\end{array} \text { Learning } \\
\text { outcomes are determined } \\
\text { based on knowledge, Skills } \\
\text { and Attitude r and } \\
\text { competencies }\end{array}$ & & $\begin{array}{l}\text { Update the learning outcomes } \\
\text { for an appropriate mastery }\end{array}$ \\
\hline $\begin{array}{l}\text { Teaching } \\
\text { Learning } \\
\text { Activities } \\
\text { [TLA] }\end{array}$ & $\begin{array}{l}\text { Effectively participate } \\
\text { in the TLA }\end{array}$ & $\begin{array}{l}\text { Application of identified } \\
\text { strategies for achieving the } \\
\text { expected learning outcome }\end{array}$ & & $\begin{array}{l}\text { Modify the teaching learning } \\
\text { methods for a better outcome }\end{array}$ \\
\hline $\begin{array}{l}\text { Continuous } \\
\text { and } \\
\text { Summative } \\
\text { Assessment }\end{array}$ & $\begin{array}{l}\text { Participates in } \\
\text { Objective Assessment }\end{array}$ & $\begin{array}{l}\text { Assessment developed to } \\
\text { assess the learning outcome } \\
\text { objectively }\end{array}$ & & $\begin{array}{l}\text { Refining the Assessment } \\
\text { pattern }\end{array}$ \\
\hline $\begin{array}{l}\text { RALO } \\
\text { Assessment }\end{array}$ & $\begin{array}{l}\text { Self-Assessment by } \\
\text { the Students on the } \\
\text { Learning } \\
\text { Outcomes[Subjective] }\end{array}$ & $\begin{array}{l}\text { Comparison between } \\
\text { Objective and Subjective } \\
\text { Assessment }\end{array}$ & - & $\begin{array}{l}\text { Feedback to curriculum } \\
\text { committee }\end{array}$ \\
\hline
\end{tabular}

Figure 1. RALO feedback and growth continuum chart, shows the connection to the learning outcome, its assessment and feedback from the assessment leading to the modification of the teaching learning activities and eventually refinement of the learning outcomes

\section{Reflective assessment of learning outcomes [RALO] in basic medical sciences subjects- [TAU MODEL]}

\section{Objectives of RALO}

Students need to learn how to assess their own progress by asking themselves some key questions about where they are in their learning: Where am I now? Where am I trying to go? What do I need to get there? How will I know I have accomplished what I set out to do?

\section{To help students determine where they are now, teachers can...}

- Ensure that students understand the criteria for quality work, so that they are able to assess themselves as fairly and accurately as possible

- Help students gradually assume more responsibility for their own learning, as they practice using self-assessment tools such as RALO

- Provide students with opportunities to discuss their self-assessments in light of peer and teacher assessments

- Ensure that all stakeholders provide specific anecdotal feedback rather than scores or grades to identify explicit next steps for student learning

To help students determine where they intend to go, teachers can ...

- Develop with students clearly articulated learning targets and provide concrete exemplars of student work; students need to understand what they're "aiming for".

- Model goal-setting for students. 


\section{To help students determine what they need to do to get there ...}

- Collaboratively identify strengths and gaps in student learning through the analysis of a variety of data.

- Help students to develop realistic action plans that are practical and directly linked to the learning goals that have been selected.

- Monitor students' progress as they implement action plans.

To help students determine whether they have accomplished what they had set out to do...

- have students revisit long-term learning goals periodically to reflect on their relevance and to make any necessary adjustments

- talk with each student about his/her learning goal(s)

- have students write a specific reflection about their learning outcome and what they did to achieve them - students may need guidance to identify their strengths and areas for improvement

\section{Methods}

- All basic medical science teachers were informed about the RALO process and they were advised to check the appropriateness of the learning outcome of their respective subjects.

- The learning outcome were made known to the students and it was published in the learning management system.

- Teachers deliver the courses through various teaching learning methodologies

- At the end of the course the students were advised to do a self-assessment and rate themselves their level of achieving competencies over the subject matter. This was done through the learning management system

\section{Results}

The results of the RALO of all the four levels of classes are given below

\section{Discussion}

\section{Mapping the learning outcome with peers}

Through RALO assessment students can compare their understanding of the learning outcomes with their classmates. This provides more insight into their learning and understanding. The following gives the overall RALO scores of a class, an individual student can rate himself against the given learning outcome and compare it with the overall class score

The following is the overall RALO Score of MD-1[2016] class in Medical Embryology. An individual student can compare his level of learning with the overall learning outcome of his class 


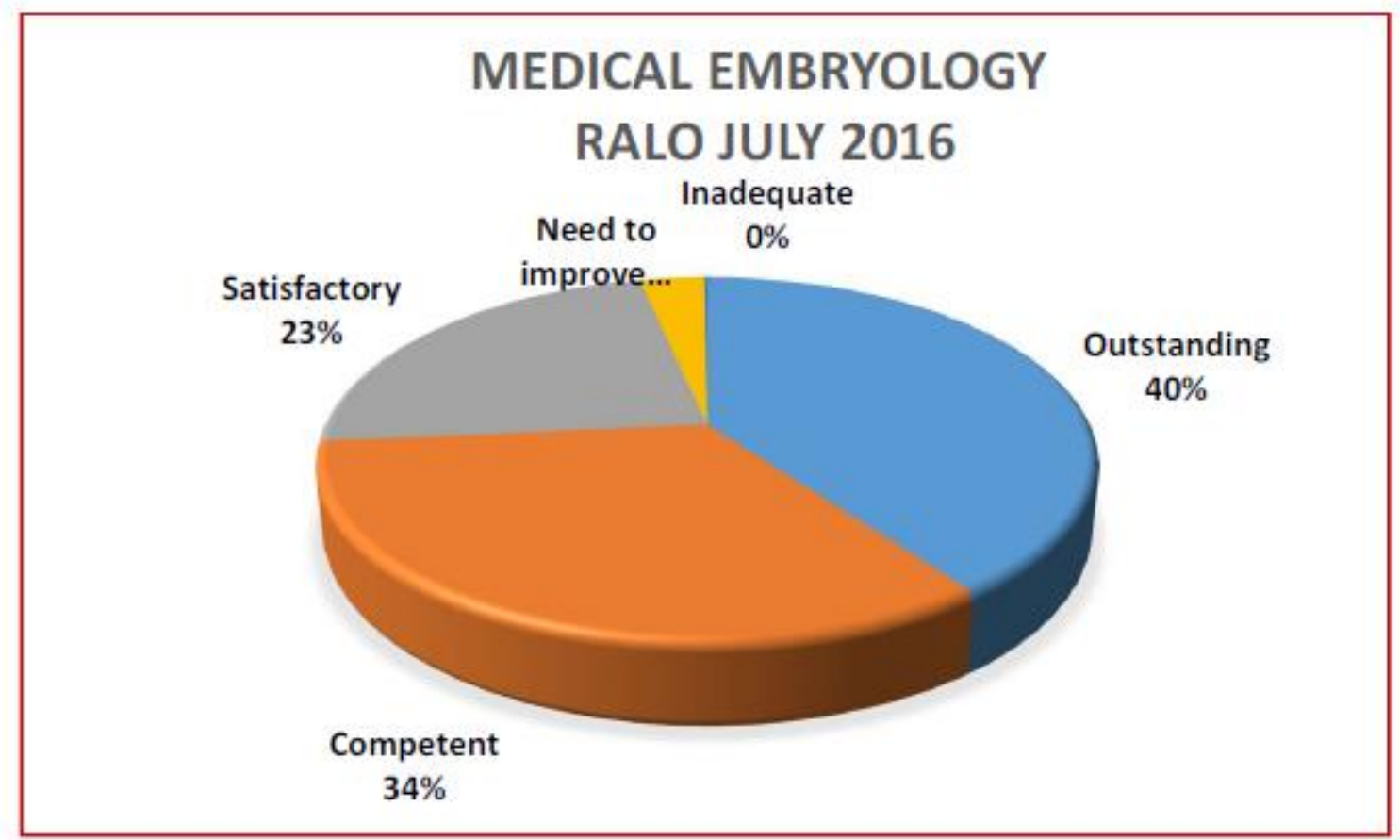

Figure 2. Class rating on the learning outcomes of the subject Medical Embryology

\section{RALO assessment}

Students to rate the following learning outcome based on their level of competency as 5: Outstanding 4: Competent 3: Satisfactory 2: Need to improve 1: Inadequate Upon completion of the course, students will be able to:

\begin{tabular}{|c|c|c|}
\hline S.No & Responses & Score \\
\hline 1 & $\begin{array}{l}\text { Understand and describe human gamete biology, embryology and } \\
\text { developmental biology from a cellular and genetic perspective }\end{array}$ & \\
\hline 2 & $\begin{array}{l}\text { Describe the key events in early and systematic embryological } \\
\text { development }\end{array}$ & \\
\hline 3 & Apply developmental theory of anatomical development & \\
\hline 4 & $\begin{array}{l}\text { Apply developmental theory to abnormalities of development and } \\
\text { current medical research techniques }\end{array}$ & \\
\hline 5 & $\begin{array}{l}\text { Students are able to broadly understand the abnormalities in the } \\
\text { development and current applications in medical research }\end{array}$ & \\
\hline 6 & $\begin{array}{l}\text { Identify and define key structural and molecular elements involved in } \\
\text { each stage of human development, the precursors of each structure, } \\
\text { and the functional significance of each structure }\end{array}$ & \\
\hline 7 & $\begin{array}{l}\text { Construct a temporal sequence of key events in each developmental } \\
\text { period }\end{array}$ & \\
\hline 8 & $\begin{array}{l}\text { Explain and identify the normal embryological anatomy and identify } \\
\text { anomalies in the development of various tissues through a comparison } \\
\text { of normal and abnormal development }\end{array}$ & \\
\hline 9 & $\begin{array}{l}\text { Understand, using a comparative approach, the key differences in } \\
\text { embryological development across animals }\end{array}$ & \\
\hline 10 & $\begin{array}{l}\text { Accurately and effectively communicate scientific ideas through } \\
\text { written assignments and reports within the lab and a case study } \\
\text { presentation }\end{array}$ & \\
\hline
\end{tabular}


DOI: 10.21522/TIJBMS.2016.02.02.Art006

ISSN: $2519-500 \mathrm{X}$

An individual can score himself against the learning outcome for the subject Medical embryology and total his score and percentage in the table given below and compare it with his peers

\begin{tabular}{|l|l|l|l|l|}
\hline S.No & $\begin{array}{l}\text { Score and Level of } \\
\text { Understanding }\end{array}$ & Total Score & Percentage & Class \% \\
\hline 1 & 5: Outstanding & & & $40 \%$ \\
\hline 2 & 4: Competent & & & $34 \%$ \\
\hline 3 & 3: Satisfactory & & & $23 \%$ \\
\hline 4 & 2: Need to improve & & & $3 \%$ \\
\hline 5 & 1: Inadequate & & & $0 \%$ \\
\hline
\end{tabular}

\section{Summary}

After the assessment is complete, those faculty and/or other parties most involved in the RALO, analyze the results and determine how to use them to improve students' success in achieving Learning Outcomes. For example, they might decide to change or augment instruction in a particular way, change curriculum, or improve future RALO assessments in a specific way.

\section{References}

[1]. Altbch, P.G., Reisberg, L, \& Rumbley, L.E. (2009). Trends in global higher education. Tracking an academic evolution. United Nation Educational, Scientific, and Cultural Organization. Retrieved from

[2]. Bruce, L. B. (2001). Student self-assessment: Encouraging active engagement in learning. Dissertation Abstracts International, Vol. 62-04A, 1309.

[3]. Driscoll, A. and Wood, S. (2007). Developing outcomes-based assessment for learner-centered education: A faculty introduction. Sterling, VA: Stylus.

[4]. Jonson, J. (2006). A guidebook for programmatic assessment of student learning outcomes: University of Nebraska, Lincoln. University of Nebraska, Lincoln: office of Undergraduate Studies.

[5]. Rolheiser, C., \& Ross, J.A. (2000). Student self-evaluation - What do we know? Orbit, 30(4), 33-36.

[6]. Shoemaker, J. (2008). Guidelines for writing student learning outcomes. University of California, Irvine: Assessment \& Research Studies, Division of Undergraduate Education. Irvine, CA. 


\title{
The Human Inter Vertebral Disc - A Histological Approach
}

\author{
Article by Anuradha $\mathrm{K}^{1}$, Sujatha Kiran $\mathrm{P}^{2}$ \\ ${ }^{1}$ Department of Anatomy, Maheshwara Medical College, Patancheru, Telangana, India \\ ${ }^{2}$ Professor, Kamineni Institute of Medical Sciences, Narketpally, Nalgonda, India \\ E-mail: dkanuradha2003@gmail.com ${ }^{1}$
}

\begin{abstract}
The human intervertebral disc (IVD) is a very complex joint structure that can be made up of highly organized matrix laid down by relatively few cells in a specific manner. Macroscopically it can be separated in to three distinct components. The central gelatinous nucleus pulposus is contained within the more collagenous anulus fibrosus laterally and the cartilage end plates inferiorly and superiorly. The anulus consists of concentric rings or lamellae, with fibers in the outer lamellae continuing into the longitudinal ligaments and vertebral bodies. This arrangement allows the discs to facilitate movement and flexibility within what would be an otherwise rigid spine. With increasing age, the disc-particularly the nucleus-becomes less gelatinous and more fibrous, and cracks and fissures eventually form. More blood vessels begin to grow into the disc from the outer areas of the annulus. There is an increase in cell proliferation and formation of cell clusters as well as an increase in cell death. In the present study the microscopic anatomy of intervertebral disc of full term human foetus was examined the alignment of collagen Fibers \& distribution of chondrocytes in the annulus is observed with the help of Haematoxylin \& Eosin stain and Vangieson's stain. The Haematoxylin \& Eosin study reveals that the collagen fibers are arranged circularly \& the nucleus pulposus is of mucoid material, which is made up of degenerated notochordal cells.
\end{abstract}

Keywords: Inter vertebral disc, Anulus fibrosus, Nucleus pulposus, Histology.

\section{Introduction}

The Inter vertebral discs are a fibro cartilage type and provide strong attachments between the vertebral bodies, uniting them into a continuous semi rigid column and forming the inferior half of the anterior border of the inter vertebral foramen. In aggregate, the discs account for $25 \%$ of the length (height) of the vertebral column, as well as permitting movement between adjacent vertebrae, their resilient deformability allows them to serve as shock absorbers (1).

Mesenchymal cells between cephalic and caudal parts of the original sclerotome segment do not proliferate but fill the space between two precartilaginous vertebral bodies and forms the intervertebral disc. Notochord contributes the nucleus pulposus, which is later surrounded by circular fibers of the anulus fibrosus. Combined, these two structures form the intervertebral disc (2).

The human intervertebral disc (IVD) is a very complex joint structure that can be separated macroscopically into at least three distinct components: 1) the nucleus pulposus (NP) representing a centrally located gelatinous homogenous mass and of mucoid material with a few multinucleated notochordal cells 2) the anulus fibrosus (AF) consisting of concentrically organized layers of collagen fibrils 3) the cartilaginous endplates (EP), which separate the nucleus pulposus and anulus fibrosus from the adjacent vertebral bone. Any disturbance of the integrity and interplay of one of the three structures can result in a compromised function of the intervertebral disc (3)

According to Buckwalter JA et al like no other musculoskeletal tissue, the lumbar intervertebral disc undergoes very extensive destructive changes with age and degeneration (4). The degree of this tissue destruction is closely linked to age, but different components of the disc undergo more extensive alterations than others (5).

The present study focuses on the extent of cellularity, structural changes of granular matrix degeneration, the formation of clefts and tears and mucoid matrix changes in the nucleus pulposus and annulus fibrosus of the intervertebral disc by the histochemical approach. 
ISSN: $2519-500 \mathrm{X}$

\section{Materials and methods}

The material for present study consists of 25 fully formed dead foetuses (14 male, 9 female). They were collected from Meenaz maternity hospital, Gulbarga, Karnataka, MNR medical college \& hospital, Sangareddy, Telangana India.

The dead foetuses with anomalies like spina bifida, cervical spondylosis, degenerative disc diseases and other skeletal \& vertebral deformities were excluded from the study. Normal dead foetuses were considered for this study.

All the lumbar vertebral discs are harvested during routine autopsy under anterior approach. Lumbar intervertebral discs are choose because of bigger and convenient than other region. After dissection Length and Breadth of inter vertebral discs were measured with the standard sliding calipers.

All the slices were fixed in buffered $10 \%$ formaldehyde for 24 hours and subsequently decalcified depending on the calcification of the osseous matrix of the vertebral bone. The decalcified disc slices were then embedded into paraffin as routinely performed. From the resulting blocks, paraffin sections were cut and placed on salinized glass slides for routine staining using standard histochemical protocols. The following staining methods are used

i. Haematoxylin and eosin to identify cells and fibres.

ii. Vangieson method to identify collagen fibers.

A histomorphological distinction between anular and nuclear disc tissue was performed by use of light microscopic criteria particularly under polarized light, allowing the evaluation of the organization of the collagen network.

\section{Result \& observations}

Morphological observation: The length and breadth of intervertebral disc were calculated by standard sliding callipers.

Table 1. Mean and SD of intervertebral disc in male \& female

\begin{tabular}{|l|l|l|l|l|}
\hline \multirow{2}{*}{ Sex } & \multicolumn{3}{|l|}{$\begin{array}{l}\text { Average length in } \\
\text { mm }\end{array}$} & $\begin{array}{l}\text { Average breadth in } \\
\text { mm }\end{array}$ \\
\cline { 2 - 5 } & mean & SD & Mean & SD \\
\hline Male & 11.21 & 1.01 & 18.9 & 0.85 \\
\hline Female & 11.27 & 1.05 & 18.54 & 0.78 \\
\hline
\end{tabular}

\section{Histological observations}

For descriptive purpose, the disc was analyzed in 2 parts -anulus fibrosus and nucleus pulposus. The collagen fibers in anulus are circularly, concentrically arranged and centrally placed nucleus pulposus shows multi nucleated degenerated notochordal cells seen in the form of mucoid material. 
Table 2. Histological observations of intervertebral disc

\begin{tabular}{|l|l|l|l|}
\hline \multirow{2}{*}{$\begin{array}{l}\text { Staining } \\
\text { Method }\end{array}$} & \multicolumn{2}{|l|}{ Anulus fibrosus } & Nucleus Pulposus \\
\cline { 2 - 4 } $\begin{array}{l}\text { Haematoxylin } \\
\text { \& Eosin }\end{array}$ & $\begin{array}{l}\text { Seen in lacunae } \\
\text { more in number } \\
\text { then fibers }\end{array}$ & $\begin{array}{l}\text { Circularly \& } \\
\text { Concentrically } \\
\text { arranged }\end{array}$ & $\begin{array}{l}\text { Degenerated multi } \\
\text { nucleated notochordal } \\
\text { cells are seen in the } \\
\text { form of mucoid } \\
\text { material }\end{array}$ \\
\hline Vangieson & $\begin{array}{l}\text { Seen in lacunae } \\
\text { more in number } \\
\text { then fibers }\end{array}$ & $\begin{array}{l}\text { Circularly \& } \\
\text { Concentrically } \\
\text { arranged }\end{array}$ & $\begin{array}{l}\text { Degenerated multi } \\
\text { nucleated notochordal } \\
\text { cells are seen in the } \\
\text { form of mucoid } \\
\text { material }\end{array}$ \\
\hline
\end{tabular}

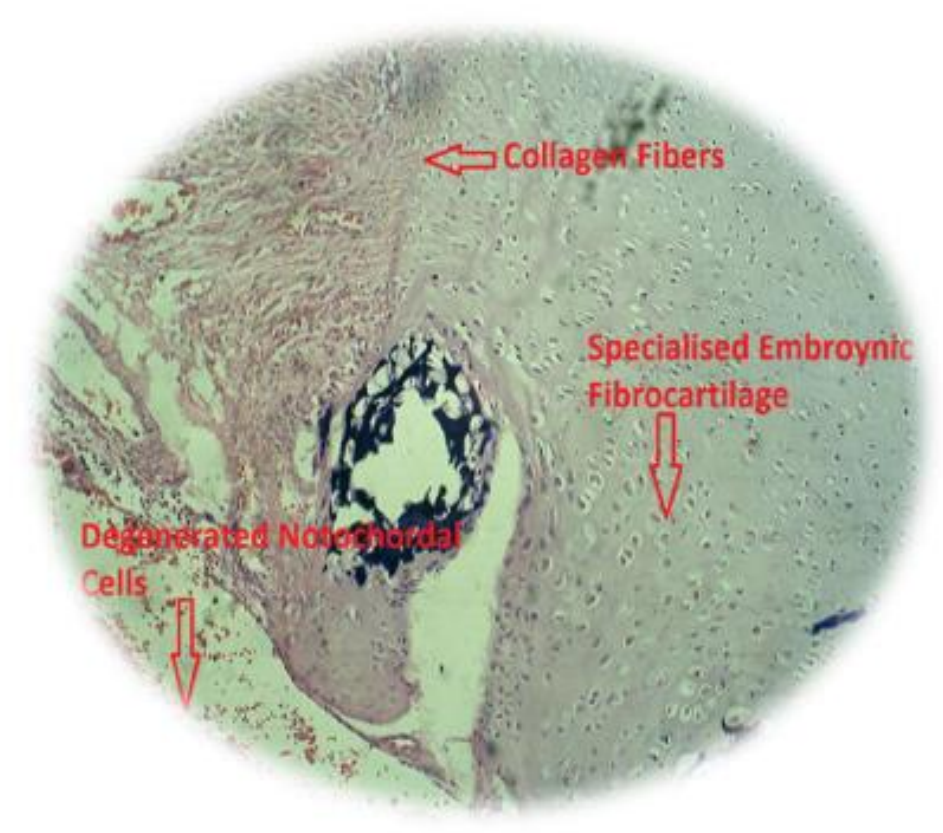

H \& E STAIN TOTAL MAGNIFICATION 10X10=100

Figure 1. Intervertebral disc showing specialized embryonic fibro cartilage 


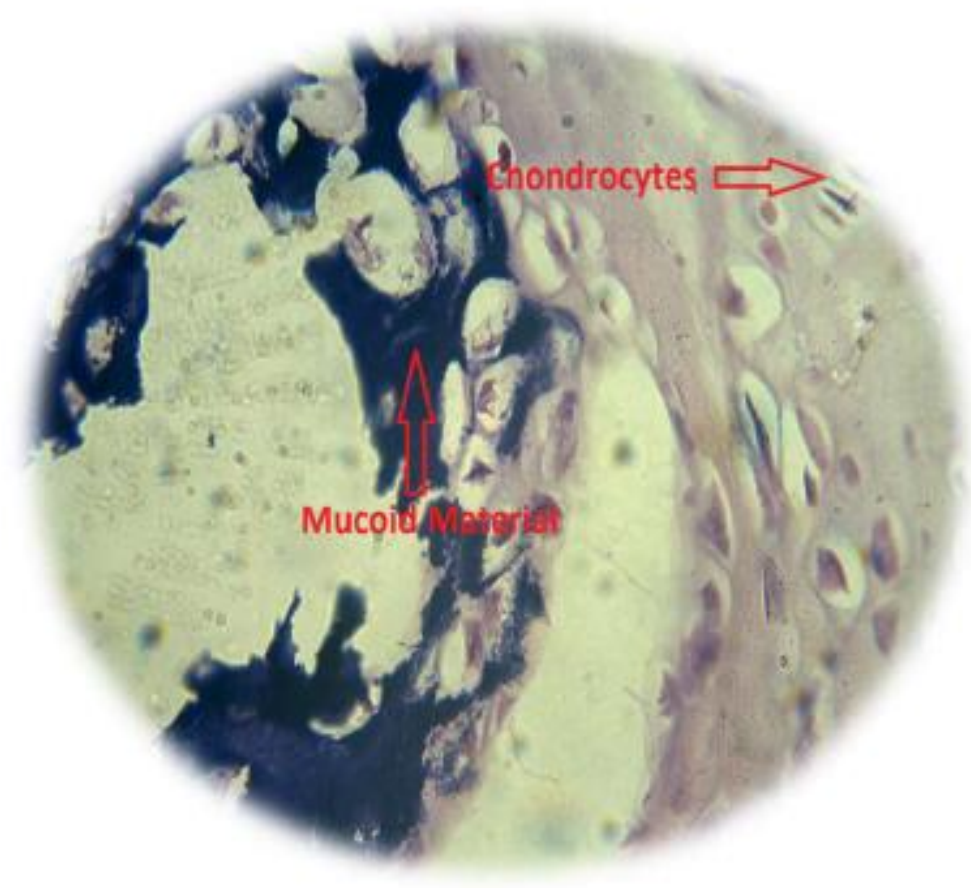

H \& E STAIN TOTAL MAGNIFICATION 40X10=400X

Figure 2. Intervertebral disc showing mucoid material

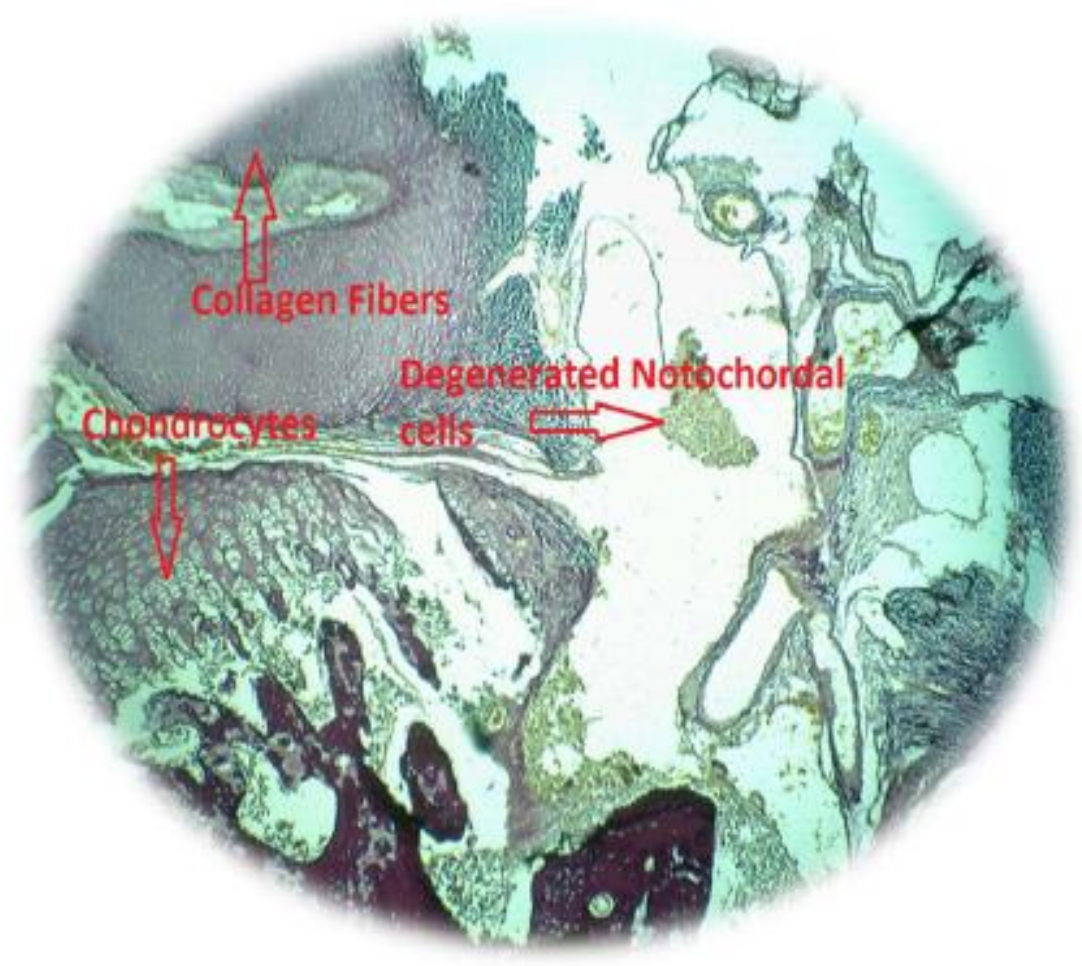

VANGIESON STAIN TOTAL MAGNIFICATION 4X10=40X

Figure 3. Intervertebral disc showing degenerated notochordal cell 


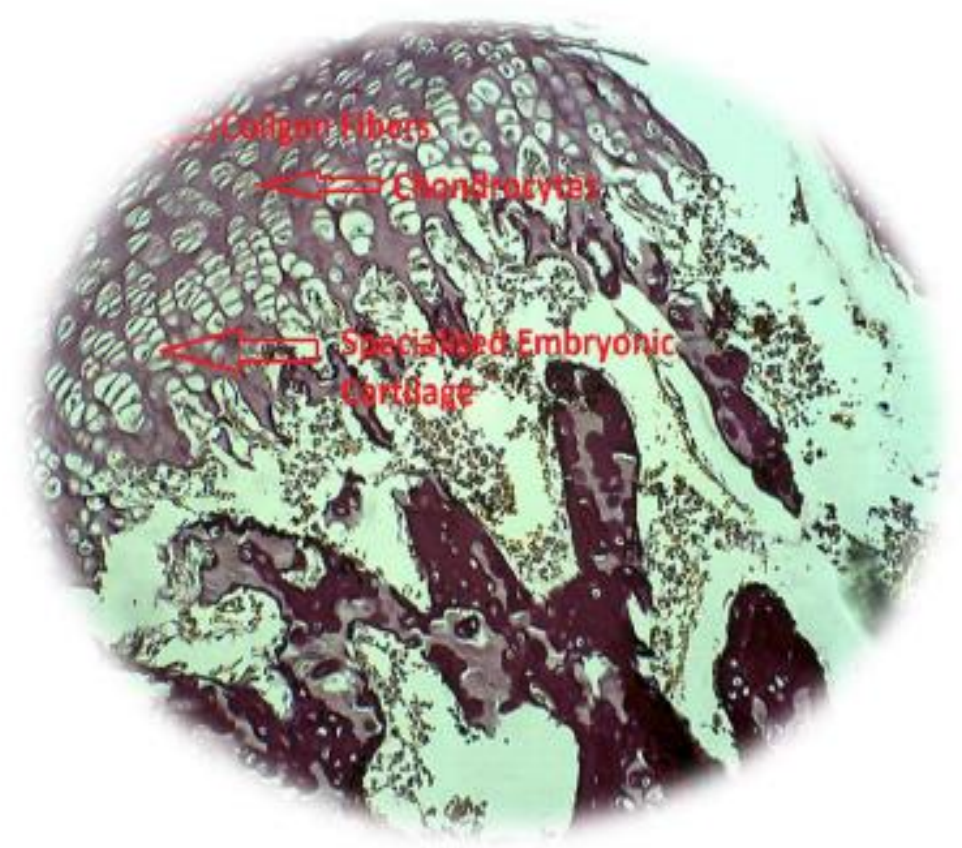

VANGIESON STAIN TOTAL MAGNIFICATION 4X10=40X

Figure 4. Intervertebral disc showing specialized embryonic fibro cartilage

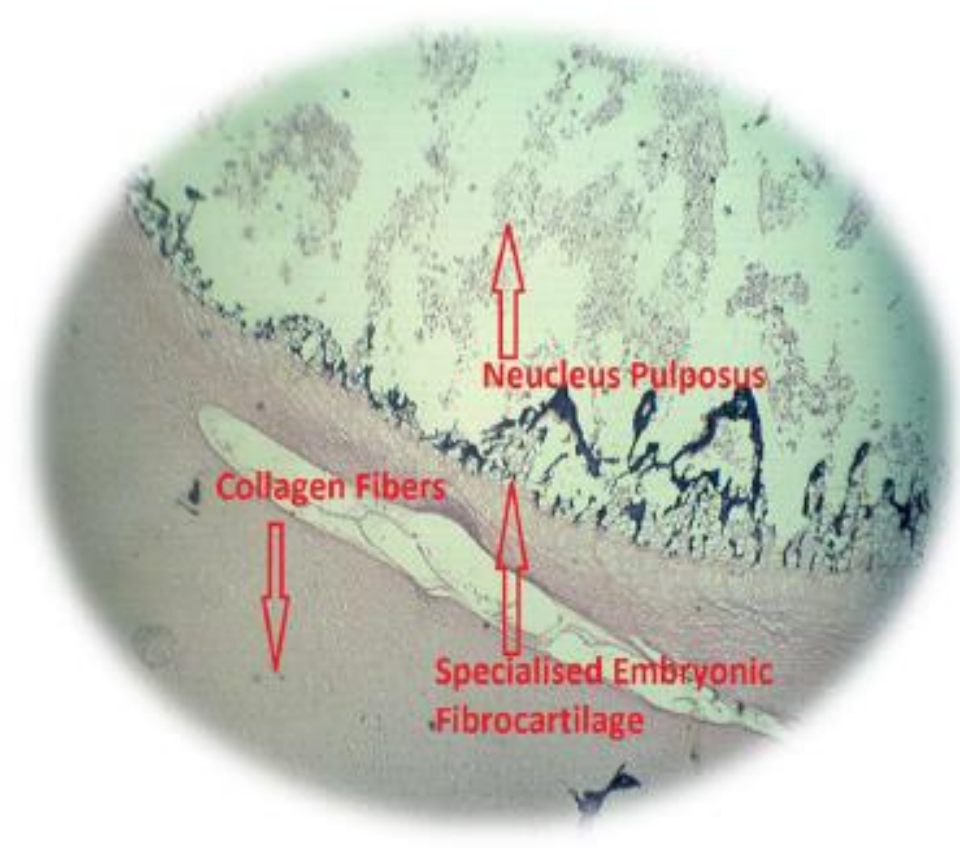

H \& E. STAIN TOTAL MAGNIFICATION 4X10=40XFig.

Figure 5. Diagrammatic representation of intervertebral disc showing anulus fibrosus and nucleus pulposus 


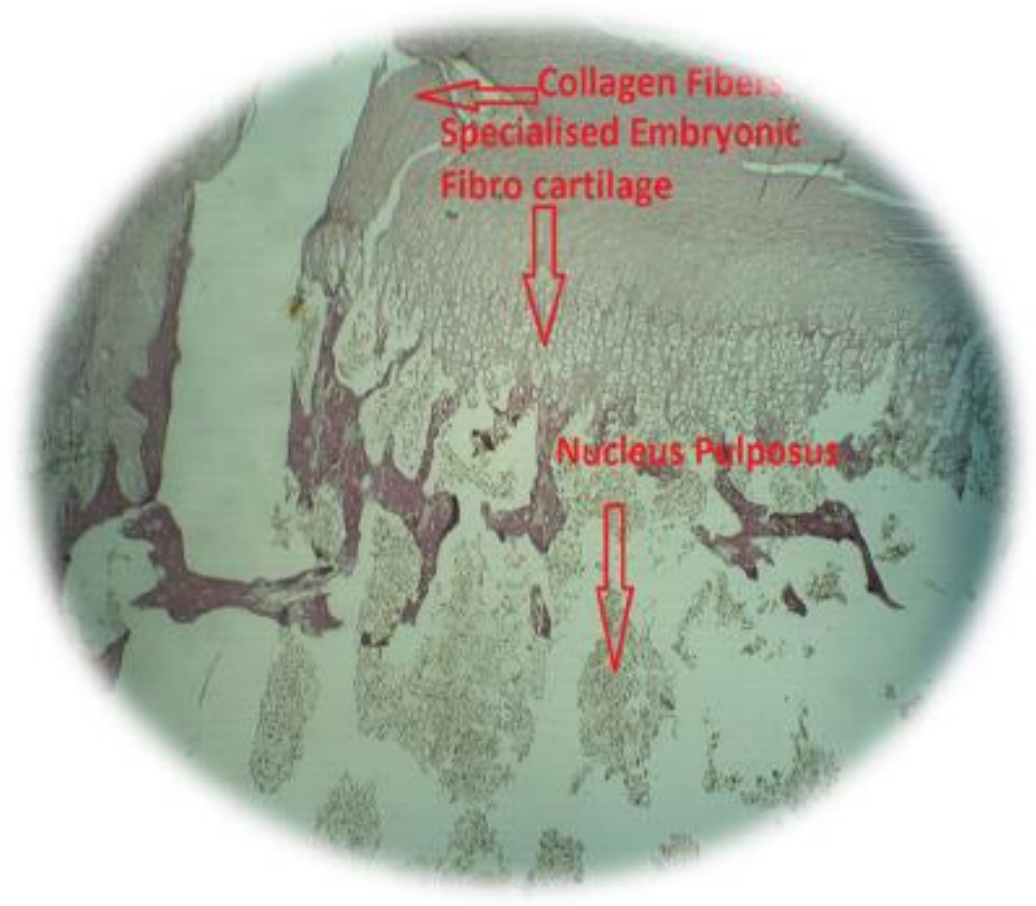

VANGIESON STAIN TOTAL MAGNIFICATION 4X10=40X

Figure 6. Diagrammatic representation of intervertebral disc showing anulus fibrosus and nucleus pulposus

\section{Discussion}

In prenatal development, the anulus fibrosus has collagen fibers which are circularly arranged and centrally placed nucleus pulposus show degenerated notochordal cells .

The intervertebral discs are subject to continuous and progressive changes throughout life so marked that it is difficult to determine what is normal and what is pathologic. (6)

Annular changes are characterized by a gradual loss of fine fibrous connective tissue meshwork and its replacement by increasingly hyalinized collagen fibers, the occurrence of fissures beginning in the third decade, cellular proliferation and enhanced cell death in the fourth decade, and finally the invasion of blood vessels along tears and clefts. In the nucleus pulposus of infants, residues of notochordal cell aggregates are replaced by proliferating chondrocytes, beginning in the second life decade. This is followed by the occurrence of tissue clefts, beginning in the fourth decade, and the progressive replacement of the nucleus by fibrous tissue from the fifth decade onward. (7).

In the morphological observations the average length of disc in males is 11.21 and $\mathrm{SD}$ is $1.01 \mathrm{~mm}$ but in females average length is 11.27 and SD is 1.05. The values showing length of the disc is minutely higher in males than females (Table 1).

The average breadth of disc in males is $18.9 \mathrm{~mm}$ and SD is 0.85 and in female average breadth is 18.54 and SD is 0.78 . These values showing breadth of the disc is slightly higher in males than females (Table 1).

In the histological observation of present study, anulus fibrosus shows circularly, concentrically arranged collagen fibers on peripheral part and centrally placed nucleus pulposus shows multi nucleated degenerated notochordal cells seen in the form of mucoid material (figure $1-6)$. 


\section{Conclusion}

It is shown by previous authors that the intervertebral disc development starts by $4^{\text {th }}$ week of intrauterine life as Mesenchymal condensation. By $10^{\text {th }}$ week, this Mesenchymal condensation differentiates in to anulus and nucleus pulposus.

The present extensive study by different special staining techniques on full term human intervertebral discs show the definite circular, concentrically arranged collagen fibers in anulus fibrosus and chondrocytes and degenerated notochordal cells in nucleus pulposus. Notochordal cells disappear after birth in the first decade of life, followed by gradual replacement of mucoid material by fibro cartilage.

\section{References}

[1]. Antoniou J, Goudsouzian NM, Heathfield TF, et al. The human lumbar endplate: Evide nce of changes in biosynthesis and denaturation of the extracellular matrix with growth, maturation, aging, and degeneration. Spine 1996; 21:1153-61.

[2]. Buckwalter JA. Spine update: Aging and degeneration of the human intervertebral disc. Spine 1995; 20:1307-14.

[3]. Coventry MB, Ghormley RK, Kernohan JW. The intervertebral disc: Its microscopic anatomy and pathology: Part II. Changes in the intervertebral disc concomitant with age. J Bone Joint Surg [Am] 1945; 27:233-47.

[4]. Coventry MB, Ghormley RK, Kernohan JW. The intervertebral disc: its microscopic anatomy and pathology: part I. anatomy, development and pathology. J Bone Joint Surg [Am] $1945 ; 27: 105-12,1945 ; 27: 460-74$.

[5]. Langman's Medical Embryology 9th edition - T. Sadler (2003)

[6]. Moore, Keith L.; Dalley, Arthur F. Clinically Oriented Anatomy, 5th Edition

[7]. Saunders JB, Inman VT. Pathology of the inter vertebral disk. Arch Surg 1940; 40: 389-416. 


\title{
Assess the Pre Test Knowledge and Practice of Post-Operative Exercises among Abdominal Surgery Patients Before Video Assisted Teaching
}

\author{
Article by Chakrapani Cheekavolu ${ }^{1}$, Vinod kumar Gurram² ${ }^{2}$ P.Leela ${ }^{3}$, Jagan Nadipelly ${ }^{4}$, G. \\ Obulesu $^{5}$ \\ ${ }^{1}$ Assistant Professor, Department of Pharmacology, Kerala Medical College Hospital, Mangode, \\ Palakkad, Kerala, India \\ ${ }^{2}$ Assitant Professor, Department of Anatomy, Kerala Medical College Hospital, Mangode, \\ Palakkad, Kerala, India \\ ${ }^{3} P G$ student, Department of Bio chemistry, SVIMS, Tirupati. Andhra Pradesh, India. \\ ${ }^{4}$ Faculty of Medicine - Pharmacology, Texila American University, Georgetown, Guyana, South \\ America \\ ${ }^{5}$ Assitant Professor, Department of Microbiology, Kerala Medical College Hospital, Mangode, \\ Palakkad, Kerala, India \\ E-mail: chakri14783@gmail.com ${ }^{1}$
}

\begin{abstract}
Background: A study to determine the effectiveness of video assisted teaching in knowledge and practice on post-operative exercises among abdominal surgery patients in selected hospitals at Kerala.

Methodology: A pre experimental research with group pre-test and post-test design and chosen 40 patients was chosen to assess the effectiveness of video assisted teaching programme on post-operative exercises among abdominal surgery patients in tertiary care hospital in Kerala. The study was conducted in tertiary care hospital after obtained the ethical committee approval during the period of July to Dec 2017.

Results: The pre-test knowledge, out of 40 patients all of them 40 (100\%) had inadequate knowledge on post-operative exercises. In post-test knowledge, out of 40 patients one (2.5\%) of them had moderately adequate knowledge, 39 (97.5\%) of them had adequate knowledge and none of them had inadequate knowledge in post-test on post-operative exercises.

Conclusion: The pre-test knowledge had inadequate knowledge on post-operative exercises among abdominal surgery patients in tertiary care hospital in Kerala.

Keywords: knowledge and practice, post-operative exercises, abdominal surgery.

\section{Introduction}

Surgery is the art and science of treating diseases, injuries and deformities by operation and instrumentation". Surgery may be performed for the purpose of diagnosis, cure, palliation, cosmetic improvement and prevention. Surgery may be elective in which it is carefully planned and anticipated. The need for surgery may sometimes arise with sudden and unanticipated surgery and is called emergency surgery. The term abdominal surgery broadly covers surgical procedures that involve opening the abdomen. Exercise is important to keep both your body and mind "in shape". Physical exercise is important for maintaining physical fitness and can contribute positively for maintaining a healthy weight, building and maintaining healthy bone density, muscle strength, and joint mobility, promoting physiological well-being, reducing surgical risks, and strengthening the immune system.

Exercising plays an important role in regaining function and strength after undergoing an operation. The goal of post-operative care is to prevent complications such as infection, to promote healing of the surgical incision, and to return the patient to a state of health. Particular patient groups susceptible to fluid or electrolyte disturbances include the elderly, those with pre-existing
\end{abstract}


DOI: $10.21522 /$ TIJBMS.2016.02.02.Art008

ISSN: $2519-500 \mathrm{X}$

cardiovascular/cerebrovascular/renal disease and patients who have suffered a peri-operative myocardial ischemic event [1]. In cases of common conditions can affect peri-operative care include ischemic heart disease, congestive cardiac failure, chronic respiratory disease, diabetes mellitus and liver or renal dysfunction [2]. Hypotension is also common post-operatively and has been defined as a systolic blood pressure below $90 \mathrm{mmHg}$ [3]. Causes include hypovolemic due to bleeding or dehydration, or drug therapy. These variables should be measured multiple times during the day, depending on the type of surgery involved. Other examples of monitoring include ECGs, arterial blood gas analysis (ABGs) and central venous pressure (CVP) monitoring [4]. In addition, assessment of drainage and bleeding should also be performed routinely [5].

Having surgery is a major event in any person's life. Some of the patient may respond with expression of helplessness, security and isolation due to discomfort, pain and fear of breaking stitches. These feeling can be minimized with pre-operative teaching about postoperative practice related to activities, nutrition, medication and ambulation. [6]

A study was conducted regarding chest physiotherapy during immediate post-operative period among patients undergoing abdominal surgery. Chest physiotherapy during immediate post-operative period following laparotomy was effective for improving oxygen haemoglobin saturation without increased abdominal pain. Breathing exercises could be adopted post anaesthesia care units with benefits for patients. [7]. the present assessment to determine the effectiveness of video assisted teaching in knowledge and practice on post-operative exercises among abdominal surgery patients in selected hospitals at Kerala.

\section{Methodology}

\section{Research design}

A pre experimental research with group pre-test and post-test design and chosen 40 patients was chosen to assess the effectiveness of video assisted teaching programme on post-operative exercises among abdominal surgery patients in tertiary care hospital in Kerala. The study was conducted in tertiary care hospital after obtained the ethical committee approval during the period of July to Dec 2017. It is a 250 bedded multi-speciality hospital and conducted study in general surgery department.

\section{Inclusion criteria}

Who are in age group between 20-50 years?

Who undergoing abdomen surgery for first time?

Who undergoing abdomen surgery through open laparotomy?

Who are willing to participate?

Who are planning for surgery electively?

\section{Exclusion criteria}

Who are undergoing emergency surgery?

Who are affected with sensory and motor disabled persons? 
Table 1. Distribution of demographic variables among abdominal surgery patients $(n=40)$

\begin{tabular}{|c|c|c|}
\hline \multirow[t]{2}{*}{ Demographic Variables } & \multicolumn{2}{|c|}{ Abdominal Patients } \\
\hline & Frequency & Percentage $(\%)$ \\
\hline $\begin{array}{l}\text { 1. Age (in years) } \\
\text { a. } 20-30 \\
\text { b. } 31-40 \\
\text { c. } 41-50\end{array}$ & $\begin{array}{l}9 \\
17 \\
14\end{array}$ & $\begin{array}{l}22.5 \\
42.5 \\
35.0\end{array}$ \\
\hline $\begin{array}{l}\text { 2. Gender } \\
\text { a. Male } \\
\text { b. Female }\end{array}$ & $\begin{array}{l}25 \\
15\end{array}$ & $\begin{array}{l}62.5 \\
37.5\end{array}$ \\
\hline $\begin{array}{l}\text { 3. Educational Qualification } \\
\text { a. Non formal education } \\
\text { b. Primary } \\
\text { c. Secondary } \\
\text { d. Higher Secondary } \\
\text { e. Graduate }\end{array}$ & $\begin{array}{l}0 \\
2 \\
12 \\
17 \\
9\end{array}$ & $\begin{array}{l}0.0 \\
5.0 \\
30.0 \\
42.5 \\
22.5\end{array}$ \\
\hline $\begin{array}{l}\text { 4. Occupation } \\
\text { a. Farmer } \\
\text { b. Driver } \\
\text { c. Worker in a company } \\
\text { d. Student } \\
\text { e. House wife }\end{array}$ & $\begin{array}{l}4 \\
8 \\
11 \\
4 \\
13\end{array}$ & $\begin{array}{l}10.0 \\
20.0 \\
27.5 \\
10.0 \\
32.5\end{array}$ \\
\hline $\begin{array}{l}\text { 5. Monthly Income } \\
\text { a. Less than Rs. } 10,000 \\
\text { b. Rs. } 10,000-15,000 \\
\text { c. Rs. } 15,001-20,000 \\
\text { d. Above Rs. } 20,001 \\
\end{array}$ & $\begin{array}{l}4 \\
13 \\
18 \\
5 \\
\end{array}$ & $\begin{array}{l}10.0 \\
32.5 \\
45.0 \\
12.5\end{array}$ \\
\hline $\begin{array}{l}\text { 6. Family Type } \\
\text { a. Joint } \\
\text { b. Nuclear }\end{array}$ & $\begin{array}{l}29 \\
11 \\
\end{array}$ & $\begin{array}{l}72.5 \\
27.5 \\
\end{array}$ \\
\hline $\begin{array}{l}\text { 7. Personal Habits } \\
\text { a. Smoking } \\
\text { b. Tobacco and betel leaves } \\
\text { c. Alcohol } \\
\text { d. Nil }\end{array}$ & $\begin{array}{l}8 \\
1 \\
6 \\
25 \\
\end{array}$ & $\begin{array}{l}20.0 \\
2.5 \\
15.0 \\
62.5 \\
\end{array}$ \\
\hline $\begin{array}{l}\text { 8. Chronic Diseases } \\
\text { a. Diabetes Mellitus } \\
\text { b. Hypertension } \\
\text { c. Asthma } \\
\text { d. Nil }\end{array}$ & $\begin{array}{l}5 \\
4 \\
3 \\
28\end{array}$ & $\begin{array}{l}12.5 \\
10.0 \\
7.5 \\
70.0\end{array}$ \\
\hline
\end{tabular}


DOI: $10.21522 /$ TIJBMS.2016.02.02.Art008

ISSN: $2519-500 \mathrm{X}$

Table 2. Distribution of level of knowledge on post-operative exercises in pre-test among abdominal surgery patients $(n=40)$

\begin{tabular}{|l|l|l|}
\hline Level of Knowledge & Frequency & Percentage \\
\hline Inadequate Knowledge & 40 & 100.0 \\
\hline Moderate Knowledge & - & - \\
\hline Adequate Knowledge & - & - \\
\hline Total & 100.0 & 100.0 \\
\hline
\end{tabular}

Table 3. Distribution of level of knowledge on post-operative exercises in post-test among abdominal surgery patients $(n=40)$

\begin{tabular}{|l|l|l|}
\hline Level of Knowledge & Frequency & Percentage \\
\hline Inadequate Knowledge & 0 & 0.0 \\
\hline Moderate Knowledge & 1 & 2.5 \\
\hline Adequate Knowledge & 39 & 97.5 \\
\hline Total & 100.0 & 100.0 \\
\hline
\end{tabular}

Table 4. Mean and standard deviation for knowledge on post-operative exercises in pre-test and post-test ( $\mathrm{n}=40)$

\begin{tabular}{|l|l|l|}
\hline $\begin{array}{l}\text { Knowledge on post-operative } \\
\text { exercises }\end{array}$ & Pretest & Post test \\
\hline Mean & 4.55 & 18.00 \\
\hline Standard deviation & 1.39 & 1.13 \\
\hline
\end{tabular}

Distribution of samples in age 20-30years were 9 (22.5\%), 17(42.5\%) were in age 31-40 years and 14 (35\%) were in age41-50 years. Distribution of samples with gender were male $25(62.5 \%)$ and female $15(37.5 \%)$. According to their educational qualification 9(22.5\%) were graduates, $17(42.5 \%)$ were higher secondary, $2(5 \%)$ were primary education (Table 1).

Distribution of samples with their occupation as $4(10 \%)$ were farmers, $8(20 \%)$ were drivers, $11(27.5 \%)$ were worker in a company, students were $4(10 \%)$ and $13(32.5 \%)$ were housewife. Distribution regarding their monthly income $4(10 \%)$ was less than $10,000 /$ month, 13(32.5\%) were 10,000-15,000 rupees/month, $18(45 \%)$ were around 15000-20000 rupees/month and 5(12.5\%) were above 20000 rupees of monthly income. Out of 40 samples $29(72.5 \%)$ were from nuclear family and 11(27.5\%) were from joint family (Table 1).

According to personal habits $8(20 \%)$ having habit of smoking, $1(2.5 \%)$ has chewing tobacco and betel leaves, 6(15\%) were alcoholic and $25(62.5 \%)$ were having none of these habits. Distribution of samples with chronic disease $5(12.5 \%)$ having diabetes mellitus, hypertension for 4(10\%) samples, 3(7.5\%) having asthma and $28(70 \%)$ were not having such associated disease.

Out of 40 patients all of them $40(100 \%)$ had inadequate knowledge on post-operative exercises. (Table 2). And out of 40 patients one (2.5\%) had moderately adequate Knowledge, 39 (97.5\%) had adequate knowledge (Table-3). The pre-test mean for the samples was 4.55 with standard deviation 1.39 and in post-test samples mean was 18.00 with standard deviation 1.13 . It shows that there is an increase in mean and standard deviation between pre-test and post-test (Table 4).

\section{Discussion}

The aim of the present study was to determine the effectiveness of video assisted teaching in knowledge and practice on post-operative exercises among abdominal surgery patients in selected hospitals at Kerala. Out of 40 patients in pretest knowledge level, all of 40 (100\%) had inadequate knowledge on post-operative exercises which was explained in table 2 . The previous studies reported that, 
awareness and knowledge regarding post-operative exercise is still inadequate among the abdomen surgery patients. The study was conducted with 100 samples were 50 for control group and 50 for experimental group. In that structured teaching was given for experimental group and the scores were compared for both groups, the paired' $t$ ' test value for experimental group was $t=36.686$ which is highly significant at the level $\mathrm{P}=0.000$ and for control group was $\mathrm{t}=0.829$ which is not significant at the level $\mathrm{P}=0.411$.

There is no difference in measured pain during the preoperative and postoperative periods for either group, or after physiotherapy. These findings are at odds with the reasoning that mobilization may increase pain intensity after abdominal surgery Nonetheless; these same findings are in line with the notion that not only analgesic treatment but also physiotherapy for abdominal and thoracic surgery can reduce the hospital stay and improve recovery. [8]. There was no difference in measured pain during the preoperative and postoperative periods for either group, or after physiotherapy. Some patients in the chest physiotherapy group even reported some pain reduction after the exercises. These findings are at odds with the reasoning that mobilization may increase pain intensity after abdominal surgery [9]. The effects of different chest physiotherapy regimens have been evaluated among high-risk postoperative patients and none of them could be considered highly satisfactory with regard to preventing such complications. [10] Nonetheless, these same findings are in line with the notion that not only analgesic treatment but also physiotherapy for abdominal and thoracic surgery can reduce the hospital stay and improve recovery. [11]. the postoperative spirometry results presented in this study by the two groups did not show any significant differences. Spirometry as a means of quantifying lung function is controversial. Its best results may not be achieved after abdominal surgery, since patients are un-able to perform at their best or even to make a moderate effort to reach total pulmonary capacity or produce maximal forced expirations [12] Intraoperative, bronchospasm occurs most commonly during the induction and maintenance stages of anesthesia and is less often encountered in the emergence and recovery stages [13].

\section{Conclusion}

The pre-test knowledge had inadequate knowledge on post-operative exercises among abdominal surgery patients in tertiary care hospital in Kerala.

\section{References}

[1]. Beaussier M. Frequency, intensity, development and repercus-Frequency, intensity, development and repercussions of postoperative pain as a function of the type of surgery]. Ann Fr Anesth Reanim. 1998; 17(6):471-93.

[2]. Chumillas S, Ponce JL, Delgado F, Viciano V, Mateu M. Prevention of postoperative pulmonary complications through respiratory rehabilitation: a controlled clinical study. Arch Phys Med Rehabil.1998; 79(1):5-9.

[3]. Christensen EF, Schultz P, Jensen OV, et al. Postoperative pul-monary complications and lung function in high-risk patients: a comparison of three physiotherapy regimens after upper abdominal surger $\mathrm{y}$ in general anesthesia. Acta Anaesthesiol Scand. 1991; 35(2):97-104.

[4]. Chumillas S, Ponce JL, Delgado F, Viciano V, Mateu M. Prevention of postoperative pulmonary complications through respiratory rehabilitation: a controlled clinical study. Arch Phy+ s Med Rehabil. 1998; 79(1):5-9.

[5]. Hall JC, Tarala R, Harris J, Tapper J, Christiansen K. Incentive spirometry versus routine chest physiotherapy for prevention of pulmonary complications after abdominal surgery. Lancet. 1991; 337(8747):953-6.

[6]. Kassavin DS, Kuo YH, Ahmed N. Initial systolic blood pressure and ongoing internal bleeding following torso trauma. J Emerg Trauma Shock. 2011; 4(1):37-41.

[7]. Malcolm R. Calmer Moroney's Surgery for Nurses. $16^{\text {th }}$ Edition. 2002; Pp 1-25.

[8]. Nesbitt I. Postoperative monitoring. Curr Anaesth Crit Care. 2006; 17:55-64.

[9]. Paulo.et al. Chest Physiotherapy during immediate post-operative period among patients undergoing abdominal surgery. Sao Paulo Medical Journal. 2009

[10]. Ravindra P, Fitzgerald E. Surgical preoperative assessment: What to do and why. Student BMJ , 2012 (08) $12 ; 20$ 
DOI: $10.21522 /$ TIJBMS.2016.02.02.Art008

ISSN: $2519-500 \mathrm{X}$

[11]. Scottish Intercollegiate Guidelines Network (SIGN) Postoperative management in adults: a practical guide to postoperative care for clinical staff. SIGN publication [Internet] Available from: http://www.sign.ac.uk/ 2004.

[12]. Vimlati L, Gilsanz F, Goldik Z. Quality and safety guidelines of postanaesthesia care: Working Party on Post Anaesthesia Care (approved by the European Board and Section of Anaesthesiology, Union Europeenne des Medecins Specialistes) Eur J Anaesthesiol. 2009; 26 (9):715-21.

[13]. Westhorpe RN, Ludbrook GL, Helps SC. Crisis management during anaesthesia: Bronchospasm. Qual Saf Health Care. 2005; 14:7. 


\title{
Role of Artificial Sweeteners in Development of Type 2 Diabetes Mellitus (DM): A Review
}

\author{
Article by Jagan Nadipelly ${ }^{1}$, Niharika Anand ${ }^{2}$ and Hannah Persaud ${ }^{3}$ \\ ${ }^{1}$ Faculty of Medicine- Pharmacology, Texila American University, Guyana, South America \\ ${ }^{2}$ Doctor of Medicine (MD1), Texila American University, Guyana, South America \\ ${ }^{3}$ Faculty of Premedical-Biology and Clinical Nutritionist, Texila American University, Guyana, \\ South America \\ E-mail: jaganalwaysright@gmail.com ${ }^{1}$, niha1798@gmail.com ${ }^{2}$,hannah.persaud@tau.edu.gy ${ }^{3}$
}

\begin{abstract}
A number of lifestyle factors are known to be important to the development of type 2 Diabetes mellitus $(D M)$. These are physical inactivity, sedentary lifestyle, cigarette smoking, dietary habits and generous consumption of alcohol. Recently, it has been reported that 385 million people had diabetes and the number of people with type 2 DM is increasing in every year. Obesity has been found to contribute to approximately 55\% of cases of type 2 DM. Consumption of sugar-sweetened beverages has been increasingly associated with obesity and type 2 DM. Hence, many people have turned to high-intensity sugar substitute sweeteners like aspartame, sucralose and saccharin as a way to reduce the risk of these consequences. However, accumulating evidence suggests that frequent consumers of these sugar substitutes may also be at increased risk of excessive weight gain, metabolic syndrome, type 2 diabetes and cardiovascular disease. A rise in the percent of the population who are obese coincides with an increase in the widespread use of noncaloric artificial sweeteners, such as aspartame (e.g., Diet Coke) and sucralose (e.g., Pepsi), in food products. This paper discusses these findings and considers the hypothesis that consuming sweet-tasting but noncaloric or reduced-calorie food and beverages interferes with learned responses that normally contribute to glucose and energy homeostasis. Because of this interference, frequent consumption of high-intensity sweeteners may have the counterintuitive effect of inducing metabolic derangements. This review is based on a search of articles published in PUBMED, Medline, the Cochrane Database of Systemic Reviews, and mainly focused on type 2 diabetes mellitus, current diagnosis, treatment and role artificial sweeteners in development of diabetes.
\end{abstract}

Keywords: Type 2 diabetes mellitus; Artificial Sweeteners; Obesity

\section{Type 2 diabetes mellitus (T2DM)}

Type 2 diabetes mellitus is a metabolic disorder characterized by glucose intolerance and insulin resistance leading to hyperglycemia. Type 2 diabetes mellitus (T2DM) is a global epidemic with an estimated worldwide prevalence of $6 \%$ (246 million people) in 2007, and forecast to rise to $7.3 \%$ (380 million) by 2025 . The health, social, and economic burden is great $[1,2]$; consequently, T2DM presents a major challenge to healthcare systems around the world. T2DM is a complex disorder in which the interaction between environmental and genetic factors results in the development of insulin resistance and $\beta$-cell dysfunction [3,4]. The development of insulin resistance precedes the onset of T2DM by many years [5] and is influenced by many factors including puberty, ageing, pregnancy, physical activity and oral intake [5 - 9]. Obesity is the single most important contributor to insulin resistance [9] modulating insulin sensitivity via multiple factors including imbalance of hormones (leptin and adiponectin), cytokines (tumour necrosis factor- $\alpha$, interleukin-6), suppressors of cytokine signalling (SOCS), inflammatory signalling pathways (nuclear factor-KB and IKB Kinase) and retinol binding protein-4 [10 - 13]. The most crucial factor relating obesity to insulin resistance is thought to be the release of nonesterified fatty acids (NEFAs) particularly from intra-abdominal fat. Increased NEFAs result in increased 
intracellular diacylglycerol and fatty acyl-co A., which result in phosphorylation of insulin-receptor substrate -1 (IRS-1) and insulin-receptor substrate (IRS-2); this in turn diminishes downstream events of the insulin receptor signalling resulting in insulin resistance [14]. Despite obesity being the single most important contributor to IR; most obese insulin-resistant individuals do not develop T2DM [15] because their $\beta$-cells are capable of producing significantly elevated levels of insulin to maintain glycaemic control [16 - 18]. Hence, the failure of $\beta$-cells to secrete sufficient insulin to overcome insulin resistance (i.e., $\beta$-cell dysfunction) is the crucial step in the development and progression of T2DM [19, 20]. The reason for the decline in $\beta$-cell function is not entirely clear, but appears to involve hyperglycaemia per se, together with excessive production of NEFAs, amyloid formation and genetic factors [21 - 24]. In addition to $\beta$-cell dysfunction, patients with T2DM have pancreatic $\alpha$-cell dysfunction manifesting as elevated (or non-suppression of) glucagon secretion in the presence of hyperglycemia [25].

Obesity has been strongly linked with type $2 \mathrm{DM}$, and nearly $90 \%$ of individuals with diabetes have overweight or obesity [26]. Sugar consumption is one of the common suspected culprits for the rise in obesity and may contribute to the development of type 2 DM [27]. Consequently, artificial sweeteners are commonly consumed by individuals with obesity and type 2 diabetes as they are thought to lower the caloric content and blood glucose response. However, recent studies have proven that, use of artificial sweeteners may also increase weight gain over time [28], and may promote glucose intolerance through the altered function and composition of intestinal microbiota [29].

\section{Complications of diabetes}

Chronic hyperglycemia causes many of the major complications of diabetes, including nephropathy, retinopathy, neuropathy, macro and microvascular damage. The risk for microvascular and neuropathic complications is related to both duration of diabetes and the severity of hyperglycemia [30]. In particular, diabetes increases the risk of microvessel disease [31,32]. As a result, serious conditions such as retinopathy, neuropathy and nephropathy are frequently encountered among patients with diabetes. Diabetic retinopathy is estimated to account for 5\% of all cases of blindness globally [33] and up to 50\% of patients receiving renal replacement therapy have diabetic nephropathy [34]. Diabetic peripheral neuropathy (DPN) is associated with considerable morbidity, mortality and diminished quality of life and affects up to 50\% of people with diabetes [35]. Hyperglycemia is a pre-requisite for the development of diabetic complications and in chronic diabetes, hyperglycemia instigates activations of hexosamine biosynthetic pathway, sorbitol- aldose reductase pathway [36], mitogen activated protein kinases (MAPKs) [37] and protein kinase C [38]. Further, hyperglycemia increases the expression of growth factors and cytokines such as transforming growth factor- $\beta$ (TGF- $\beta$ ), vascular endothelial growth factor (VEGF), platelet-derived growth factor, insulin-like growth factor (IGF) and tumor necrosis factor- $\alpha$ $(\mathrm{TNF}-\alpha)$. Reactive oxygen species (ROS) are important arbitrator factors involved in all these events [39, 40] and activate intracellular signal transduction and transcription cascades, in which MAPKs and nuclear factor kappa B (NF-kB) play the most significant roles [41, 42] and damage proteins, lipids, and nucleic acids by oxidation (Fig. 1). Clinical studies have demonstrated that chronic diabetic complications occur late after disease onset, reflecting structural abnormalities in nerves, kidney, retina and blood vessels, with the appearance strongly correlated with the duration of the diabetes and the level of glycemic control [43]. Large clinical trials have demonstrated that normalization of glycemia can greatly reduce the incidence of diabetic complications. However, in clinical practice, normalizing blood glucose is not a trivial task and almost 50\% of diabetic subjects fail to reach the recommended target of an HbA1c lower than 7\% [44]. Based on the present perceptive of pathophysiology of diabetes mellitus, plentiful pharmacological and non pharmacological interventions have been employed in the previous 50 years in order to treat hyperglycemia and interrupt the progression of disease. However, most of the observed initial improvements in hyperglycemia are not constant because of the progressive nature of disease [45]. These pharmacotherapies also have undesired side effects, such as hypoglycemia, weight gain, gastrointestinal symptoms and peripheral edema, variable effects on $\beta$-cell function and decline [46, 47]. 


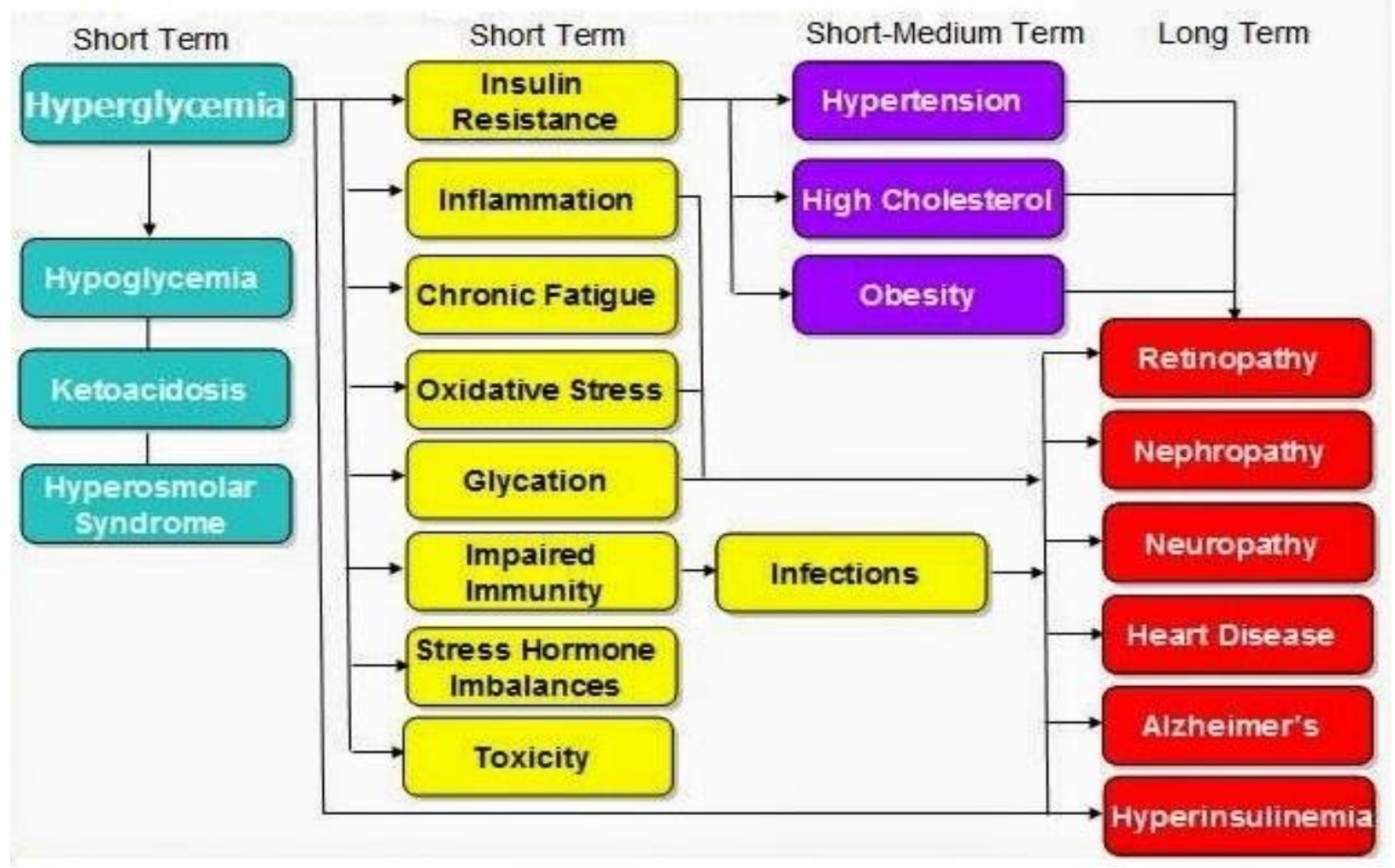

Figure 1. Complications of type 2 diabetes mellitus

\section{Current treatment options for diabetes}

Based on the current understanding of the pathophysiology of T2DM, multiple pharmacological and non-pharmacological interventions have been developed over the past five decades with the aim of improving glycaemic control and hopefully slowing disease progression. Treatment modalities include lifestyle modifications, treatment of obesity, oral hypoglycemic agents, and insulin sensitizers like metformin, a biguanide that reduces insulin resistance, is still the recommended first line medication especially for obese patients. Other effective medications include non-sulfonylurea secretagogues, thiazolidinediones, alpha glucosidase inhibitors, and insulin. Recent research into the pathophysiology of type $2 \mathrm{DM}$ has led to the introduction of new medications like glucagon like peptide 1 analogoues: dipeptidyl peptidase-IV inhibitors, inhibitors of the sodium-glucose cotransporter 2 and 11shydroxysteroid dehydrogenase 1, insulin-releasing glucokinase activators and pancreatic-G-proteincoupled fatty-acid-receptor agonists, glucagon-receptor antagonists, metabolic inhibitors of hepatic glucose output and quick-release bromocriptine. Inhaled insulin was licensed for use in 2006 but has been withdrawn from the market because of low patronage. These treatments may also have undesired side effects, such as hypoglycemia, weight gain, gastrointestinal symptoms and peripheral oedema, in addition to variable effects on $\beta$ - cell function and decline [46, 47]. Hence, interventions that can slow and/or reverse $\beta$-cell decline, which result in weight loss (or at least cause no weight gain) and have low risk of hypoglycemia, might be expected to have an important impact in patients with T2DM. Incretin-based therapies are a new class of antidiabetic medication that may address some of the abovementioned shortfalls of current treatments. In addition, other therapies are in development with the potential to address some of the disadvantages of currently available treatments. 
DOI: 10.21522/TIJBMS.2016.02.02.Art008

ISSN: $2519-500 \mathrm{X}$

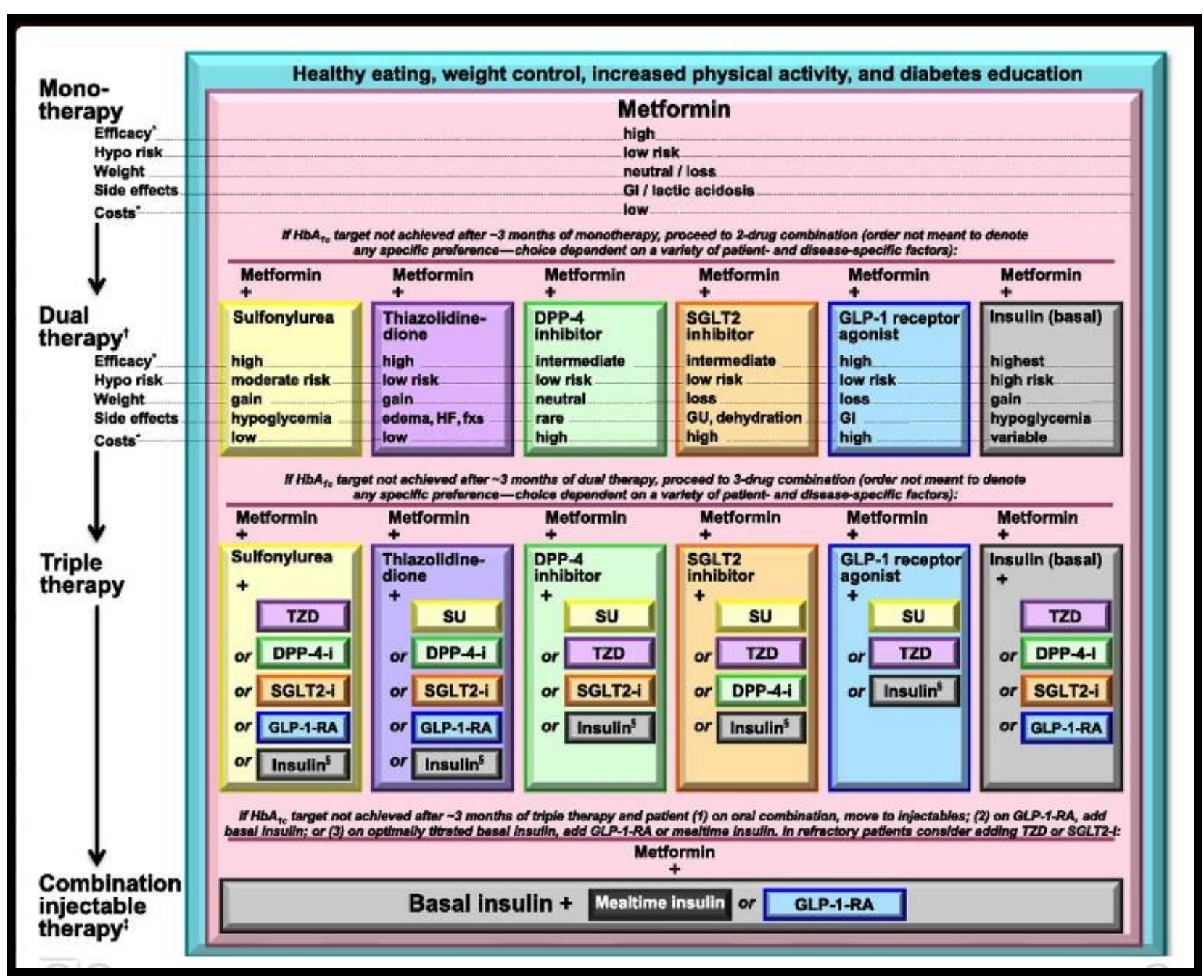

Figure 2. Strategies for treatment of type 2 diabetes miletus (DM).

Source: Silvio inzucchi et al., 2015, diabetes care 38(1): 140-149.

\section{Role of artificial sweeteners in development of type 2 DM}

There are five artificial sweeteners currently ruling the arena of food processing, which include saccharin, neotame, acesulfame potassium, aspartame, and sucralose. Of the five main artificial sweeteners, sucralose and aspartame are the most pervasive and dangerous substitutes found in products on store shelves today. All these artificial sweeteners are marketed under the names of Splenda, Equal and NutraSweet and there are many everyday eatable products such as yogurt, sodas, pudding, tablets, chewing gum, bread, etc consist of these artificial sweeteners.

Many accumulating evidence suggests that frequent consumption of these sugar substitutes may increase risk of excessive weight gain, metabolic syndrome, type 2 diabetes, and cardiovascular disease. $[48,49]$. Significant risk of weight gain, obesity, increased body mass index (BMI) and increased body fat percentage in males and females after consumption of artificial sweeteners containing food products was observed in few recent studies [50, 51]. Several large-scale studies, including the National Health and Nutrition Examination Survey (NHANES) and the San Antonio Heart study, have shown a associations between artificial sweetener intake and incidence of the metabolic syndrome and its components, including waist circumference, blood pressure, and fasting blood glucose [52, 53]. Recent studies conducted in adults have demonstrated the link between artificial sweetener consumption and insulin 
resistance, incidence of type 2 diabetes, and poor glucose control in patients with pre-existing diabetes [54]. In the European E3N study and the Health Professionals Follow-up (HPFS) [55] risk for type two diabetes was more than doubled for participants in the highest quartile of artificial sweeteners consumption compared with non-consumers. Most recently, data from the European Prospective Investigation into Cancer and Nutrition (EPIC) has also indicated that risk for type two diabetes was elevated in those consuming at least one artificial sweetener per day [56]. A study conducted by Pepino et al. (2013) [57] and Suez et al., (2014) [58] demonstrates a deleterious effect increasing glucose concentrations in subjects with a high degree of obesity after an acute and a 7-day exposure to sucralose and saccharin, respectively.

\section{Mechanism of artificial sweeteners in development of diabetes}

Several mechanisms have been proposed to account for the association between artificial sweetener use and diabetes. Recent research have provided convincing evidence that artificial sweeteners play an active role in the gastrointestinal tract, thus providing a mechanistic explanation for observed metabolic effects. Sweet-taste receptors, including the taste receptor T1R family and $\alpha$-gustducin, respond to artificial sweeteners [59, 60]. In both humans and animals, these receptors have been situated in gastrointestinal tract and glucagon-like peptide-1 (GLP-1) [61]. Consumption of artificial sweeteners containg products along with normal day to day food products resulting in stimulation of taste receptors in GI tract and secretion of more amount of GLP-1 [62]. This could lead to more and rapid absorption food materials from intestine into the blood stream and as well as increase GLP-1 stimulates insulin, which enhances the glucose absorption by cells and eventually it lead to weight gain and central visceral adiposity. Many previous studies revealed the crucial role of adiposity in the pathogenesis of type 2 diabetes.

\section{References}

[1]. Burcelin, R., Knauf, C., \& Cani, P. D. Pancreatic alpha-cell dysfunction in diabetes. Diabetes Metab 2008; 34 (Suppl 2): 49-55.

[2]. Barroso, I. Genetics of type 2 diabetes. Diabet Med 2005; 22: 517-535.

[3]. Brownlee, M. Biochemistry and molecular cell biology of diabetic complications. Nature 2001; 414, 813-820.

[4]. Black, C., Donnelly, P., McIntyre, L., Royle, P.L., Shepherd, J.P., Thomas, S. Meglitinide analogues for type 2 diabetes mellitus. Cochrane Database of Systematic Reviews 2007.

[5]. Brown RJ, Walter M, Rother KI. Ingestion of diet soda before a glucose load augments glucagon like peptide1. Diab care 2009; 32(12):2184-2186.

[6]. Brown RJ, et al. Artificial sweeteners: a systematic review of metabolic effects in youth. Int J Pediatr Obes. 2010; 5:305-312.

[7]. Buchanan, T. A., Metzger, B. E., Freinkel, N., \& Bergman, R. N. Insulin sensitivity and B-cell responsiveness to glucose during late pregnancy in lean and moderately obese women with normal glucose tolerance or mild gestational diabetes. Am J Obstet Gynecol 1990; 162: 1008-1014.

[8]. Chen, M., Bergman, R. N., \& Porte, D. Insulin resistance and [beta]-cell dysfunction in aging: the importance of dietary carbohydrate. J Clin Endocrinol Metab 1988; 67: 951-957.

[9]. Dhingra R, Sullivan L, Jacques PF, et al. Soft drink consumption and risk of developing cardio metabolic risk factors and the metabolic syndrome in middle-aged adults in the community. Circulation 2007; 116(5):480-488.

[10]. Del, P.S., Bianchi, C., Marchetti, P. Beta-cell function and anti-diabetic pharmacotherapy. Diabetes/Metabolism Research and Reviews 2007; 23: 518-527.

[11]. De Koning L, et al. Sugar-sweetened and artificially sweetened beverage consumption and risk of type 2 diabetes in men. Am J Clin Nutr. 2011; 93:1321-1327.

[12]. Dunlop, M. Aldose reductase and the role of the polyol pathway in diabetic nephropathy. Kidney International 2000; 77: 3-12.

[13]. DeFronzo, R. A. (1979). Glucose intolerance of aging. Evidence for tissue insensitivity to insulin. Diabetes 1979; 28: 1095-1101. 
DOI: 10.21522/TIJBMS.2016.02.02.Art008

ISSN: $2519-500 \mathrm{X}$

[14]. De Groot, M., Anderson, R., Freedland, K. E., Clouse, R. E., \& Lustman, P. J. Association of depression and diabetes complications: a meta-analysis. Psychosom Med 2001; 63: 619-630.

[15]. Fowler SP, et al. Fueling the obesity epidemic? Artificially sweetened beverage use and long-term weight gain. Obesity (Silver Spring). 2008; 16:1894-1900.

[16]. Fagherazzi G, et al. Consumption of artificially and sugar-sweetened beverages and incident type 2 diabetes in the Etude Epidemiologique aupres des femmes de la Mutuelle Generale de l'Education Nationale-European Prospective Investigation into Cancer and Nutrition cohort. Am J Clin Nutr. 2013; 97:517-523

[17]. Facchini, F. S., Hua, N., Abbasi, F., \& Reaven, G. M. Insulin resistance as a predictor of age-related diseases. J Clin Endocrinol Metab 2001; 86: 3574-3578.

[18]. Goodyear, L. J., \& Kahn, B. B. Exercise, glucose transport, and insulin sensitivity. Annu Rev Med 1998; 49: 235-261.

[19]. Hu, F.B., and Malik, V.S. Sugar-sweetened beverages and risk of obesity and type 2 diabetes: epidemiologic evidence. Physiol. Behav 2010; 100: 47-54.

[20]. Hoogwerf, B.J., Complications of diabetes mellitus. International Journal of Diabetes in Developing Countries 2005; 25: 63-69.

[21]. Hoerger, T.J., Segel, J.E., Gregg, E.W., Saaddine, J.B. Is glycemic control improving in U.S. adults? Diabetes Care 2008; 31, 81-86.

[22]. Hull, R. L., Westermark, G. T., Westermark, P., \& Kahn, S. E. (2004). Islet amyloid: a critical entity in the pathogenesis of type 2 diabetes. J Clin Endocrinol Metab 2004; 89: 3629-3643.

[23]. Jacobson, A. M. Impact of improved glycemic control on quality of life in patients with diabetes. Endocr Pract 2004; 10: 502-508.

[24]. Jang HJ, Kokrashvili Z, Theodorakis MJ, et al. Gut-expressed gustducin and taste receptors regulate secretion of glucagonlike peptide-1. Proc Natl Acad Sci USA 2007; 104(38):15069-15074.

[25]. Kahn, S. E. (1993). Quantification of the relationship between insulin sensitivity and Bcell function in human subjects. Evidence for a hyperbolic function. Diabetes 1993; 42: 1663-1672.

[26]. Koshikawa, M., Mukoyama, M., Mori, K., Suganami, T., Sawai, K., Yoshioka, T., Nagae, T., Yokoi, H., Kawachi, H., Shimizu, F., Sugawara, A., Nakao, K. Role of p38 mitogen-activated protein kinase activation in podocyte injury and proteinuria in experimental nephrotic syndrome. Journal of American Society of Nephrology 2005; 16: 2690-2701.

[27]. Kutner, N.G., Johansen, K.L., Zhang, R., Huang, Y., Amaral, S. Perspectives on the new kidney disease education benefit: early awareness, race and kidney transplant access in a USRDS study. American Journal of Transplantion 2012; 12, 1017-1023.

[28]. Kahn, S. E., Haffner, S. M., Heise, M. A., Herman, W. H., Holman, R. R., Jones, N. P., et al. Glycemic durability of rosiglitazone, metformin, or glyburide monotherapy. N Engl J Med 2006; 355: $2427-2443$.

[29]. Laska MN, et al. Longitudinal associations between key dietary behaviors and weight gain over time: transitions through the adolescent years. Obesity (Silver Spring). 2012; 20:118-125.

[30]. Lutsey PL, Steffen LM, Stevens J. Dietary intake and the development of the metabolic syndrome: the Atherosclerosis Risk in Communities study. Circulation 2008; 117(6):754-61.

[31]. Lee, M.-J., Feliers, D., Mariappan, M.M., Sataranatarajan, K., Sataranatarajan, K., Mahimainathan, L., Musi, N., Foretz, M., Viollet, B., Weinberg, J.M., Choudhury, G.G., Kasinath, B.S. A role for AMP activated protein kinase in diabetes-induced renal hypertrophy. American Journal of Physiology - Renal Physiology 2007; 292: 617627.

[32]. Meier, M., Menne, J., Park, J.K., Haller, H. Nailing down PKC isoform specificity in diabetic nephropathy two's company, three's a crowd. Nephrology Dialysis Transplant 2007; 22: 2421-2425.

[33]. Mackenzie T, Brooks B, O'Connor G. Beverage intake, diabetes, and glucose control of adults in America. Ann Epidemiol 2006; 16(9):688-691.

[34]. McNaughton SA, Mishra GD, Brunner EJ. Dietary patterns, insulin resistance, and incidence of type 2 diabetes in the Whitehall II study. Diabetes Care 2008; 31(7):1343-1348. 
[35]. Mooney, R. A. Suppressors of cytokine signaling-1 and -6 associate with and inhibit the insulin receptor. A potential mechanism for cytokine-mediated insulin resistance. J Biol Chem 2001; 276: 25889-25893.

[36]. Mace OJ, Affleck J, Patel N, et al. Sweet taste receptors in rat small intestine stimulate glucose absorption through apical GLUT2. J Physiol 2007; 582(Pt 1):379-392.

[37]. Nelson G, Hoon MA, Chandrashekar J, et al. Mammalian sweet taste receptors. Cell 2001; 106(3): 381-390.

[38]. Perley, M., \& Kipnis, D. M. Plasma insulin responses to glucose and tolbutamide of normal weight and obese diabetic and nondiabetic subjects. Diabetes 1966; 15: 867-874.

[39]. Pepino MY, Tiemann CD, Patterson BW, Wice BM, Klein S. Sucralose affects glycemic and hormonal responses to an oral glucose load. Diabetes care. 2013; 36(9):2530-2535.

[40]. Polonsky, K. S., Given, B. D., \& Van Cauter, E. Twenty-four-hour profiles and patterns of insulin secretion in normal and obese subjects. J Clin Invest 1988; 81: 442-448.

[41]. Qiu, C., Cotch, M.F., Sigurdsson, S., Garcia, M., Klein, R., Jonasson, F. Retinal and cerebral microvascular signs and diabetes the age, gene/environment susceptibility-reykjavik study. Diabetes 2008; 57: 1645-1650.

[42]. Reaven, G.M. Role of insulin resistance in human disease. Diabetes 1988; 37: 1595-1607.

[43]. Robertson, R. P., Harmon, J., Tran, P. O., Tanaka, Y., \& Takahashi, H. Glucose toxicity in beta-cells: type 2 diabetes, good radicals gone bad, and the glutathione connection. Diabetes 2003; 52: 581-587.

[44]. Resnikoff, S., Pascolini, D., Etya'ale, D., Kocur, I., Pararajasekaram, R., Pokharel, G.P., Mariotti, S.P. Global data on visual impairment in the year 2002. Bulletin of the World Health Organization 2004; 82: 844851.Robertson, R. P., Harmon, J., Tran, P. O., \& Poitout, V. Beta-cell glucose toxicity, lipotoxicity, and chronic oxidative stress in type 2 diabetes. Diabetes 2004; 53 (Suppl 1): 119-124.

[45]. Resnick, H.E., Howard, B.V. Diabetes and cardiovascular disease. Annual Review of Medicine 2002; 53: 245267.

[46]. Romaguera D, et al. Consumption of sweet beverages and type 2 diabetes incidence in European adults: results from EPIC-InterAct. Diabetologia. 2013; 56:1520-1530.

[47]. Rui, L., Yuan, M., Frantz, D., Shoelson, S., \& White, M. F. SOCS-1 and SOCS-3 block insulin signaling by ubiquitin-mediated degradation of IRS1 and IRS2. J Biol Chem 2002; 277: 42394-42398.

[48]. Swithers, S.E., Sample, C.H., and Davidson, T.L. Adverse effects of highintensity sweeteners on energy intake and weight control in male and obesity-prone female rats. Behav. Neurosci 2013; 127: 262-274.

[49]. Suez, J., Korem, T., Zeevi, D., Zilberman-Schapira, G., Thaiss, C.A., Maza, O., et al. Artificial sweeteners induce glucose intolerance by altering the gut microbiota. Nature 2014; 514: 181-186.

[50]. Saydah, S., Bullard, K.M., Cheng, Y., Ali, M.K., Gregg, E.W., Geiss, L., and Imperatore, G. Trends in cardiovascular disease risk factors by obesity level in adults in the United States, NHANES 1999-2010. Obesity, 2014; 22: 1888- 1895.

[51]. Stumvoll, M., Goldstein, B. J., \& van Haeften, T. W. Type 2 diabetes: principles of pathogenesis and therapy. Lancet 2005; 365: 1333-1346.

[52]. Shulman, G. I. Cellular mechanisms of insulin resistance. J Clin Invest 2000; 106: 171-176.

[53]. Stumvoll, M., Goldstein, B. J., \& van Haeften, T. W. Type 2 diabetes: principles of pathogenesis and therapy. Lancet 2005; 365: 1333-1346.

[54]. Suez J, Korem T, Zeevi D, Zilberman-Schapira G, Thaiss CA, Maza O, et al. Artificial sweeteners induce glucose intolerance by altering the gut microbiota. Nature. 2014; 514(7521):181-186.

[55]. Shanik, M. H., Xu, Y., Skrha, J., Dankner, R., Zick, Y., \& Roth, J. Insulin resistance and hyperinsulinemia: is hyperinsulinemia the cart or the horse? Diabetes Care 2008; 31: 262-268.

[56]. Tesfaye, S. Recent advances in the management of diabetic symmetrical polyneuropathy. Journal of Diabetes Investigation 2010; 2 : 33-42.

[57]. Valko, M., Leibfritz, D., Moncol, J., Cronin, M.T., Mazur, M., Telser, J. Free radicals and antioxidants in normal physiological functions and human disease. The International Journal of Biochemistry \& Cell Biology 2007; 39: 44-84.

[58]. Wellen, K. E., \& Hotamisligil, G. S. Inflammation, stress, and diabetes. J Clin Invest 2005; 115: 1111-1119. 
DOI: $10.21522 /$ TIJBMS.2016.02.02.Art008

ISSN: $2519-500 \mathrm{X}$

[59]. Wolf, I., Sadetzki, S., Catane, R., Karasik, A., Kaufman, B. Diabetes mellitus and breast cancer. The Lancet Oncology 2005; 6: 103-111.

[60]. Yuan, S.Y., Breslin, J.W., Perrin, R., Gaudreault, N., Guo, M., Kargozaran, H. Microvascular permeability in diabetes and insulin resistance. Microcirculation 2007; 14: 363-373.

[61]. Yang Q. Gain weight by "going diet?" Artificial sweeteners and the neurobiology of sugar cravings: Neuroscience 2010. Yale J Biol Med. 2010; 83:101-108. 


\section{TEXILA \\ JOURNAL}

Texila American University Ltd,

Unit T 1/F, Mau Lam Comm Building,

16-18 Mau Lam Street, Jordan,

Kowloon, Hong Kong.

E-mail: ejournal.assist@tau.edu.org

Skype: texila.aco32

Whatsapp: +918056580933 